University of Rhode Island

DigitalCommons@URI

Open Access Master's Theses

1978

\title{
THE COLLABORATIVE CONCEPT: A DESCRIPTIVE ANALYSIS
}

Rebecca L. Glovsky

University of Rhode Island

Follow this and additional works at: https://digitalcommons.uri.edu/theses

\section{Recommended Citation}

Glovsky, Rebecca L., "THE COLLABORATIVE CONCEPT: A DESCRIPTIVE ANALYSIS" (1978). Open Access Master's Theses. Paper 383.

https://digitalcommons.uri.edu/theses/383

This Thesis is brought to you for free and open access by DigitalCommons@URI. It has been accepted for inclusion in Open Access Master's Theses by an authorized administrator of DigitalCommons@URI. For more information, please contact digitalcommons-group@uri.edu. 


\section{THE COLLABORATIVE CONCEPT:}
A DESCRIPTIVE ANALYSIS 
A DESCRIPTIVE ANALYSIS OF

THE CONCEPT OF COLLABORATION

BY

REBECCA L. GLOVSKY

A THESIS PROJECT SUBMITTED IN PARTIAL FULFILIMENT OF THE REQUIREMENTS FOR THE DEGREE OF MASTER OF COMMUNITY PLANNING 


\title{
TABLE OF CONTENTS
}

\author{
PREFACE
}

ACKNOWLEDGEMENTS

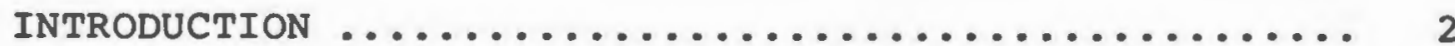

PART ONE: DESCRIPTIVE ANALYSIS OF COLLABORATION ..... 8 INTRODUCTION $\ldots \ldots \ldots \ldots \ldots \ldots \ldots \ldots \ldots \ldots \ldots \ldots \ldots . \ldots \ldots$

DESCRIPTIVE VARIABLES ................... 13

Who is United in Collaboration ........... 13

Legal status of the Collaborative ......... 17

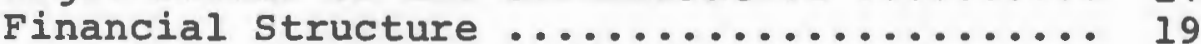

Governing Board Membership ............. 22

Decision-Making ..................... 24

Collaborative Accountability ............ 27

Goals of the Collaboration .............. 29

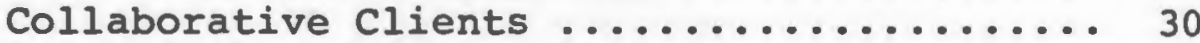

Role of the Collaborative .............. 32

Communication \& Information Networks ...... 34

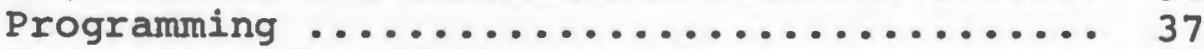

Incentives for Participation ............ 38

Benefits of Collaboration to Participants .. 40

COLIABORATIVE DESCRIPTIONS ............... 41

MASBO Cooperative Corporation ........... 41

Metropolitan Cultural Alliance .......... 49

Metropolitan Planning Project........... 60

Metropolitan Council for Educational

Opportunity, Inc. ................ 69

Educational Collaborative for

Greater Boston, Inc. ............... 84

Voluntary Educational Collaboratives ....... 92

Boards of Cooperative Educational Services.. 104

Museums Collaborative, Inc. ............ 112

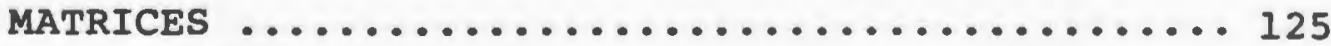

CONCLUSION .......................... 127 
PART TWO: THE CULTURAL EDUCATION COLLABORATIVE .. 135

THE CASE FOR CULTURAL EDUCATION ........ 136

CULTURAL EDUCATION COLLABORATIVE, INC. .... 143

CRITICAL ISSUES ................... 166

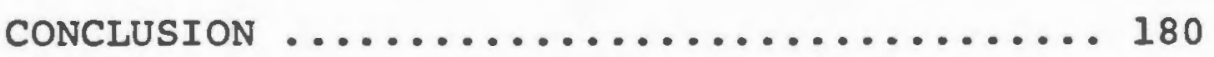

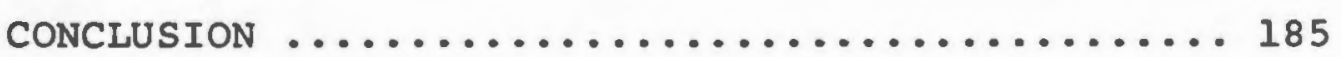

FOOTNOTES

BIBLIOGRAPHY 


\section{PREFACE}

This thesis is written in partial fulfillment of the Masters Degree of the University of Rhode Island, Department of Community Planning and Area Development, and in behalf of the Cultural Education Collaborative, Boston. Its purpose is twofold: to study the concept of collaboration as a mechanism for innovative service delivery, by surveying eight collaboratives; and to analyze the collaborative structure of the Cultural Education Collaborative by applying the conclusions of the previous section.

This is a formal analysis of the concepts and components of collaboration. It is descriptive and analytic, and is not intended to be evaluative or exhaustive of any collaboratives surveyed, including the Cultural Education Collaborative. Instead, particular dittention has been paid to the purpose and variables of these collaboratives in the hope of better understanding this exciting concept. 


\section{ACKNOWLEDGEMENTS}

I would like to thank Polly Rabinowitz, Executive Director of the Cultural Education Collaborative, who provided much consideration, time and energy towards the development of this analysis.

In addition, I am grateful to those persons who provided invaluable information and assistance, in particular: Mr. Michael Spock, Executive Director of the Childrens Museum and President of the Board of Directors of the Cultural Education Collaborative; Ms. Holly Sidford, Director of the Cultural Voucher Program of the Museums Collaborative; Dr. Richard Lavin, Executive Director of the Merrimack Education Center; Mr. Robert Pritchard, Executive Director of the MASBO Cooperative Corporation; Mr. Marcus Mitchal, Administrative Assistant of METCO, Inc.; Mr. John Green, Executive Director of EdCo, Inc.; and Mr. Peter Murphy, Director of the Bureau of School District Reorganization and Collaboration of the Massachusetts Department of Education.

And special thanks to the dedication of two persons: Dr. Marcia M. Feld, of the University of Rhode Island, and my husband, Bob, whose insights and patience were invaluable to this thesis project. 
Why Collaboration?

Collaboration has emerged in the last two decades as a popular mechanism for the efficient delivery of services and innovative programs. Service organizations and institutions have increasingly employed this model to achieve benefits which would not accrue without cooperation. Collaboration, however, is not a new concept. As early as 1919, the Metropolitan Sewerage Commission, the Metropolitan Water Board, and the Metropolitan Parks District were consolidated under the Metropolitan District Commission in the belief that, greater economy and improved efficiency would be possible if all three were grouped under a single agency. "Collaboration" is a dynamic concept founded on two simple ideas - sharing and cooperation. Collaboration creates partnerships between two or more groups who work together in cooperative association, or collaboration, to achieve various goals. Collaboration occurs when two or more organizations share information, skills and resources to identify and achieve common goals and objectives. The styles of collaboration vary greatly as private or public efforts, or both. As will be seen, collaborations present different styles of financing and governance, decision- 
making and programming services. Organizations may collaborate to develop innovative programs and services beyond the scope of the individual organization; to reach new audiences and service broader clienteles; to jointly address issues important to their own organizational growth and development; to capture additional funding and so strengthen and supplement their present service and program provision; and/or to coordinate multiple activities already in existance and so prevent service overlap, duplication, or contradiction. Collaboration thus offers an innovation to the existing order of services.

Collaboration confers multiple benefits which may be additionalily attractive to participating organizations. In particular, collaboration provides for:

- the pooling of organizational resources to achieve economic efficiency and economies of scale for participating organizations, as well as the potential for generating public and private revenues;

- shared understandings and communication between different organizations and their clienteles;

- a higher level of community through a wide range of participation in goal setting and decision-making;

- the reduction of feelings of powerlessness and alienation experienced by small organizations of limited resources when dealing with larger, possibly unresponsive organizations and institutions;

- a greater degree of public accountability to collaborating organizations by according the opportunity to respond to various community pressures.

Thus, collaboration offers enormous potential as a mechanism for deliver ${ }^{i n g}$ services in a flexible and innovative way. However, there are several difficulties inherent in 
collaboration to which collaboratives must be attentive.

First, collaboration unites a number of participants. This number may be quite large. Additionally, each collaborating organization may itself have a number of clients. As a result, communication between the collaborative and the participants and their clients may be quite complex and time consuming, and tends to grow at a geometric rate.

Secondly, participation in collaboration demands that the participants share their resources and invest time and energy. Participants must therefore be willing to make a commitment for the success of the collaboration. Reluctant members may not be swept along in the activities of the collaborative and may slow or stall collaborative programming.

Third, collaboration requires the facilitation and coordination of diverse programming and administration operations. Administrators are therefore required to be adept at a various number of diverse responsibilities. At this point in time, there are few administrators with experience in collaborative management. Most administrators are still learning by trial and error.

Fourth, as with other non-profit organizations, collaboratives may become so caught up with organizational self-maintainance that programming becomes a secondary function.

Finally, with few defined program boundaries collaboratives may encounter problems of territoiality and conflict in service and program delivery with other organizations and collaboratives.

The Role of the Collaborative

The collaborative is that special organization which exists to unite two or more groups in formal cooperation, or collaboration. The collaborative may exist as an independent organization of public, private non-profit, or quasi-public status. Participation in a collaboration is voluntary. Groups may subscribe as full-time dues paying members, or may participate on an ad hoc program or service basis. 
Although groups may have diverse secondary motivations to participate, the primary incentive to participate is, again, the innovation achieved.

Collaboratives exercise the role of facilitator and coordinator. The participating groups may have no reason to work together save for the special product achieved through collaboration. Collaboration between groups may not be possible, or as effective, without the special coordinating efforts of the collaborative organization. The collaborative may additionally serve the role of catalyst, making of the individual offerings of different participating groups a new program(s) or service(s). Generally, collaboration is very cost-effective as the special efforts of the collaborative can generate savings and benefits not possible if the individual organizations were to attempt the innovative service or program delivery independently. Further, collaboration is flexible and enables the delivery of many services and programs without superimposing a permanent and cumbersome bureaucratic structure.

Collaboratives serve the specialized roles of program generator and/or broker. As program generators, the collaborative staff develops programs which utilize the resources (such as funds, skills, materials) of participating groups to respond to a perceived need. As brokers, collaboratives introduce and coordinate outside resources (services, speakers, specialists, programs) to meet the service needs of member organizations, ad hoc collaborative 
participants, and occasionally, the direct people within the service district. Finally, a few collaboratives which exist as outgrowths of institutions, may themselves be considered a service of that institution. Examples of these collaboratives will be presented in Part one.

In conclusion, the collaborative exists as facilitator/initiator and serves the specialized role(s) of program planner and generator, broker, and fundraiser. The special efforts of the collaborative produce a service(s) that is cost-effective, and/or not otherwise available. The groups participating in collaboration may offer a gamut of motivations and provide diverse services, but a balance is achieved between these differing interests to seek the goals of the collaboration. Decisions about how to achieve these goals reflect to some degree the views of the participating groups. Groups participating contribute diverse resources to the collaborative. In turn, collaborating groups receive innovative solutions to meet their particular organizational and client needs, and/or participate in an innovative, systematic approach to a jointly perceived problem.

However varied the styles and approaches, all collaboratives must satisfy the following fundamentals:

First, organizations must have a commonly shared goal(s) to underlie their collaboration. Participating groups may seek diverse individual benefits but must be able to agree on the contextual goals (or mandate for collaboration), active goals (organizational goals), and program objectives to ensure coordination and cooperation. To this end, collaborating organizations must be able to identify a problem(s) towards which to fashion goals and allocate resources. 
Second, collaboration must have a base of financial support to sponsor collaborative activities. Collaboration requires some sharing of the resources of participating groups, yet this may not be sufficient to support activities. Collaboration may require additional public and/or private subsidization.

Third, collaboration must be founded on two way communication between the participating groups, and the participating groups and the collaborative organization. Communication is requisite for the determination of goals, the sharing of resources, and for the coordination of activities.

Fourth, to be dynamic and so meet the goals of collaboration, the collaborative must be responsive to the needs and problems of its direct clients, the participating organizations.

Fifth, the collaborative must be an effective planning mechanism, not just an informal association. The collaborative must employ a systematic approach which defines goals, identifies problems, examines alternatives, and designs a program and/or service strategy. The collaborative must display leadership and organizational skills in order to facilitate a collaboration, plan an approach, or service a need.

Finally, collaborations must provide a program(s) and/or service(s) that is not duplicated within the service area. The product of the collaboration must be perceived by potential clients as unique and highly desirable. A critical factor to effective collaboration is, therefore, the resultant product of a unique and innovative service.

Thus, collaboration is an organizational mechanism which secures a new resource base for organizations so las to provide new and innovative programs and services. Collaboration provides a systematic approach to perceived pressing social and organizational needs. And, as a cooperative venture, collaboration confers benefits to the participating organization and the community which are beyond their individual scope. 
PART ONE

DESCRIPTIVE ANALYSIS OF COLLABORATION 


\section{INTRODUCTION}

The mechanism of collaboration has been employed increasingly for the delivery of innovative services and programs. Collaboration has assisted two groups of institutions, public education agencies and cultural agencies (museums, zoos, historical societies, aquaria, literary, visual and performing arts groups), to support internal growth and development, to service their clientele more effectively, and to service a broadened clientele in the face of multiple constraints. 'Without collaboration, these agencies and institutions may not be able to effectively service client needs or to reach new clients because of diverse institutional pressures and problems. Examples of collaboration which focus on education and on the cultural arts will be examined below. These institutions, cultural agencies and public education agencies, have initiated collaborations to overcome the following problems and pressures, and to provide innovative programs and services to meet client needs.

Cultural agencies, for example, long considered resources to only the "cultural elite", are facing increasing pressures to open their vast resources to a wider segment of the community at large. Many cultural agencies additionally realize the education potential of their collections but 
require the mechanism to extend these collections to a

larger public. As the Museums Collaborative writes,

Current economic realities have forced arts institutions to depend increasingly on public rather than private bases of support. This increasing public subsidy has been accompanied by democratic demands that the cultural institutions substantially broaden the audience they serve, expand and improve their educational functions, and demonstrate their accountability to the public by providing evidence of impact on a wide cross-section of citizens. To address these mandates, cultural institutions need to bring the range of people they reach into parity with the amount of public subsidy they request, and effort which requires the review of previous policies, and the design of new ways to involve people who, in the past, have not been part of the arts audiences.

Thus, the cultural agencies have three general needs: to broaden clientele, to increase program and operational funding, to promote institutional growth and development.

Schools have been experiencing diverse, and sometimes contradictory, pressures to increase the quality and quantity of education. For example, recent federal legislation and state regulations have affirmed the equality of educational opportunity to minority, handicapped, and nonEnglish speaking children (Chapters 636,766 , respectively). Additional pressures have called for increased public participation in school decision-making. Despite these pressures for social change, curricula has "responded to a new conservatism that demands a reemphasis on content and skills. Today, the mood is to reestablish structure, emphasize disciplines, hold the line, prepare for SAT's, and combat grade inflation."ii These pressures tax the school budget beyond its limits prohibiting innovative changes and creating 
educational inequities for children of lower income communities. "The question of fiscal equity should be addressed in terms of how fairly to share the burden of substantially equalized educational resources availability for children, not in terms of how to equalize the ability of a district to raise revenues which it may not choose to raise or spend."iii

As will be illustrated by the following eight collaboratives, collaboration may provide a mechanism. For institutions to more effectively meet client needs as well as respond to the pressures for social change and crosscut many fiscal constraints.

In this chapter, a three step analysis will be conducted of the eight collaboratives to better understand the general nature, potential and elements of collaboration. These steps include:

First, a descriptive analysis will be presented of the individual elements and variables of collaboration. These elements combine in different degrees to define the structure and role of individual collaboratives.

Second, a brief description will be presented of the structure, purpose, goals and operations of eight collaboratives. These collaborative employ a variety of approaches to collaboration and seek diverse goals.

Third, an examination of these collaboratives will reveal that many collaboratives of different goals share similar characteristics. These collaboratives will be grouped by similar purposes and characteristics under several typologies.

An analysis of typologies makes explicit the strategies employed by collaboratives to acheive goals, as well as the role, audience, impact and rationale of individual collaboratives. Such a typology is thus a valuable way to 
order data to answer policy questions concerning a collaborative's potential and limitations. 


\section{WHO IS UNITED IN COLLABORATION}

Organizations may collaborate to develop innovative programs and services beyond the scope of the individual organization; to reach new audiences and service broader clientele; to jointly address issues important to their own organizational growth and development; to capture additional funding and so strengthen and supplement their present program and service provision; and/or coordinate multiple activities already in existence and so prevent service overlap, duplication, or contradiction. Collaboration offers an innovation to the existing order of services. Thus, collaboration creates partnerships between different groups in servicing needs and seeking defined goals. These collaborative partnerships take several forms, and may be conceptualized in three models of collaboration.

In one model, groups with resources may be linked through collaboration to other groups with specific needs for those resources. The organizations which require resources and the organizations which provide resources may be of disparate goals, purposes and needs. The client organizations participate in cooperative projects. 
The collaborative operates, in this situation, principally as a broker. This model is most characteristic of private, non-profit collaboration.

In another model of collaboration, different groups with varied resources but similar needs or goals are united in programs or services to meet those needs or goals. These organizations derive diverse benefits from collaboration (figure 2). In another variation of this model, groups of similar needs, resources and goals collaborate together to share their resources to more efficiently and effectively meet their common goals. This situation requires the collaborative to serve a program and service planning role. The participating organizations derive similar benefits from collaboration. Or collaboratives may unite in collaboration organizations of similar purposes and organizations of diverse purposes (figure 4). In this latter situation, collaborative programming and roles become quite complex. Moreover, the collaborative may serve to generate additional program funds and broker outside resources. 


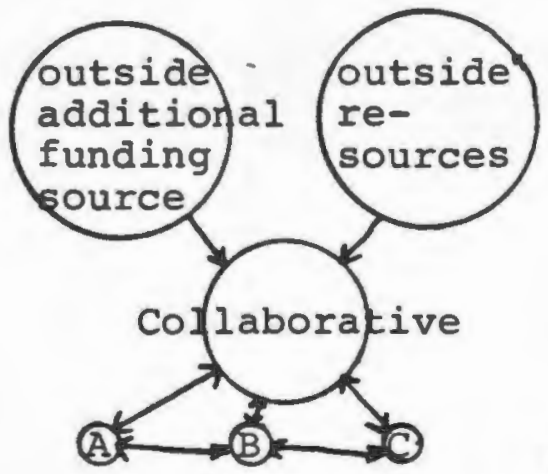

organizations of disparate resources but similar needs or goals FIGURE 2

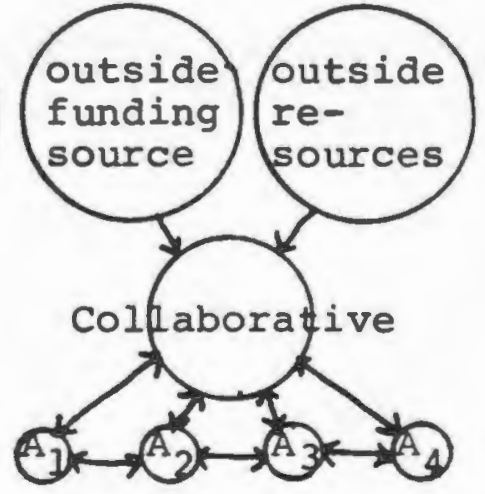

organizations of similar needs and goals, share resources to acheive more effective services and new innovative programing FIGURE 3

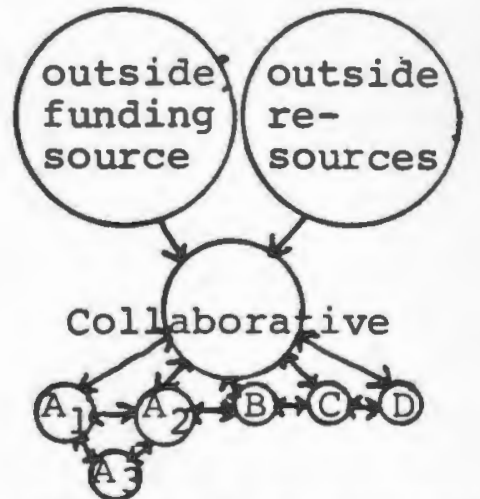

variation - several organizations of similar purpose and needs work with organizations of diverse purposes, needs and goals

FIGURE 4

This model may be characteristic of public or quasi-public, or private, non-profit collaboratives.

In a final model, collaboratives exist as an outgrowth or extension of a particular organization(s), institution(s), or agency (s). The collaboration is voted into being by the sponsoring institution(s) to enable that institution(s) support and supplement existing services. The participants in the

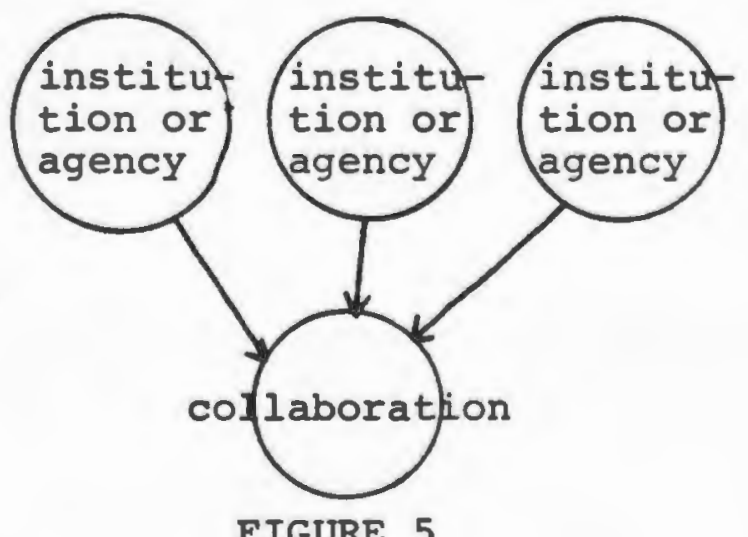
collaborative are therefore the institutions of similar purpose, goals and needs, plus the clients of these institutions. The collaborative may additionally be voted out of existance by the sponsoring institution(s). The collabora- 
tive may be of few or many programming roles - brokering, program generation, fundraising, communication, and/or technical assistance. This model of collaboration is often employed by local education agencies.

In conclusion, a collaborative may unite participants in one of the above models or a variation of the above models. From two to more than twenty groups may be united in a single collaborative program or service. A collaborative which is conducting several operations and is serving both program planning and broker roles may find itself dealing with hundreds of groups and organizations. 


\section{LEGAL STATUS OF THE COLLABORATIVE}

All collaboratives, public or private, are organized under the public laws of that state. Public laws may be exclusively for the enabling and funding of collaboratives designed to facilitate a public sector responsibility. For example, many public education collaborative have been established in this fashion. Chapter 40 , Section $4 E$, of the Massachusetts General Laws was the first legislation enabling two or more school committees to authorize agreements for joint educational activities. Several chapters have followed that authorize school systems to use collaboratives as vehicle to provide supplementary programs and special services in education. ${ }^{l}$ other collaboratives are organized under public laws which define organizations as private non-profit. For example, Chapter 180 of the Massachusetts General Laws provides for the organization of charitable corporations for one or more purposes including:

(a) for any civic, educational, charitable, benevolent or religious purpose;

(b) for the prosecution of any antiquarian, historical,

: literary, scientific, medical, chiropractic, artistic, monumental or musical purpose. 2

Many collaboratives, however, are organized under more than one public chapter, conferring on the collaborative both a public and private non-profit legal status. This enables collaboratives to receive certain 
federal, state and local monies as well as private grants and private payments. Moreover, many collaboratives, whether public, private, or quasi-public, are eligible to bid for public contracts in providing programs or services to a state or locality. Additional legislation administers funding and technical assistance to educational organizations that provide:

- magnet programs,

- equal opportunity,

- special education. ${ }^{3}$

As will be demonstrated, several collaboratives are organized as both public and private organizations, holding various state and federal contracts.

Additionally, many collaboratives elect to organize under Section 501 (c) (3) of the Internal Revenue Code which confers a tax exempt status to,

corporations, and any community chest, fund, foundation, organized and operated exclusively for religious, charitable, scientific, testing for public safety, literary, or educational purposes, or for the prevention of cruelty to children or animals, no part of the net earnings of which inures to the benefit of any private shareholder or individual, no substantial part of the activities of which is carrying on propaganda, or otherwise attempting to influence legislation, and which does not participate in, or intervene in (including the publishing or distributing of statements), any political campaign on behalf of any candidate for public office. 4 


\section{FINANCIAL STRUCTURE}

A critical element to collaboration is the sharing of financial resources by the cooperating organizations. The financial contribution of the cooperating organizations to the collaboration takes several forms.

First, certain collaboratives may require participating organizations to subscribe as dues paying members. Membership dues may be described as "hard money" because they assure a steady support, however small, to the existance of the collaborative. These dues, collected annually, usually support the administration and daily operations of the collaborative organization. In the case of many school systems, the dues take the form of a per capita assessment for the student body. Membership dues are required whether or not the participating organization chooses to participate in any of the collaborative programs or services for that year. Seldom, however, are these membership dues sufficient to pay for the individual programs or services generated by the collaborative.

Secondly, most collaboratives, member and nonmember alike, may require the participating organizations to pay an assessment for the individual services and/or programs. Additionally, the collaborative may charge a tuition to school districts for students who participate in a collaborative on a regular basis. The benfits of collabora- 
tion are in particular evidence here. The collaborative is able to acheive cost savings in program operation/service provision due to the economies of shared resources and larger scale. Thus, the program/service assessment to each particular organization is much less than the actual cost of that program/service if attempted independently by the participant.

Many collaboratives receive supplemental support from sources other than the participating organizations. Certain collaboratives eligible for public (federal, state) grants or apply for private foundation, or both. Collaboratives must apply for these grants each fiscal year (or grant period) and cannot be guaranteed of these revenues for successive years. Such private and public grants provide an uncertain financial foundation and are appropriately termed "soft monies": Moreover, many collaboratives contract with public agencies to deliver services and programs to school systems, in particular.

Finally, some collaboratives additionally seek private contributions through fundraisers and finance campaigns. Collaboratives may seek these small, private contributions because they require additional support for collaborative operations, and/or seek to symbolize a publicly accountable or grass roots organization. A collaborative, then, requires a sound financial base to support its diverse operations - administration and staffing, program planning and supervision, information dissemination, and 
evaluation. Although some collaboratives exist on one financial source alone, most collaboratives rest on a combination of "hard money" and "soft money".

In general, the more diversified the financial structure of the collaborative the less the operations of the collaborative will be crippled by reductions in dues paying members, program participants (hence fewer assessments) or grants. 


\section{GOVER NING BOARD MEMBERSHIP}

The governance is that body which directs the collaborative's activities. The governing board, whether designated a board of directors, trustees, supervisors, etc., is generally responsible for supervising the establishment of the collaborative, the setting of collaborative goals and policy directions; and the supervision of collaborative operations. A governing board is organized according to the legal status of the collaborative. The governing boards of principally public collaboratives (such as public education collaboratives) are constituted by public law; the governing boards of private collaboratives are consituted by by-laws or letters of incorporation; and the governing boards of quasi-public collaboratives may be constituted by by-laws as set within the general prescriptions of a public law. The board membership and role are both defined with these legal documents.

\section{As will be illustrated within the following} matrices (see matrices section), the membership of governing boards is based upon the purpose and exigencies of the collaborative. For example, the typical brokering collaborative, dedicated to providing support services, tends to have direct consumers represented on the board in order to be reflective of client needs; and the private non-profit 
collaborative which rests primarily on "soft money" may attempt to build political, community and philanthropic support for their endeavors through board membership of community power leaders.

Governing boards are principally membered by the following:

- direct consumers,

- professionals of each agency or organization,

- school committee members,

- citizens,

- community power leaders (including politicians, philanthropists, community leaders, etc.),

- union representatives.

Board membership will influence the ultimate direction and policy making of the collaborative and provide an important perspective on the clients needs and problems to be addressed. The governing board of a collaborative is most commonly a Board of Directors, but in the case of certain educational collaboratives, may be a Board of Trustees or a Board of Education. An Executive Committee, drawn from members of the board, may be vested with the active management of the collaborative between board meetings.

All board members are formally responsible for defining major goals and directing the policy of the collaborative. Most boards are additionally required to approve the administrative budget and program/service allocations of the collaborative. 


\section{DE CISION - M A K I NG}

Decision-making is here defined as the actions and considerations that occur within the collaborative administration and programming. As opposed to policy setting, decision-making occurs as the daily operations of the collaborative. Shared decision-making is one characteristic of collaboration. However, this decision-making occurs in different degrees and by diverse means with various collaborations. Minimally, all groups must agree upon the mandate and the major goals of the collaboration in order to participate effectively. Maximally, certain collaborations exist to generate dialogue in policy and programming between multiple interest groups. Between these extremes, collaborations manifest a range of approaches to decision-making and participation.

Generally, four groups may be responsible for the administrative decision-making and programming that occur within the collaborative. This decision-making may include broad program goals and objectives, and making program decisions; and/or, in a few instances, making budget, personnel, and major policy decisions. Additional responsibilities of the decision-makers may include adjudicating disputes, screening program participants, and conducting field operations. 
The four groups variably involved in decision-

making are:

Executive Director and Staff:

This group supervises and conducts the daily operations administrative planning and programming - of the collaborative, but may be additionally responsible for major policy decisions: plus

Governing Board:

The board might informally exceed its constituted responsibilities and become more actively involved in the daily operations of the collaborative. A few governing boards supervise staff operations, mediate in participant controversies, and advise in programming; and/or

Advisory Boards, Advisory Committees, or Task Forces:

These groups may be formally constituted in the by-laws or established informally to provide leadership or supervision in a specific policy, administrative, or program area. Most often, the advisory committee is composed of subject area experts and exists to supervise a program(s) or service area; and/or

Other Groups or Parties:

These groups, such as parents, community, or interest groups, may participate in setting objectives, defining issues, and designing and effectuating programs.

Individual collaboratives evidence different modes of decision-making based on collaborative purpose, goals and needs. Even different program areas within one collaborative may require different decision-making approaches. In general, however, the more complex the operations and diverse the program responsibilities of a collaborative, the greater the likelihood of participation in collaborative decision-making from an active board (or individual board members), advisory groups, and/or interest groups. The participation of advi- 
sory groups and/or interest groups, and in some cases, board members, provide a channel for the input of necessary technical or subject area information, client needs, or community preferences. Thus, the greater the participation of clients and interest groups, the greater the sharing of information between participants and the collaborative organization. 


\section{COLLABORATIVE ACCOUNTABILITY}

To whom is the collaborative accountable? Accountability is a formal concept here defined as that line of authority or responsibility by one group over the activities of another organization. Collaboratives are formally answerable or accountable in varying degrees to different organizations. All collaboratives are accountable in some degree to their funding source (grantors, contractors, purchasers, members) for the proper use of funds. Generally, the greater the funding from the organization, the more a collaborative is answerable to that funding source.

However, the major collaborative accountability often accrues to that organization(s) which is responsible for the creation of the collaborative - its parent or sponsor. Beyond their respective funding sources, collaboratives are primarily accountable:

- To themselves: most private non-profit collaboratives are relatively independent of outside control and can conduct their operations based on their own best judgement. These collaboratives are primarily accountable to their own members and internal governance.

- To a supervisory organization: this supervisory organization, whether public or private, sponsored the establishment of the collaborative, supervises the operations of the collaborative through annual evaluations, audits and/or representation on the board. Further, this organization grants legitimacy to the collaborative and may be a principal financial or other resource base. 
- To member school districts: in many cases the collaborative is initiated by, and may be voted out by. the local school districts. The local school districts constitute the governing board and a funding source for the collaborative. The collaborative is thus the instrumentality of the member school districts and continues to exist at their pleasure.

Thus, the nature and degree of accountability of a collaborative determines the autonomy of operations and continued existance of a collaborative. 


\section{GOALS OF THE COLLABORATION}

The goals of a collaboration are a set of ends towards which the collaborative organizes activities and develops strategies. Certain goals denote the conceptual foundation of the collaborative. Other goals direct its daily operations. Specifically, these goals include:

\section{Contextual Goal (Mandate):}

The conceptual foundation underlying the collaboration. It arises from the fundamental values and beliefs of collaboration and the participating groups and rarely changes.

\section{Active Goal(s) (Objectives):}

The goal which has been singled out and made the focus of the activity of the collaborative. Within this context, a distinction between incidental and principal ends should be made: An incidental end is one which has been relevant only if it can be acheived without additional cost or with only trivial cost. If, however, a higher sacrifice or other end is made to attain a certain goal, that end is one of its principal ends.

Operational Goal(s) (Strategies):

A series of specific steps which acheive the active goal. These operational goals are developmental and directive. They are a way of evaluating whether the

" active goal can be met. Operational goals are less explicit in their value commitments.

\section{Outcome/Products:}

The results of the application of the operational and specific goals set to the substantive issues or problems. Purpose:

The purpose of the collaborative is the organizational objective. The collaborative exists to create or to implement this objective. 


\section{COLLABORATIVE CLIENTS}

The client is the intended recipient or consumer of the organization's programs, services and other activities. Organizations design programs and services to satisfy the diverse needs of, and to extend benefits to, a client group or groups.

In the case of a collaborative, however, there may be several levels of clients. The primary clients of the collaborative are the cooperating groups which the collaborative seeks to catalyze. These cooperating groups, in turn, maintain their own clients which they seek to service. With the purpose of the collaborative most often to assist groups to better service their consumers, these consumers additionally become the ultimate clients of the collaborative. This dual client level may be reflected in the multiple roles of the collaborative. For example, a collaborative may design programs directly for school children and concomitantly provide teacher training or technical assistance to school authorities.

To be most effective, a program or service must reach its intended client without wasteful spillovers on unintended groups. As one program evaluator writes, "program accomplishments can be measured in the proportion of the client population served, in the levels of service actually 
provided in relation to the minimum standards, and in the rates of progress towards serving the entire client population at minimum standards." 6 Thus, the careful identification of clients becomes critically important for the impact of collaborative efforts. Peter Rossi presents an innovative approach to the identification of clients by categories of program (or service) clients within a hierarchy.

Impacted:

These individuals and groups that are the direct beneficiaries of the program or service.

Involved:

Those individuals and groups participating in a program or service. Beyond the collaborative staff, this category includes both impacted client groups as well as the resources (specialists, vendors, consultants) brought to bear.

\section{Concerned:}

Those individuals and groups generally affected by, or interested in, the results of the program or service. Those concerned may include education systems, taxpayers, employers, ethnic and racial groups, and other community interests.

Rossi views all parties present in the above matrix as clients of the program, to some degree. Such an approach is valuable to the effective programing of a collaborative by providing a hierarchy for the prioritizing and targeting of scarce resources and the directing of program objectives. The client hierarchy serves additionally as a standard by which to measure and evaluate programs and services. 


\section{ROLE OF THE COLLABORATIVE}

The collaborative exists to facilitate sharing and cooperation between groups of different resources to meet a determined need or provide a solution to a defined problem. The participating groups may have no reason to work together save for the special product acheived through collaboration. Collaboration between groups may not be possible, or as effective, without the special coordinating efforts of the collaborative organization. The collaborative may additionally serve the role of catalyst, making of the individual offerings of participating groups a new program(s) or service(s). In the above capacities, the collaborative serves the following programming roles:

\section{Brokering Role:}

As broker, collaboratives link outside resources (services, speakers, programs, equipment, etc.) to meet the service needs of member organizations, ad hoc participants, and occasionally, the direct people within the service district.

Program/Service Planning Role:

As program and service generators, the collaborative staff develops, plans and administers programs which utilize the resources (funds, skills, materials) of participating groups to respond to a perceived need. Program generation necessitates a larger staff than the typical brokering agency in order to perform the development and planning of programs. The planning role generates

- programs

- supporting services to the cooperating organizations or their clients 


\section{Collaboration Support Role:}

In this role, the collaborative provides additional services to maintain the existance of the collaboration. These services may include

- fundraising: for grants for the support of collaborative administration and collaborative activities;

- communication: between collaborating groups, their clients and interested parties;

- technical assistance to client operations;

- information dissemination: to the general public regarding the activities of the collaboration.

Although a few collaboratives serve primarily as either brokers or program planners, the following matrices depict that most collaboratives serve a combination of the above roles (see matrices section). 


\section{COMMUNICATION-\& INFORMATION NETWÖRKS}

Shared understanding and communication between different organizations, their clients and the collaborative is an element critical to effective collaboration. However, this communication may become extremely complex as the number of collaborating groups and their clients grow geometrically. Shared understanding requires shared information as well as communication. This communication and information occurs through formal and informal mechanisms. More formal procedures established for the express purpose of communication or information gathering and sharing, include: annual meetings, newsletters and publications, needs assessment surveys, among others. While these structured opportunities are helpful, they tend to direct communication in a single direction and are infrequent.

opportunities for information sharing and communication must be continual and must allow for exchange of ideas in many directions - between policy makers, program planners, consumers and clients. Some collaboratives present spontaneous opportunities for such exchange. Other collaboratives must be responsible for establishing such communication and information networks for exchange of and response to ideas, concerns and problems, constraints, and needs. Some of the more common methods of structuring communication and information networks include: 
Board Membership:

Board membership (particularly of consumers and/or subscribing members enables only communication and information sharing at the policy level, and may be ineffective if the board is inactive.

\section{Subscribing Membership:}

Subscribing membership offers a potential for a communication and information network, particularly if the members are well acquainted with each other. These members are represented to some degree on the governing board. Moreover, the payment of dues to the collaborative may secure a more active interest in the operations of the collaborative. However, this mechanism provides minimal input from the ultimate clients of the collaborating groups.

\section{Advisory Groups of Clients:}

Advisory groups of the clients (impacted, involved, concerned) may provide valuable client information, and communication between the program and service planners of the collaborative and the intended recipients.

\section{Liaison or Ombudsman:}

The liaison or ombudsman is located at the critical point where most information and communication is generated, or where most organizational or programming problems arise.

Opportunities for communication and information sharing vary widely between collaboratives. However, these opportunities are useless unless the communication and information shared, forms the basis for collaborative operations and programing. Communication is requisite for the determination of goals, the sharing of resources, the identification of issues and defining of needs, and for the coordination of collaborative activities.

Moreover, collaboratives may find it necessary or desirable to cooperate with other collaboratives when 
seeking similar goals or operating under similar strategies. Communication and the sharing of information and data resources may facilitate the most effective cooperation between collaboratives in best meeting its individual goals. 


\section{PROGRAMMING}

Programs and service offerings of different collaboratives display various degrees of structure. Each collaborative may employ various styles for each program and service provided. In general, collaborative programs and services are structured and offered in one of the following manners :

more flexible programing and service design

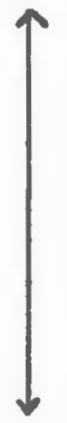

more rigid programming and service design greater planning function

$$
\downarrow
$$

greater brokering function multiple, - Programs and services are diverse designed by the collaborapartici- tive and individual propants

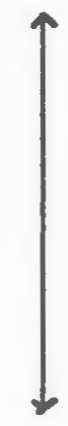

participants of similar needs and - Collaborative designs and motivation gram participants (or clusters of participants) to suit their own needs. Programs are flexible enough to support a wide range of specific plans within established program guidelines under supervision of the collaborative.

- Collaborative provides a selection of programs or services around one program concept or one program core.

offers one program or service offering per area or client need in which participants choose to participate or not after all program planning has been performed by collaborative staff. 


\section{INCENTIVES FOR PARTICIPATION}

Organizations evidence a gamut of reasons for participating in collaboration. These incentives may be defined as the motivations that encourage an organization to seek an alternative mechanism for service and program delivery. These motivations for collaboration extend beyond the actual benefits and returns collaborations confer. A single organization may itself hold diverse motivations for collaboration. These incentives range from the draw of collaboration as a more effective delivery mechanism to the necessity to collaborate and may vary with-individual programs within an organization.

Defining an organization's incentive to collaborate is valuable because it reflects that organization's degree of commitment to the collaboration. Organizations that collaborate for less compelling reasons may be less impelled to actively participate or cooperate because their need for collaboration is not as great as for other organizations. Levels of commitment may be located along a continuum of organizational motivations for collaboration. Again, collaborating groups often evidence different incentives for collaboration, and few collaborating groups will fall at a single point along the continuum. However, certain incentives may hold more weight, thereby determining commit- 
ment to the collaborative. The continuum of motivation presents the following generalized tendencies for commitment to the collaboration:

Degrees of Organizational Commitment to Collaboration

least commitment to collaboration

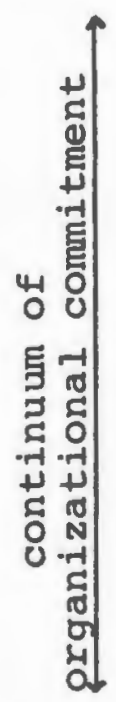

greatest commitment to collaboration
Organization Motivation for Collaboration

- enhance service or program provision

- improve ability to deliver services and programs already being delivered, albeit with difficulty

- ideological attachment to goals of an established collaboration

- capture increased funding for organizational activities

- meet strong external demands on organization (public mandates, community pressures)

- meet a specific client need not possible without collaboration

Thus, the collaborative can identify the predominant motivations of the participating groups, can often predict the commitment, participation, and cooperation of that participant. 


\section{BENEFITS OF COLLABORATION TO PARTICIPANTS}

Participants seek and generally receive diverse benefits from collaboration. Collaboration as a mechanism for cooperation and sharing can:

- pool resources to acheive cost-efficiency and economies of scale in program and service provision;

- share communication and understanding between organizations of similar goals and purposes;

- augment the power of smaller organizations by increasing resources and improving public images;

- generate innovative programs and services to meet the needs of, and extend benefits to, an organization's clients.

The special efforts of the collaborative may additionally provide:

- technical assistance and staff development to enable organizations to better conduct operations;

- fundraising and public contracting;

- public information dissemination.

Each individual collaborative, however, displays certain advantages over other collaboratives according to its particular purpose, role and the needs (client needs and organizational needs) of its participants. 


\section{MASBO COOPERATIVE CORPORATION}

Overview

MASBO Cooperative Corporation, Inc. (MASBO Coop)

is a non-profit corporation which has been formed to provide programs and services to school business officials, managers and administrators to assist them in more effectively conducting the management of schools. MASBO COOp's programs and services are offered to these school businesses and administrative officials as "cooperative projects" because programs and services recipients share some of the shaping, and all of the costs of the services. Cooperative projects are formulated with prospective school districts, who jointly agree in advance to the extent of the project, the methods of prorating costs among the school districts, and the goals and objectives to be acheived. 7 Thus collaboration occurs between the participating school districts on an individual program basis and is evidenced in shared costs, shared goalsetting, and shared decision-making to meet common participant needs.

MASBO Coop is a subsidiary of the Massachusetts Association of School Business officials, Inc. (MAsBo Inc.), a professional membership society of education administrators in the field of school business administration. MASBO Inc. is involved with MASBO Coop's operations. MASBO 
Coop's members and participants must not only be members of the Massachusetts Association of School Business Officials, but the latter organization is present as a voting member on MASBO COOp's Board of Directors. Thus, the Massachusetts Association of Business Officials plays an active role in shaping MASBO Coop's policies. And MASBO Coop benefits from this affiliation. The Massachusetts Association of School Business officials provides communication and information distribution for MASBO Coop between school districts. All members of the Massachusetts Association of School Business officials are familiar with the activities of MASBO Coop. Not only does this provide advertisement for MASBO COOp, but MASBO Coop learns of the particular program and service needs of MASBO, Inc. members. MASBO Coop is thus able to design programs and services relevant and particular to school business managers and administrators. MASBO Coop additionally has members from other professional associations. As MASBO Coop writes,

It is unique in that it has working relationships with and may use not only the resources of the memberships of its parent professional association, but of other educational and quasi educational organizations, such as the Massachusetts Business Task Force, who are dedicated to improving business management and administration practices in public education in the Commonwealth. 8

Robert Pritchard, present Executive Director of MASBO Coop, identifies this affiliation as the key to MASBO Coop's continued success. 9 
MASBO

MASBO Coop is a private non-profit tax exempt

COOP

Financial

structure

corporation organized under Chapter 501 (c) (3) of the Internal Revenue Code. As a membership collaboration, MASBO

Coop charges a small membership assessment annually.

However, MASBO Coop receives most of its financial support

from program and service assessments of participating member school districts.

MASBO

Coop

Governance

Structure

\begin{abstract}
are responsible for "the property, affairs, and business of the corporation."10 The board is responsible for setting
\end{abstract} the policy of the corporation, disbursing funds, and supervising its activities. The board is restricted to seven members, including the Executive Director of MASBO Coop. Further, each director must hold memberships in the Massachusetts Association of School Business Officials. The directors are elected by a majority vote of MASBO, Inc., after first being nominated by the present Board of Directors of MASBO Coop. Thus MASBO, Inc. is very much involved in the decisions of MASBO Coop. The directors serve a three year term and are elected on a staggard basis. The President of MASBO Coop, who presides at all board meetings and appoints all committees, is formally responsible for the policy direction of MASBO Coop. There are additionally two Vice Presidents and a Treasurer.

School districts must be members of MASBO Coop in order to participate in programs and services. The 
member school districts must be approved by a vote of the Board of Directors. Other corporations and associations may additionally become members of MASBO Coop by a vote of the Board of Directors. Upon election to membership, each member designates a representative who attends meetings and holds a single vote. Finally, MASBO, Inc. is a voting member of MASBO CoOp.

The Executive Director, however, has responsibility for the day to day decision-making making and programming of MASBO Coop within the policy set by the board. He may be assisted in any special committees (appointed by the President) that are deemed necessary. Today, MASBO Coop has a full-time paid staff of two and an employee in marketing, besides the Executive Director.

MASBO

COOp Gals purpose:

The major purpose and goals of MASBO Coop include:

To promote, facilitate, and implement joint ventures and cooperative programs...to improve the capability of people who run the administration and business of schools.

\section{Contextual Goal:}

To advance education and lessen the burden of government at elementary, secondary, college, and post-graduate levels.

Active Goals:

- To conduct research programs in management of schools and all levels of other organizations related to school administration and management.

- To provide services, programs, technical assistance, training to assist state and local governments, 
school officials and personnel and the general public better conduct the management of schools.

- To improve the planning, organization and coordination of school management and business operations.

MASBO MASBO CoOp provides the following cooperative

CoOp

projects and services: 12

$\frac{\text { Services \& }}{\text { Programs }}$

Cooperative Projects:

- Audio-visual inventory control system cooperative

- Teacher recruitment program

- Audio-visual materials and control system cooperative

- Programmed budgeting and accounting

- School property accounting and inventory control system

Publishing Services:

- Print and distribute Early Education Project Reports

- Develop, publish and print Chapter 766 Administration Manual

- Comply, publish and print Mass Bay Cooperative Data Reports (MASCODS)

- Print and distribute Metro Project Reports

- Print and distribute School Vandalism Study Report

Business Services:

- Provide school business system coordinator and trouble-shooter

- Provide accounting services and monitoring of financial affairs

- Provide transportation and custodial services

- Develop and install new accounts payable system

- Evaluate school business mangement organization, and recommend changes

- Install Encumbrance Accounting System 
Seminars:

- School property damage control

- Chapter 766, Business and Financial Management

- Management training and development

MASBO

The purpose and goals of MASBO Coop establish the COOP

Clients following clients:

Impacted: school managers

(direct business officials

beneficiaries) school administrators

Involved: school adminstrators, managers, district

(in programs/

services) officials

school officials

business and administration experts

Massachusetts Association of School

Business officials

Concerned: $\quad$ school officials

(with program/ parents, students, teachers

service outcomes) interested community groups

taxpayers

Massachusetts Association of School

Business officials

MASBO

COOP

Roles

has been formed to "promote, facilitate, and implement

joint ventures and cooperative projects."13 In this role, the MASBO Coop's Executive Director and his small staff

develop and coordinate programs and services in response to

member needs and requests using resources of the business

administration community to provide technical assistance,

instruction and technical equipment, in-service training,

continuing education, and subject area programs. In addition,

MASBO COOp initiates and plans programs and services which 
the staff perceives may be of need to collaborative members. MASBO CoOp writes,

MASBO COOp will serve as a vehicle through which voluntary cooperative ventures can be administrated and implemented without the 'governance' hindering or interfering with the successful completion of the proposal. The organization will solicit contracts, hire and supervise personnel, incur necessary expenses, and will be responsible for the overall management and fulfillment of project operations.

Robert Pritchard explains, "MASBO Coop is a business and administrative cooperative which exists for the purpose of implementing rather than membership. "14

MASBO Coop businesses, and management personnel from various school districts in cooperative projects. MASBO COOp links existing business and management resources to meet the needs of its participating members.

These school management and administration officials are responsible for an increasing number of business operations which demand sophisticated management knowledge and training. MASBO COop provides school management and administrators with workshops and training seminars, technical assistance, as well as management systems, technical reports, equipment, and other programs which modernize the operations of school business and administration. Some services may strengthen or supplement an area of responsibility; other services may meet a more urgent school need. Cooperation in each MASBO Coop project is 
likely to be high because each participant is contracting for a specific service to be provided by MASBO Coop. MASBO Coop members voluntarily choose in advance to participate in each individual program or service. As the costs are prorated between the participants, the greater number of participants the lower the individual program or service assessment for each participant. Thus the participating school districts benefit by receiving needed programs and services which are cost-effective and relatively tailored to participant needs. 


\section{METROPOLITAN CULTURAL ALLIANCE}

Overview

The Metropolitan Cultural Alliance is a private

non-profit cultural arts organization. The Metropolitan

Cultural Alliance is a membership collaborative of cultural institutions, commercial arts organization, businesses, and individuals, dedicated to the advancement and support of the cultural arts.

The Metropolitan Cultural Alliance was formed in 1969 by an assemblage of directors and administrators of greater Boston's cultural institutions concerned over escalating institutional operating costs, intensified competition for funding, and inefficient management practices. These cultural institution directors and administrators sought collaboration in order to share ideas, raise funds, and provide cost-effective programing. As the Metropolitan Cultural Alliance writes,

We're realistic about art. We know creativity alone won't always keep the doors open... We help over 100 organizations prepare and analyze budgets. Raise and spend funds. Hire and manage employees. Promote themselves to the media, the public, government and business. We offer group health insurance. Management seminars and workshops. Computerized financial services. Centralized purchasing. A publicity guide. At the Metropolitan Cultural Alliance, our only business is keeping the arts in business. 15

Alliance Financial Structure

The Metropolitan Cultural Alliance is organized 
pursuant to Section 501 (c) (3) of the United States Internal Revenue Code. Contributions to the corporation qualify as charitable deductions. The Alliance has a very diversified financial structure which generates funds for Alliance programs and services. Alliance public support and other revenues have increased from Fiscal Year 1976 - 1977 by thirty-three percent. 16 The Metropolitan Cultural Alliance receives revenues from three major sources. First, the Alliance receives membership fees from collaborating cultural institutions, commercial arts organizations, businesses, and individuals. Member institutions are charges between one hundred dollars and six hundred dollars a year, depending on the size of their staff and budget. Individual members are charged a flat fee of twenty-five dollars a year. ${ }^{17}$ In 1977, membership dues constituted twenty percent of all revenues received. This was down from the 1976 figure of thirty-one percent. Secondly, the Alliance receives financial support from public and foundation grants. This has been an increasing source of Alliance support, rising from forty-seven percent of total 1976 revenues to sixty-six percent of total 1977 revenues.

Thirdly, the Alliance charges assessments for selected programs, services, worksops and seminars. These assessments constituted thirteen percent of total 1976 revenues and eleven percent of total 1977 revenues. 
The Metropolitan Cultural Alliance is conducting a fundraising program worthy of particular note. The Matching Membership Program, initiated in July 1976 with grants from the Permanent Charities Foundation and the National Endowment for the Arts, seeks to increase and broaden the direct financial support of cultural institutions by businesses and their employees.

The Matching Membership Program is based on the belief that,

if more arts organizations would institute membership plans offering tangible benefits and priveleges, more people would join and automatically renew their memberships each year. Arts organizations could count such membership fees as earned income, and businesses could see their matching grants as extentions of their employee benefit plans, rather than as substitutes for direct corporate giving. Everyone would gain, the plan offering a democratic process for selecting cultural institutions that would receive additional help. 18

The Matching Membership Program requires that participating businesses match two dollars for every one dollar of membership purchased by their employees in any cultural institution. In return, the new members are eligible to participate in such services as the Alliance's Blue Cross/Blue Shield Plan or the Harvard Community Health Plan. $19-$ All program promotion and coordination is provided by the Alliance. In its first eighteen months ending December 31 , 1977, the Program generated over seventy-two thousand dollars for Alliance member - cultural institutions. The Matching Membership Program is expected to generate over one hundred thousand dollars annually by 1980. 20 
Alliance Governance
As a membership collaborative, the Metropolitan

Cultural Alliance is governed by its member organizations. The members meet annually to conduct general Alliance business and hear reports, and to elect a Board of Trustees. Each member organization has two votes in choosing trustees. All trustees must be representatives of the member organizations. Thus, the Alliance serves at the direction of its membership. As the Alliance Annual Report writes, "The Metropolitan Cultural Alliance is a service organization shaped by the cultural institutions to meet their needs." 21

The Board of Trustees consists of representatives of cultural institutions, public offices, educational institutions, businesses, and educational services. Sixty percent of the trustees must be directors, officers, or trustees of member organizations. Thus, the Board reflects the needs of the administration of cultural institutions. The Board of Trustees "shall consist of not less than fifteen nor more than sixty persons elected by the members of the corporation". Each trustee serves a three year, nonsuccessive, term. The Board sets the policy direction and is responsible for the "general supervision and control over the porpoerty and affairs of the corporation." 22 The Board additionally has the power to appoint any committee deemed desirable to serve under the supervision and approval of the Board. For example, a task force of trustees was formed to assist the Executive 
Director in planning, implementing, and monitoring a single program, the Boston Arts Computer Hook-Up. The officers of the Board of Trustees include the President, as "Cheif Executive Officer", aided by a Secretary and Treasurer. The Alliance Executive Director and staff conduct the daily decision-making of Alliance operations and programming. However, the Board has indirect influence over even these daily operations as it is responsible for appointing the Executive Director, choosing all members of the Alliance staff, and approving all budget and program suggestions of the staff.

Moreover, the Board is organized into "Membership Divisions" according to art discipline or area of responsibility. The standing divisions include: choral groups, dance groups, museum directors, community service grganizations, and the Boston League of Resident Theatres. These divisions, which meet regularly to exchange information and share ideas, provide a valuable information input to collaborative programming. The Alliance reports,

It is the Alliance's intention... to expand the number of divisions among member institutions while also strengthening the existing divisions by providing more active use of outside resource people who are willing to share their insights and their experience. 23

Alliance

Goals

The major purpose and goals of the Metropolitan

Cultural Alliance include: 


\section{Purpose:}

To provide a vehicle by which cultural institutions and interested groups may join together to improve their management and funding capacity, and address common issues in the growth and development of the cultural arts.

\section{Contextual Goal:}

To advance and support the arts and culture of greater Boston.

\section{Active Goals:}

- To strengthen the communications and management effectiveness of member institutions;

- To institute cost-effective services which improve the capacities of member cultural institutions;

- To express the concerns of these institutions and promote the value of these cultural institutions to the community-at-large;

- To provide new sources of earned income for the cultural institutions;

- To reduce members' operating costs.

Major

Programs

The Metropolitan Cultural Alliance's programs

\& Servicesand services are organized into two areas of program operation:

Membership Services - Those services available to all full institutional members of the Alliance;

Special Projects - Those projects of limited duration or involving a small pilot group of members. These programs are tested for their feasibility as regular Alliance Membership Services. 24

Membership Services - in particular:

1.) Central Purchasing System - an entirely new type of 
service, cooperative buying for members. The CPS model provides Alliance members with lower-cost office supplies, printing and paper products, fuel, artists app plies, library materials, mailing services, and a central answering service from a vendor selected by an extensive bid process. In return for coordinating, monitoring, and promoting this service, the Alliance receives five percent of the profits from the vendors.25

2.) Management Training Services Program - a monthly series of workshops which provide institution directors with in-depth technical management information and with opportunities for staff development. The workshop topics include: audience development, taxes \& charitable giving, fundraising, licensing, box office management, marketing the arts, unemployment compensation, pricing, tax shelter annuities. 26

3.) Information Services - provide opportunities for the administrators of member institutions to improve their management information and their sharing of that information. These opportunities include:

a.) ten monthly issues of the Alliance's newsletter, Currents, distributed to the cultural community which provides news on institutional management, staffing, funding opportunities and the results of Alliance surveys;

b.) problem-solving meetings and other workshops to generally provide technical assistance to Alliance members;

c.) a monthly bulletin identifying people interested in working for a cultural institution who have paid ten dollars to have their resumes so published.

Special Programs (in addition to the Matching Membership program, supra)

1.) The Boston Area Computer Hook-Up (BACH) - a comprehensive financial management system that provides Alliance member institutions with the automated accounting services and professional audits at less cost than they would have to pay individually.... This pioneer development is expected to have far-reaching impact on the ability of arts organizations to cope and survive, to enhance their fiscal credibility and to meet the ever increasing disclosure requirements of federal and state agencies as well as public and private funding sources. 27 
for the Metropolitan Cultural Alliance:

First, the Metropolitan Cultural Alliance coordinates such services as management experts, auditors, purchasing agents, and office suppliers to provide management and budget services, and workshops to Alliance members. However, the Alliance discovered that, "it was not sufficient to simply broker these services, but that it was necessary to have someone on the staff who was ultimately acquainted with the system and who could spend full time on consulting, training, and monitoring activities." 28

Secondly, the Metropolitan Cultural Alliance generates, develops, and monitors special projects and programs. The 1976-77 Annual Report writes,

During the period under report, we have devoted our principal effort to strengthening and expanding programs already underway. An unusually high proportion of the new Board members have become valuable and engetic participants in Alliance programs, partly through a highly productive task force structure. 29

Thirdly, the Metropolitan Cultural Alliance provides a communications link between member institutions and individuals. This communication occurs as the sharing of ideas and common problems at members meetings in group discussions and within membership divisions. Groups which meet regularly include: choral groups, community service organizations, museum directors, and resident theatres. The Alliance library provides literature on management and cultural arts, and the Alliance newsletter, Currents. 
disseminates management and cultural arts information to the cultural arts community. Additionally, the Alliance disseminates information on the activities and concerns of the cultural arts community to the general public.

Fourthly, the Metropolitan Cultural Alliance raises public and foundation grants, and matching business gifts which go to fund Alliance programs and services or are routed directly to member institutions.

Finally, the Alliance provides technical assistance to member organizations in proposal writing, staff development, and plan design for the Matching Membership Program.

Alliance establish the following clients of Alliance collaborative efforts:

\author{
Impacted: \\ (direct \\ beneficiaries)
}

Involved:

(in programs/ services) member cultural institutions and arts agencies

member individuals member businesses and their employees

members

vendors of management, auditing, computer, and office supply services

education and business consultants businesses and their employees funding sources

cultural arts community business community cultural arts audiences funding sources community at large 
collaboration cultural institutions, commercial arts organizations, concerned individuals and businesses to support cultural institutions in their growth and development. The Alliance links member institutions with business and management resources.

In particular, cultural institutions and arts organizations experience escalating operating costs in the face of increasing competition for funding. Member cultural institutions contribute towards collaboration their participation in Alliance governance and activities and pay assessments for membership and programs. Through collaboration, Alliance members save money, raise funds, promote the cultural arts, and share ideas. As an Alliance brochure concludes,

We offer central purchasing that saves member organizations 15-20 percent on office supplies, paper and other needs. Our computerized financial services help institutions get professional accounting, auditing, reporting and tax services. All at a minimum expense. We provide group health insurance. Discounts on MBTA fares. Employment listing and resume services. And a Live Calendar of all cultural events to avoid scheduling conflicts. Our Matching Membership Program encourages businesses and their employees to support the arts. We bring staff people and directors from members organizations together. To meet and discuss common problems. And to meet with outside experts to find answers. 30

And businesses benefit from membership in the Metropolitan Cultural Alliance. Businesses face dual pressures for employee and public responsibility. For example, businesses are called upon to provide employee 
group health plans. These group health plans are available through Alliance membership for mitnimal:cost:- Businesses. can begin to meet both these areas of public and employee responsibility by contributing to cultural institutions through the Matching Membership Program. As the Alliance writes,

Matching Membership is an employee benefit plan that brings businesses and arts together. Everyone benefits from Matching Memberships, Employees discover, enjoy, and support the arts. Business strengthens the cultural life in its community. And the arts receive the support they need to survive and grow. 31

Thus, the Metropolitan Cultural Alliance provides diverse services and programs for its member cultural institutions, arts organizations, and individuals which are cost-effective and generally designed by the members to meet their institutional needs. And the Alliance-generates funds for the support and advancement of the member cultural institutions. The Metropolitan Cultural Alliance, as a model of collaboration, uses the

position of the Alliance to open for /our7 members new opportunities to increase the memberships, subscriptions, ticket sales and other earnings, without interfering in the relationship of the institutions to their publics and without the Alliance assuming responsibility as a sponsoring organization. 32 


\section{METROPOLITAN PLANNING PROJECT}

collaborative of fifty-six school districts within the Boston metropolitan area working together voluntarily. The MPP is, as its name depicts, a planning collaborative, established in 1973 by a grant under The Emergency School Aid Act of 1972 from the U.S. Office of Education. The mandate of this planning project is to develop a ten year plan for the phased elimination of racial and ethnic isolation in the schools of the area through the school districts collaborating on a voluntary basis.

The programmatic efforts of the MPP are based on the active participation of groups involved in education school administrators, teachers, parents, students and community groups - to define problems, to generate ideas, and to incorporate their respective understandings into a workable plan. The ten year formula plan, "Metro Ways to Understanding", developed after the first year of planning, "is aimed at promoting voluntary collaboration between urban and suburban school districts and includes students, parents, teachers, school principals, superintendents, community organizations and others concerned with education."33 The plan contains broad policy and program recom- 
mendations for alternative metropolitan education programs which meet MPP's mandate and objectives. In 1975, a three hundred thousand dollar allocation from the U.S. Office of Education financed fourteen pilot projects to test the objectives presented in the formula plan. The projects included pre-kindergarten through high school age and focused on curriculum in human relations and cultural history and such topics as business and economics, art ecology, and energy. 34

The MPP is, foremost, a participatory planning effort. As an MPP report writes, the project seeks "to acheive effective community participation in an effort to design quality learning-environment programs for students."35 "Metro Ways to Understanding" was based on a multitude of meetings, workshops, presentations, and discussions between the administrators and faculty, parents, students of collaborating school districts as well as community groups, and legislators. However, participation and discussion between these diverse groups did not conclude with the presentation of the formula plan. Rather, "Metro Ways to Understanding served to focus and structure discussion, "beyond the initial planning goal to a programmatic and operational stage." The ten year plan is, therefore,

a working paper for a changing metropolitan area, not a blueprint. It includes a process to develop a consensus which will meet the ten year goal. The Project's intention is to break down artificial barriers as they exist today and transcend the social and political barriers as they may occur in the future. Its mandate is the framework for a consensus, and the 
variety of people and institutions within the Boston region are the resources for a pluralistic response. Between the presentation of the ten year plan and June 1975, the recommended metropolitan education programs will be discussed and debated throughout the Boston metropolitan area and, then, hopefully, adopted by school committees and community groups as that debate continues. 36

Further, the MPP has compiled an extensive data base from the information generated through group dialogue and staff research. This data base, in combination with the group dialogues, has provided an in-depth needs analysis and resource inventory upon which to develop the recommended educational programs.

Financ $\overline{\text { MPP }}$ Structure grants from the U.S. Office of Education under the Emergency School Aid Act of 1972. The express purpose of the Emergency School Aid Act, Section 709 (a) (2) of 1972, is:

to encourage the voluntary elimination, reduction, or prevention of minority group isolation in elementary and secondary schools with substantial proportions of minority group students. 37

In 1975, the MPP additionally received a three hundred thousand dollar allocation for pilot programming of the formula plan strategies.

Governance

The fifty-six school districts in the Boston

Standard Metropolitan Statistical Area which voted to collaborate in planning under the MPP constitutes the "General Membership" of the project. These participating school districts, however, pay no dues to the collaborative. 
The MPP staff and general membership are directed by a twenty-eight member governing board, which represents professionals, community power leaders, and consumers. The governing board is comprised of representatives of the seventeen local education agencies who have voted to become applicant agencies, eight members chosen by the advisory committee of the Project, one member representing METCO, one member representing the Commissioner of Education of the Commonwealth, and one member representing the Boston public schools. In addition, the secretary of Education for the Commonwealth, a representative from the Metropolitan Cultural Alliance, and a representative each from the Massachusetts Teachers Association and Massachusetts Federation of Teachers, sit on the governing board as ex-officio members. The governing board serves as the Executive Committee of the Project, determining all policies, programs, and activities of the organization. The governing board additionally directs the actions of the Executive Director and Project staff. 38

The governing board is advised by an eighteen member committee of school administrators, teachers, students, and community group representatives. The advisory committee advises the governing board in both program and policy decisions.

The officers of MPP include a Chairman, ViceChairman, Secretary and Treasurer. The Chairman, as executive officer, "presides at..all meetings of the-governing:board 
and of the general membership; reviews proposed agenda of these meetings with the Executive Director, who has prepared the same; appoints all committees; and performs any other duties as the governing board determines from time to time." 39 The officers are elected at the annual meeting by a quorum of the membership of the governing board.

The Executive Director of the Metropolitan Planning Project is selected by a search committee and approved by a vote of the governing board. The Executive Director, in turn, appoints all staff members but subject to the confirmation of the governing board. The large 1973-75 staff of the MPP was specialized in areas of planning and research, and included: support research staff, expanded community participation staff, design of learning environment staff, public information staff, administrative staff, and the Local Education Agency Field Agent staff. The MPP staff was supported by summer research assistants, and legal and technical assistants.

Thus, the collaborating groups participated in the formal and informal governance of the MPP through their active participation or representation on the governing board or advisory committee. Both bodies were responsible for the policy direction of the MPP. And the governing board participated in the daily decisions, and planning operations through their power of appointment of Director and staff, and power of approval over all staff proposals and programs. 
Planning Project include:

\section{Purpose:}

To plan programs involving the voluntary participation

of communities, organizations, and individuals in the

Boston Standard Metropolitan Statistical Area (SMSA)

for the purpose of reducing minority pupil isolation. 40

\section{Contextual Goal:}

To eliminate ethnic and racial isolation in the Boston metropolitan area.

\section{Active Goals:}

- To initiate a dialogue within the SMSA community regarding the goals and objectives of the planning project.

- To encourage and solicit a wide range of participation from school and community groups in the process of metropolitan collaboration. 41

- To develop the technical and information bases on the educational, demographic, housing, fiscal, socioeconomic, land use, and ethnic and racial characteristics of the seventy-eight towns and cities in the Boston Standard Metropolitan Statistical Area.

\section{Program Goals:}

- To develop a phased ten year plan for the phased elimination of racial and ethnic isolation in the school of metropolitan Boston through school district collaboration. 42

- To develop and test a variety of strategies which will reduce ethnic and racial student isolation.

MPP

several of the policy recommendations developed through the participatory planning process and presented in the formula plan "Metro Ways to understanding". These recommendations included: 
METROPATHWAYS - Quality innovative educational programs which are accessible to secondary school students of different socio-economic, racial and ethnic backgrounds within the metropolitan area by utilizing mass transit routes.

METROPAIRWAYS - Parents and school personnel from pairs and triads of city and suburban districts meet to formulate educational programs of equal benefits to the students. Learning centers are developed in schools and on third sites and each serve as a supplement to the educational programs of each individual school.

METROCENTER FOR COMMUNICATIONS, COUNSELING, AND RESOURCE DEVELOPMENT - This center coordinates the metropolitan educational programs and serves as an information and resource "bank" for students, parents, community groups and educators throughout the metropolitan area who wish to be involved in urban-suburban educational programs and staff development programs aimed at eliminating racial and ethnic isolation of students.

METRO ETHNIC HERITAGE RESOURCE CENTERS - These centers are coordinated within METROCENTER and promote the study, compilation, production and distribution of materials and information related to minorities and ethnic groups of the SMSA. They are also an action program for the development of other resource centers in the metropolitan area. 43

The purpose and goals of the Metropolitan Planning

Project establish the following clients of their planning

efforts :

Impacted:

(direct

beneficiaries)

student (participants and student body)

Involved:

(participants in

faculty, administrators, personnel

parents

programs/services)

students

parents

faculty, administrators, personnel community organizations

Massachusetts Department of Education U.S. Office of Education 
Concerned:

(with program/

service outcomes) school systems

parents

community organizations

Massachusetts Department of Education

U.S. Office of Education

community at large

General Court

MPP

The Metropolitan Planning Project is a collaborative planning agency. Its primary role is therefore program development and planning. The large MPP planning staff develops, plans and pilots programs which utilize the resources (knowledge, concepts, ideas, data, and facilities) of participating school districts, representatives, community groups, and other interest groups. A substantial component of the planning stages includes the development of an extensive data base. The MPP additionally serves a brokering role to link outside resources (transportation services, education and ethnic heritage experts, etc.) with its programing and pilot efforts. Finally, the MPP staff disseminates information regarding the MPP planning model to concerned parties and the general public. collaboration of diverse participants united in the mutual desire to reduce ethnic and racial isolation in schools. The participants in dialogue and planning include: students, parents, teachers, school principals, superintendents, community organizations, and others concerned with education. These participants contribute their time, energy, and ideas, data and facilities to collaboration. As a collaborative, 
the MPP seeks

to develop a structure for meaningful interaction through participatory planning between community groups and school districts and the MPP aimed at the development of proposals which will reduce ethnic and racial student isolation, such that a substantial range of educational problems and their solutions are represented in these proposals, and such that a substantial representation from urban and suburban minority groups are involved in these proprosals.44

Thus, collaboration through the MPP benefits participants as both a product and a process. First, the MPP programming has developed and designed quality, integrated learning environment programs which benefit students and their parents, school faculty, administrators and personnel. As the MPP writes, "As a result of city and suburban exchange of ideas, the MPP has helped to promote the development of over 78 proposals in 32 cities and towns for the design of new innovative learning environments."45 secondly, all participants benefit from the mutual sharing of information and exchange of ideas. Ultimately, the community at large benefits from such innovative educational programs and shared understanding. The MPP "represents one further step in the planning process. The programs and the implementation procedures recommended are the result of a dynamic and continuing process. They signify a commitment to action and an openness to dialogue." 46 


\section{METROPOLITAN COUNCIL FOR EDUCATIONAL OPPORTUNITY, INC.}

(MEICO) is a private, non-profit, voluntary organization which seeks principally to provide the opportunity for an integrated public school education for urban blacks and other minority students from racially imbalanced schools by placing them in participating suburban schools. The movement which led to METCO began in 1963 with a group of frustrated Boston black parents and educators who desired better educational opportunities for their children but found the Boston School Committee unresponsive to their appeals. The METCO program has grown rapidly. Initiated in 1966 with seven suburban Boston school districts, MEICO participation more than doubled in the second year. In 1968, the MEICO program received four major thrusts to its development:

1) The Massachusetts Iegislature appropriated funds through the Racial Imbalance Act for Boston and Springfield MEICO programs;

2) Fiscal remuneration was now absorbed by the state via the Department of Education, Bureau of Equal Educational Opportunity (BEFO);

3) Another double in the number of participating towns that hosted Boston children brought volunteer towns up to twentyeight;

4) Springfield began participation in a MEICO program with the pioneer efforts of the Iongmeadow and East Iongmeadow school districts. 47

And by 1976, MEICO participation had grown to forty-two participating 
Boston and Springfield schools and over three thousand inner city minority students.

METCO is the largest program of its kind in the country. As a model of collaboration, MEICO facilitates cooperative association between schools, parents and students. MEICO is responsible for coordinating students, recruiting and placing students, busing students to and from participating suburban schools, and providing supporting services to students and their schools. The participation of the students and the suburban schools is voluntary. As with all collaborations, the suburban school systems are sharing their resources with the MEICO students to acheive voluntary urban-suburban integration. The voluntary integration generates shared understandings and commuication between urban and suburban students, teachers and parents; reduction of feelings of powerlessness and alienation among METCO students; and a higher level of community for all participants. As Jean MCGuire, Executive Director of METCO, writes:

The METCO program deals with many facets of one aspect in school integration desired by most people. It does not confront the institutional and individual practices which perpetuate housing segregation and economic discrimination. It is the third chapter of a long book that has yet to be completed, about schools and citizens which accept graciously their share of the burden for the elimination of racism they have helped to perpetuate. 48

MEICO, Inc. has developed a set of guidelines or prerequisites to an effective collaboration program. Selection of participating METCO communities will be based on how a community and its school system has fulfilled or plans to meet the following prerequisites:

1) The Number of Students and Their Placement A new comminity should be able and willing to admit at least eighteen students in its first enrollment (To be cost effective a bus carries forty-two students). It is desirable to have the 
students placed in consecutive grades. There should be roam for at least two to four MEICO students in each potential classroom. The rationale for the above requirements have to do with problems related to transportation arrangements, economic considerations related to busing, educational planning and overall program efficiencies, and the orientation required by suburban teachers, administrators, and other school personnel.

2) Incorporating Afro-American Studies into School Curricula It is hoped that all school systems are already well engaged in the business of integrating their curricula with Afro-American material and that multi-ethnic and multi-racial texts, trade books, audio-visual aids, magazines, etc. are available and that they become an integrated part of courses with units of study. METCO will never reach its full potential for black or white youngsters unless African and Afro-American culture, history and experience are consciously built into the curriculum at all grade levels and in all disciplines - social science, history, science, music and art. Black children and youth must see themselves in the curriculum.

3) Non-white Teachers and Administrators A potential METCO Community should show evidence of active and sincere efforts to recruit teachers and other school professionals (counselors, administrators, para-professionals) who are black. The presence of competent black personnel is important for both black and white students.

4) Host Family Program

Because METCO students travel many miles to attend school, it is essential that each METCO student have a "home away from home". In case of emergency (sickness, transportation failure, stormy weather preventing a return trip to Boston), METCO students must have a family or families in the community to turn to.

5) In-service Human Relations Training for Teachers and Administators All administrators and teachers in a given community should recognize that they are part of the community culture. We can not ignore the pressing problems of race relations and its impact upon all children. There is an urgent need for all teachers to take every opporunity afforded to became sensitive toward the problem of black-white relationships and to recognize the need for promoting a greater understanding of the multiethnicity and culture of minority groups in the greater Boston area and in our country.

It is the teachers in the METCO-receiving communities who have, aside from the children themselves, the most day to day, hour to hour, involvement in the program. 49 
MEICO, Inc. MEICO recieved initial funding in 1966-68 from a grant fran Financial Structure the Carnegie Corporation and the U.S. Office of Education under Title III of the Elementary and Secondary Education Act to develop a plan for urban-suburban education integration. Today MEICO, Inc. receives no membership dues nor charges program assessments. The METCO program has been funded entirely by public grants under Massachusetts General Laws Chapters 506 and 636. Chapter 506 of the Massachusetts General Laws was passed in 1966, to provide "for the attendance of certain children in public schools of cities and towns other than the cities or towns in which they reside." METCO receives state funds under Chapter 506 of the Massachusetts General Laws to reimburse the participating school districts for the tuition of METCO students. Chapter 636 administers funding for programs that seek "to improve the quality of education in cities undergoing desegregation, and the transportation required by such desegregation."50 Chapter 636 thus provides funding for the transportation of METCO students as well as funding the cost to participating communities for additional students. 51

Finally, MEICO, Inc. raises additional private funds to finance staff and office operations through benefits and other functions.

METCO, Inc. METCO, Inc. is governed by a policy-making Board of Directors Governance composed of seventy-three volunteers representing the city and participating suburban cormunities. A nine member executive conmittee is responsible for supervising the business and operations of the collaborative. 
The Executive Director is responsible for the overall operations of MEICO within the policy directions set by the Board of Directors, and by the State Board of Education. The Executive Director may also suggest new policy areas to the Board. The Executive Director is assisted by an Associate Director, Administrative Assistant and a full-time professional staff. The Associate Director is responsible for central office administration, staff and department operations (transportation, community liaison, combined services, counseling). The Administrative Assistant develops special projects, maintains archives, and directs public information. 52

The staff is organized into functional areas of responsibility: transpotation, guidance and counseling, curriculum development, combined services, and community liaison. These departments provide a variety of services to parents, students and schools.

1) Transportation Transportation Director - has direct responsibility for route planning and design; monitors effectiveness; enforces behavior and safety standards; maintains the METCO Transportation System (MTS); plans routing for a centralized transportation system.

Transportation Specialist - assists Director in all functions. Both members are available to receive special instructions or receive emergency calls from parents regarding transportation problems.

2) Counseling and Guidance - is conducted by the METCO staff psychologist, social worker and guidance counselor who provide counseling, testing, diagnosis, and assistance to students in course selection, training and other college placement assistance.

3) Combined Services

Placement Officer - develops and executes plans for the systematic interviewing and placement of students for new and replacement vacancies in METCO communities; coordinates with the Cormunity Liaison Team, Transportation and other staff members an such activities. 
Recruitment Specialist - identifies candidates in education and related fields for placement in regular vacancies in suburban school districts; meets with personnel directors from government and school districts and other educational institutions to identify available job opportunities.

Tutorial coordinator - is responsible for the operation of the tutorial program; maintains records on students; supervises activities of tutors; insures that students are pre- and posttested to determine need and effectiveness of tutorial sessions.

Within this department, METCO continually assesses needs to provide additional services. Limitations on funding, however, impose restrictions on what services can be provided.

4) Community Liaison

At present, five staff members function as community liaison personnel. Each member of this team is assigned to a specific number of school districts. Their tasks include representing METCO in discussions concerning student progress, problem-solving, assistance to parents and students and other school related issues. Among the other duties that these staff members perform are assisting the Data Center in keeping accurate and timely records of parent addresses and telephone numbers, assisting the placement officer in interviewing new students for the program, and assisting in the development of snow chains. 53

Finally, METCO employs one person for each school community as the METCO coordinator. Each METCO coordinator is responsible for the administrative details of transportation and after school programs for MEICO students; overseeing the educational program of each student including course selection and any tutoring that might be required; and communicating between the METCO staff and school personnel. MEICO writes, "it has been increasingly clear that an essential and vital part of the MEICO program in each school community is the position of the cordinator."54 Thus the METCO coordinator brings the METCO administrative staff closer to school operations by providing trouble shooting and cammuications between participants. 
Purpose:

To provide a vehicle in which parents of school children and friends can came together to discuss and provide programs related to the educational opportunities for participating inner-city black and minority students.

\section{Contextual Goal:}

To reduce ethnic and racial isolation and provide quality education-

al opportunites for children of metropolitan Boston.

\section{Active Goals:}

- To provide the opportunity for an integrated public school education for urban black and other minority children from racially imbalanced schools in Bostan by placing them in suburban schools.

- To provide a new learning experience for suburban children.

- To provide closer understanding and cooperation between urban and suburban parents and other citizens in the metropolitan Boston area.

\section{Program Goals:}

- To provide the transportation for MEICO students between innercity home and suburban school.

- To provide support services to help the METCO student adjust to the different educational environment of the suburban school.

- To provide support services to aid staff, students and parents of the suburban school to help them fully take advantage of the opportunity to develop a multi-ethnic and multi-cultural classroam enviromment.

- To provide opportunities for parents of MEICO students to come together and discuss programs related to educational opportunites for children and parents.

METCO

$$
\text { The goals and objectives establish the following clients of }
$$

MEICO collaborative efforts:

Impacted:

(direct

beneficiaries) inner-city black and minority (METCO) students/ parents

suburban students/parents

faculty and administrators 
Involved:

(in programs)

Concerned:

(with program/ service outcomes)
METCO students/parents

suburban students/parents

suburban school faculty, administrators, personnel

host families

friends of MEICO

State Board of Education (acting through the Bureau of Equal Educational Opportunity)

bus drivers and monitors

suburban students/parents

suburban school faculty, administrators, personnel

educators

State Board of Education

comminity-at-large
METCO

Role

The goals necessitate facilitation and coordination as the

primary role for MEICO, Inc. The METCO program requires careful

coordination and supervision by the METCO staff. As a METCO brochure concludes, "the placement of black children from Boston into classrooms of suburban school systems is a difficult venture. There is more to MEICO than just placing students on buses each day. Careful preparation for this educational and social change is essential." 55

Specifically, MEIco has two areas of responsibility. First, METCO facilitates and supports the collaborative association between parents, students, school faculty and personnel to provide urbansuburban integration. In this role, METCO coordinates the diverse program participants and activities; trains bus drivers and designs transportation routes; recruits, places and provides tutoring for participating students; provides communication between participants and involved parties (such as friends of MEICO and the Massachusetts Department of Education); coordinates community parent meetings; develops long-range plans for expansion and qualitative improvement of 
the program in the local education agency; disseminates information on the METCO model; and captures public funds for suburban school reimbursement and raises additional funds for program operations.

Secondly, the staff of MEIco develops workshops, programs and services for METCO participants. Most of these programs or services call upon the resources of comminity education specialists (particularly in Afro-American studies and human relations). In particular, the METCO program deals with: 1) double standards, 2) human relations, 3) multi-cultural/pluralistic curricula, 4) AfroAmerican materials. Such programs include: 56

1) in-service training and workshops in human relations for teachers, counselors, administrators and in curricula development for directors and teachers. METCO writes,

It is recormended that all MEICO participating communities recognize and require teachers to participate in in-service curriculum and human relations workshops sponsored by the curriculum component of METCO. This will assist teachers in developing the knowledge, attitudes and interpersonal skills needed for quality education in the integrated classroom.... Further7, the curriculum department of METCO has developed a series of in-service workshops designed to increase knowledge and understanding about Afro-American History and culture. The METCO curriculum resource library contains numerous educational resources, teacher references, audio-visual materials, and books based on the Afro-American experience. The Curriculum Department also coordinates workshops designed to assist teachers clarify, modify and re-examine their own attitudes about race and cultural differences; and the effect these attitudes have on teacher competency and sensitivity in the integrated classroom. 57

2) programs for students, teachers, and/or parents. The "Black Studies Curriculum Project" is a program funded jointly by METCO and the Newton Public Schools to systematically develop curricula on Afro-American history and culture for all grade levels in the Newton Public Schools. In Brookline's "Multicultural Program", a METCO team consisting of a coordinator and three multicultural teachers works with teachers and administrators 1) to improve how they teach human relations, and 2) to improve how they work with their colleagues or children (i.e. positive role models). 
3) orientation programs for students, school administrators, personnel, school staff, bus drivers, and monitors.

More than any other collaborative described thus far, METCO is dependent upon many participants, mostly unpaid and voluntary, working in collaboration. "Involvement is crucial to the success of each child's education."58 Beyond the efforts of the METCO staff and METCO coordinator, major participants in the METCO program are: State Board of Education, parents of METCO students, suburban school systems, and suburban host families.

State Board of Education:

The role of the State Board of Education is the setting of policy guidelines for the operation of the MEICO program in Boston 59 , and the remuneration of communities, through a METCO account, for the direct costs of MEICO student tuitions. All conmunities that wish to participate in MEICO must submit plans that demonstrate compliance with Board guidelines for approval of the Board of Education. These responsibilities have been established for the Board by Chapter 636 of 1974 . The statute further requires, "the board shall provide technical and other assistance to any city or town, or regional school district, in the formulation and implementation of any such plan" for urbansuburban desegregation. ${ }^{60}$ The Bureau of Equal Educational Opportunity provides technical assistance in the formulation and implementation of plans to these suburban communities on behalf of the Board of Education. Such technical assistance in plan formation is also available from METCO, Inc.

MEICO Students and Their Parents:

METCO students and their parents volunteer to participate. 
Students are chosen on a first-came, first-serve, basis fran racially imbalanced schools thereby insuring a fair cross section of the applicants. All MEICO students may be members in a MEICO student council. The main purpose of the student council is to provide support for MEICO students through maintaining communication among students in all communities. In this effort it sponsors educational and social events. Parents of MEICO students are encouraged to become actively involved in the METCO program. The METCO program may require a difficult adjustment experience for the student. Parents knowledgeable of the potential student difficulties can ease any difficult adjustment period their child may encounter. And parents are important role models for their children and their personal attitudes towards human relations and their committment to the MEICO program can reinforce or undo their child's suburban education experience. As the METCO Parent Handbook exhorts,

MEICO depends on all of us working together. Develop your leadership as parents, share responsibility and information and work for real change by helping MEICO and its participating communities reach the goals planned in 1966. Any activity that does not allow your participation in its governance should be viewed as unworthy of your time. METCO must have your participation to help your children to learn and achieve. What is important and successful for you will be important for them. They are why you are involved.61

In order to ensure the important cooperation of the parents of METCO students, The Parent Handbook sets the following minimum conditions for parent participation: 62

1) Each parent must attend orientation during the period of time specified by the METCO office.

2) Each parent must ensure that his or her child adheres to the MEICO bus regulations for safety and conduct.

3) Each parent must attend four of six community parent meetings 
per year at the MEICO office. Parents are responsible for conducting their own community meetings. MEICO staff and coordinators can be available to assist, if requested.

4) Parents must attend parent, teacher and student conferences at the MEICO office, when called, with the guidance, counseling or tutorial staff regarding a student's academic and behavioral progress.

5) Each parent must make personal visits to his or her child's school at least four times per year (two during the first semester, September-December; and two during the second semester, January-May) for conferences with teachers, open house, guidance counselor or principal, and especially, when a child is promoted or there is a schedule change.

\section{Other Conditions}

1) Commmication should be established and maintained with host parents, if your child has one, or with other suburban-based groups. Your liaison team member or coordinator will provide you with the necessary information.

2) Parents and families should become involved in other activities of MEICO such as school cammittee meetings, carmittee work, recreational events and field trips. We expect all parents and students over eighteen to be registered and active voters.

3) Parents are expected to volunteer at least twelve hours per year for special projects and other activities at METCO and at your child's school.

Parents of METCO youngsters are organized into groups, each group representing the suburban town in which their youngsters are students. Each group selects two representatives to serve on the parent council. The council serves in an advisory role to the METCO staff and as an information link between METCO participants.

Through their participation in MEICO, black and other minority students and their parents have benefited from interaction and learning experiences with the white suburban students. Moreover, METCO affords black students and their parents a measure of equal educational opportunity and educational equity heretofore impossible in most innercity schools. 
Suburban School Districts:

The suburban school district is responsible to provide the same educational and support services to MEICO students as their regularly enrolled students. The school district must provide additional support services (counseling, tutoring, etc.) when required by the METCO student. MEICO, Inc. aids the school system in these special support services. The State Board of Education guidelines require,

The educational and social support required is the responsibility of the teachers and other school staff of the LEA, with the coordinator as an important member of the supportive team. The major function will include strategies that will:

1) Assist the METCO pupils in adjusting educationally and socially to a different educational environment;

2) Provide local role models as a source of inspiration and encouragement for greater learning;

3) Assist with the administrative functions directly pertaining to METCO within the communities.63

Although the suburban school systems pay no tuition for MEICO students and are generally reimbursed for additional program expenditures from MEICO, Inc., school systems must contribute teacher time and school facilities for in-service training and workshops. Moreover, the school must be of strong commitment to the METCO program and be receptive to curricula changes, staff development efforts and other involvement of MEICO, Inc. In return, the suburban programs have assisted, however minimally, in educational desegregation, have diversified their curricula, and have offered their principally white student body a new learning experience.

The suburban schools benefit immeasurably from participation in programs. 
MEICO is seen as an opportunity for suburban Boston communities to improve the quality of their respective school systems and to provide new learning experiences for their resident students as well as for children fram Boston. The MEICO students bring fresh insights and new perspectives to the suburban classrocm. MEICO is a two-way street benefiting all children.

Moreover, the school has benefitted from the concomitant development of black studies and human relations curricula. The MEICO program additionally benefits the school faculty and personnel. As the Iincoln Host Family Comittee writes,

MEICO attracts teachers with the kind of motivation and commitment that tends to enrich the school program. It provides teachers already in the system opportunity for personal and professional growth.

MEICO has brought black adults into the classroams, which makes for greater diversity and provides positive role models for both black and white' students. 64

Host Families:

Host families are least involved in METCO activities, but are nevertheless important. Host families are suburban families which have opened their hame and friendship to a MEICO student. The host family provides a home-away-from-hame to the MEICO student in times of inclement weather, after school activity, or emergency. The MEICO office has prepared a detailed list of guidelines for host family selections and functions. Both the suburban family and METCO student benefits from the exchange of friendships and commuication.

In conclusion, the voluntary collaboration achieved through the efforts of METCO, Inc. confer substantial benefits to the diverse program participants. As the State Board of Education writes, "one must not overlook the simultaneous human relations benefits occuring to hundreds of white students, teachers, and educators who share the 
integrated experiences made possible by the MEICO $\infty$ ncept."65 And, as Dr. Julian Demeo, Jr., the superintendent of the Braintree Public Schools, concludes,

Better understanding, closer coperation, new learning experiences, and improved educational opportunity between blacks and whites are the outoomes of the MEICO program in Braintree. 66 


\section{EDUCATIONAL COLLABORATIVE FOR GREATER BOSTON, INC.}

Overview

The Educational Collaborative for Greater Boston, Inc., is a private non-profit corporation organized under Chapter 180 of the Massachusetts General Laws. It is the largest multi-purpose collaborative in Massachusetts. Originally chartered in 1969 by seven school districts, EdCo today includes twelve school systems from metropoli$\tan$ Boston:

Boston, Boston Archdiocese, Bedford, Brookline Cambridge, Lexington, Lincoln-Sudbury Regional High, Medford, Newton, Sudbury, Waltham, Watertown. These school systems are member districts within the collaborative. EdCo also boasts the largest staff of the collaboratives here surveyed, with thirty to forty persons in-office, and two hundred and fifty persons on the EdCo payroll.

Financial Structure

EdCo had its inception in a Federal Title III grant to stimulate voluntary urban/suburban interaction. Today, however, EdCo has several forms of funding to support its four and one-half million dollar budget. First, the twelve school systems which subscribe to EdCo pay fees based on their student enrollment. Each school system is assessed about seventy-five cents per pupil up to a maximum of ten thousand dollars for each 
member system. In 1977, EdCo received sixty thousand dollars in school membership fees.

Secondly, EdCo is also eligible for federal, state and private foundation grants and contracts. State contracts provide the majority of EdCo's subsidization. For example, EdCo contracts with the state Department of Education to provide "special education" programs and services under Chapters 753, 767 of the Massachusetts General Laws. This 'quasi-public' status permits EdCo to act as an extension of the public school systems yet have the freedom and grant eligibility of a private non-profit corporation. Under such-an arrangement, EdCo can operate the Brookline/ Newton Pre-school For Handicapped and Hearing-Impaired Children as a private school located within a public school financed with both public and private funds. Executive Director John Greene identifies this quasipublic status as a critical element to EdCo's success. Thirdly, EdCo charges assessments for many programs and services, and receives tuitions for several long-running programs.

Thus, EdCo supports a diversified funding base which includes grants, direct contracts with the state, and the pooled monies of member school systems directed to the collaborative as membership fees and program assessments. In 1974, only three percent of the funding for programs was provided through membership fees. Ninety- 
seven percent of the funding was provided by contracts, grants, and program assessments.

EdCo, Inc. Governance

EdCo is governed by a Board of Directors comprised of the superintendent and a school committee representative from each member district and a representative of the independent schools. Each director serves at the pleasure of the school district he/she represents, but sits on the board as a private member with individual veto powers. The President of the Corporation presides at the meetings of the Board. The President is vested by the By-Laws as the Cheif Executive Officer of the corporation with "general supervision and control of its affairs" but "subject to the direction of the Board of Directors." The Board sets policy for the collaborative. Meeting five times a year, the Board has the power of approval/disapproval over all major collaborative projects. 68

The more frequent EdCo decisions are made by the advisory committees, the staff and Executive Director. There are many advisory committees. A central group is the advisory committee for curriculum structure and studies made up of the assistant superintendents of all member school systems. This advisory committee, which conducts the needs assessments on which to base the educational programs, necessarily meets frequently. There are additional advisory committees for each program area. The special education advisory committee is the most active 
of the program advisory groups.

Much of the large EdCo staff is specialized in areas of educational problems and programming, and is divided into specific areas of program responsibility. This large, specialized staff has a reputation for competance and innovation. Program area logos enhance the image of specialization and professionalism.

EdCo, Inc. The major purpose and goals of EdCo include:

\section{Purpose:}

EdCo exists to provide both programming and services to schools at lower cost with provisions for higher quality than that which can be provided by a single school district. 69

\section{Contextual Goal:}

To increase the quality of education for general and special needs students in metropolitan Boston schools, and to eliminate ethnic and racial isolation in those schools.

\section{Active Goals:}

- to provide cost-effective services and programs on a collaborative basis to meet significant education needs of metropolitan Boston students and their school districts.

- to generate alternative programs which bring together white and non-white students in innovative learning environments.

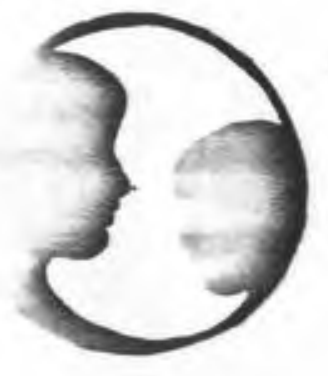

a.) Special Education Programs -

These programs seek to develop and maintain educational enviruilitents for low-incidence handicapped students presently in state institutions or making the transition into the community. 

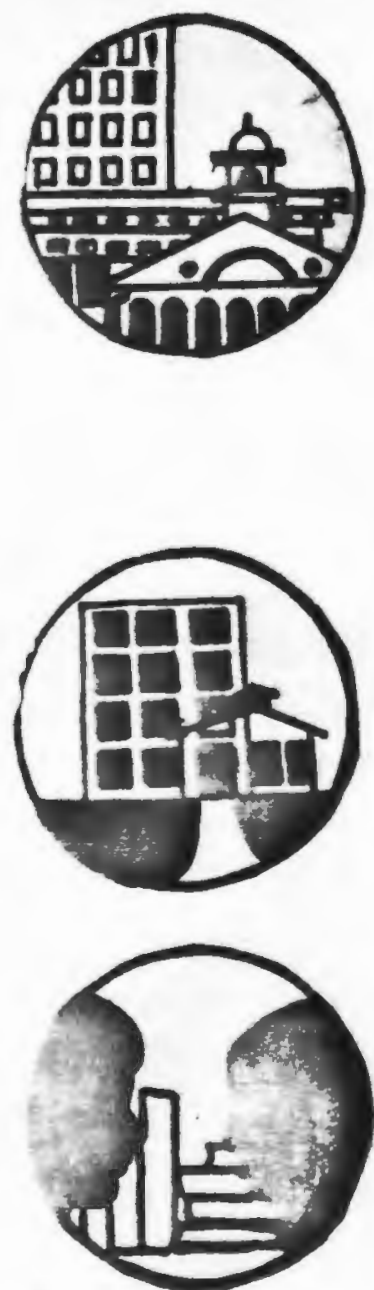

Service Goals: b.) Urban-Suburban Programs - seek to promote the use of community resources while bringing together students from diverse backgrounds in voluntary, interracial and crosscultural learning at a neutral third site. Some students participate in intensive, short-term experiences in areas such as politics and government, international education, American social and cultural history, or environmental studies.

c.) Industry-Based Career Education Programsprovide students the opportunity to explore the large variety of jobs, to acquire basic knowledge or skills related to particular careers, and so to make informed career decisions. Students work part-time after school and full-time during the summer while continuing study and receiving credit for their participation.

d.) permanent programs - such as the Reading and Learning Center which seeks to establish a diagnostic tutoring and training center to provide remedial activities in basic skill areas for students with learning difficulties.

to provide numerous educational services to member school districts including: teachers' and administrators' in-service training, curriculum and material development and dissemination, evaluation and conferences on timely topics. 70

EdCo, Inc. Clients
The contextual goal establishes the students of metropolitan Boston as the major clients of EdCo. More specifically, EdCo's clients include: 
Education Programs

Impacted:
(direct
beneficiaries)

Concerned:

(with program/ parents service outcomes) health agencies

state Board of Education employers

interested community groups

community at large

taxpayers

funding sources

special needs students

enated students

all students

faculty

State Board of Education

community professionals

funding sources
School Services

teachers

administrators

-isolated students

advisory committee members

special education experts

with whom students intern

career education employers

teachers

administrators

education experts

funding sources

school personnel parents, students state Board of Education community at large taxpayers

funding sources

EdCo, Inc. Roles

The above goals and clients require EdCo, Inc. to serve the following roles:

First, EdCo, Inc, is responsible for program development and" coordination. As EdCo writes, "program development is an on-going, creative process tapping the talents and resources of member school systems as well as EdCo staff members. ${ }^{71}$ Additionally, EdCo brokers the services of education experts and other resources (such as Lesley College) in teacher training institutes, and other workshops and seminars. Secondly, EdCo provides a communications link 
between member school districts, and between school districts and several state agencies. The EdCo staff maintains close contact with the Massachusetts Department of Education, other academic institutions, and educational groups.

Thirdly, EdCo provides fundraising to support collaborative activities. EdCo exists as an intermediate agency between the State and Federal education offices and the local school district to capture funding.

Finally, EdCo disseminates information on its innovative programs and services to education officials and other interested school systems.

In sum, EdCo develops ideas, implements those ideas, modifies the programs according to an on-going evaluation, and then disseminates information on the model's success so that it can be replicated by many school systems. 73

EdCo, Inc. Participants

Thus, school systems -- administrators, faculty, students, officials -- are united in collaborative programs and services with other school systems. Additionally, educational experts and other community resources are coordinated to meet the service needs of school systems. In their role as participants, school systems contribute staff, physical facilities, academic credit, assessments, and students towards collaborative programs and services. Participation in EdCo is voluntary. A school system becomes a member by vote of its school 
committee and approval of the EdCo Board of Directors. Once members, school systems are required to pay annual membership dues but are not bound to participate in the different programs or services. At program proposal stage, a memo is distributed to members to inform them of the program and encourage their participation.

Membership in EdCo extends many benefits to school systems, including:

- innovative programs and services which would not be possible if not for collaboration through EdCo;

- cost-savings for services and programs which school systems would otherwise have to develop independently and at higher costs;

- specialized educational services designed by knowledgeable program staff and education experts which assist school systems meet state and federal mandates;

- administrative and faculty support services such as teacher in-service training, curriculum and material development, and evaluation workshops;

- exchange of ideas which ends, isolation between school systems, education agencies, and education experts.

Thus, EdCo provides many planning and service activities under its 'umbrella' designed to meet the varied needs of metropolitan Boston school systems through collaboration. 


\section{VOLUNTARY EDUCATIONAL COLLABORATIVES}

given to a group of over forty-three formal educational organizations serving three hundred and ten cities in Massachusetts. 74 These educational organizations provide the opportunity for local schools to collaborate to overcome many fiscal and administrative needs. Educational collaboratives are thus innovative responses to local educational problems and needs. They facilitate the pooling of resources and the sharing of costs between school districts to strengthen and supplement their school programs. Schools increasingly face problems of

declining enrollments, declining revenues and declining test scores, the cooperative resource sharing may prove to be of greater value to member districts. Increased efforts will be needed for local communities to maintain quality programs in which to share resources and to evaluate the results of education endeavors.... As the problems of the future become more complex we recognize the necessity of education establishing closer partnerships with parents, communities, business and other agencies that can assist in improving services for children. 75

Voluntary Educational Collaboratives are organized principally under Chapter 797, and Chapter 40, section 4E of the Massachusetts General Laws. 76 The majority of collaboratives have been organized under Chapter 40 , Section $4 \mathrm{E}$ which was enacted in 1970 to permit two or more 
school committees to authorize an agreement for joint educational activities. 77 And Chapter 797 was enacted in 1974 to more specifically enable the school committees of "cities, towns and regional school districts" to "enter into an agreement with one or more other such committees to conduct jointly education programs and services which permit such committees to supplement or strengthen school programs and services." 78 voluntary Educational Collaboratives may additionally organize under Chapter 180 as private non-profit organizations.

The distinctive feature of the educational collaborative concept is its flexibility. Educational collaboratives are not intended as permanent structures, nor are they consolidations of school systems. Rather, educational collaboratives exist only to service the needs of schools. Local school committees, who retain their local autonomy, have the power to initiate a collaborative and to dismantle that collaborative if it is either unresponsive to the school district or has met the school district need. "A collaborative should continue only as long as it provides efficient and effective solutions to education problems confronting the individual school system. In the event that a collaborative is no longer viewed as useful by its members, it should not continue." 79

Participation in an educational collaborative is voluntary. A local school system, upon unanimous vote of 
its school comittee, can join an educational collaborative as dues paying members. The local school system can elect not to participate in collaboration, in the same manner. Educational collaboratives are thus designed as voluntary, "adhocratic" 80 instrumentalities of the localities. The Massachusetts Board of Education sets general policy guidelines for the Voluntary Educational Collaboratives. Within these state guidelines, the characteristics of voluntary educational collaboratives vary greatly, being shaped by the local needs of the member school districts. Some are single purpose and are formed to solve one focused problem for their member school systems (such as a special needs collaborative); others are multi-purposed and respond to the multiple needs of member districts.

Merrimack Education Center
The Merrimack Education Center (MEC) is one of the largest and oldest voluntary educational collaboratives in Massachusetts. MEC was established in 1966 by a three year grant under Title III of the Elementary and Secondary Education Act of 1965 to initiate supplementary service centers. Today, the Merrimack Education Center is organized as a voluntary educational collaborative under Chapter 797 and as private non-profit organization under Chapter 180 with twenty-two member cities and towns. MEC serves over ninety thousand students and over six thousand teachers and administrators in northeastern Massachusetts. The Merrimack Education Center holds to the view that, 
MEC is not an answer. It is a means to an answer. It provides options for change. /I $t /$ provides a choice. Its goal is to help members acheive their aspirations. It is a vehicle to be used by students, teachers, administrators and towns. If it isn't used, it has no future. Without it, each member district will have to do it alone. It is the opportunity to try-out and share in the development of new approaches and ideas. The chance to solve a problem when it is pertinent. It is the opportunity to be a cause, not an effect. 81

Merrimack Education

Center Financial

Structure tives. As a public agency and private non-profit organization, MEC is eligible to receive three forms of funding. First, MEC charges a per capita annual assessment for membership in the collaborative. This assessment, which is intentionally quite small (twenty-five cents per pupil) is charged to assure a two way accountability between MEC and its members. School systems are assessed a nominal fee in the hope that the community will remain interested in the operations of the collaborative in order to supervise their expenditures. MEC, in turn, will remain responsive to a consumer client. Dr. Lavin suggests another reason for the small membership assessment. If MEC were to charge membership assessments, MEC would be forced to customize and/or equalize services. This approach is unfeasible for most collaboratives. 82

Secondly, MEC charges assessments for programs and services. Schools "buy into" programs and services upon the vote of individual school wards. Additionally, 
MEC may receive tuitions for certain long running or continuous programs.

Finally, MEC, as extensions of the school systems, is eligible to receive federal and state grants and contracts. Under Chapter 797, state and federal grants administered by the Massachusetts Department of Education may be distributed directly to a collaborative's trust fund. Other public monies, intended for support of collaboration, can be distributed only to a local school system but are redirected through program assessments and state school districts grants (up to ten thousand dollars) to the collaborative. As a private, non-profit organization, MEC is further eligible for business and private foundation grants. From July 1, 1976 to March 31, 1978, MEC accounted for over three quarters of a million dollars from program assessments and received the same amount in state, federal and school district grants. All funds are required by the state to be deposited in a collaborative trust fund, to be distributed only by the Treasurer of that collaborative.

Merrimack Education

Center Governance

Structure organization of voluntary educational collaboratives.

Accordingly, the Merrimack Education Center:

- operates with a Board of Directors comprised of a school committee member from each participating school system, the superintendent of schools or a representative of each school committee, and the coordinator of a state Regional Education Center in which a majority of the school systems are located. 
- operates under a formal binding agreement between/ among school committees which must be approved by the State Department of Education.

- may hire a full-time staff and a director. ${ }^{83}$

MEC's Board of Directors exercises a policy making function, directing policy instructions to the Executive Director and MEC staff. The board is additionally required to work closely with the Regional Education Centers, reviewing annual collaborating agreements, making recommendations or changes, and reviewing the annual collaborative report. The operating and program decisions are made by the MEC Executive Director and staff, but are subject to approval of the board. Each major program is advised by a committee of administrators, parents and teachers.

Voluntary Educational Collaboratives, including MEC, are accountable to both the State Department of Education and the local school systems. The collaborative must comply with state regulations while responding to local school district needs. The collaborative board is accountable to the local education districts who determine the collaborative exeistence.

Merrimack Education Center Education Center are reflective of the goals of other Goals

voluntary educational collaboratives throughout the state. 84 The program and service goals, however, will vary with the nature of the collaborative and the needs of the member districts. 


\section{Purpose:}

To establish a vehicle by which local school systems might join together in providing an alternative delivery system to fulfill current and temporary local need(s).

\section{Contextual Goal:}

To enlarge the scope, quality and accessibility of programs and services in education.

\section{Active Goals:}

"Centering VEC viewpoints is the conviction that the education enterprise is improvable and can be made more efficient. " 85

- To assist school districts to provide certain education services more effeclently than the school districts could do individually.

- To assist local school administrators to be more responsive to the needs of their academic community and community at large.

Merrimack Education

Services on a voluntary basis. School systems select those programs

that help meet the needs of their students and staff from among the following:

- In-service programs for staff development

- Special education programs and classes

- Teacher training Resource Center

- Professional Information Center

- Evaluation of local districts

- Educational Management Development

- State wide collaborative coordination through the Massachusetts Organization of Educational Collaboratives 
- Liaison with state colleges and other educational agencies

- Local capacity building and assistance to the regional offices in state capacity building

Merrimack Education

Center cilients

Center and all voluntary educational collaboratives, establish the following clients for collaborative efforts.

Impacted:

(direct

beneficiaries)

Involved:

(participants in programs/services)

Concerned:

(with program/

service outcomes)

\section{Education Program}

general students special student needs

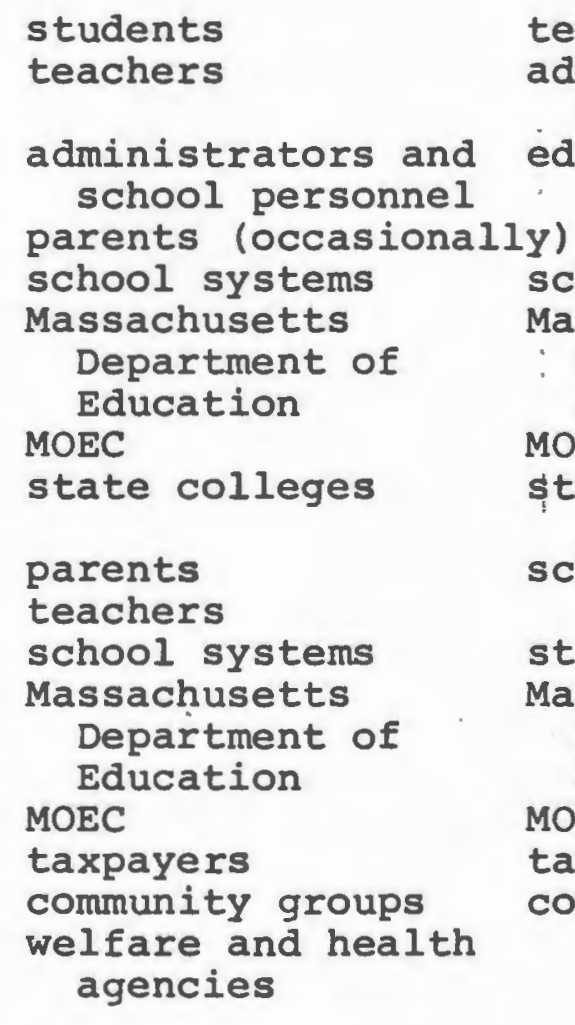

students

teachers

administrators and school personnel parents (occasionally) school systems Massachusetts Department of Education MOEC

state colleges

parents
teachers
school systems
Massachusetts
Department of
Education
MOEC
taxpayers
community groups
welfare and health
agencies

Supporting Services

teachers

administrators

school personnel

teachers

administrators and school personnel education experts

sc)

Massachusetts Department of Education

MOEC

ștate colleges

school personnel

students

Massachusetts Department of Education

MOEC

taxpayers

community groups
Merrimack

Education

$\frac{\text { Center }}{\text { Role }}$
The Merrimack Education Center is one of the few multi-purpose collaboratives 87 in the state. MEC is principally a brokering agency in the belief that many resources 
already exist at the local, national and state levels which may be linked to meet the needs of school districts. MEC describes the style of operation characteristic of the center as one of both linking and brokering. "In planning for the more effective uses of resources we attempt to do things that schools cannot do alone and to suggest joint programs." 88 The brokering role permits a small collaborative staff by circumventing the need for a large planning and development staff. MEC maintains an administrative staff of three, a program staff of five, and a technical and support staff of fourteen. Brokering also avoids the needless duplication of existing services, programs and resources.

A second role for the Merrimack Education Center is fundraising. MEC seeks funding support from private and public agencies for support of school programs and services. Finally, MEC conducts school district needs assessments which form the basis for collaborative programs and services. "We have found it to be of significant importance to keep updated on needs, trends and directions that are external to the regions as well, through a process of monitoring state and federal goals and guidelines." 89 The Merrimack Education Center also collects and tabulates other education data for local school districts and the Massachusetts Department of Education.

Merrimack Education $\frac{\text { Center }}{\text { ipants }}$ Thus, the Merrimack Education Center links member school districts - students, teachers, administration, and personnel - with resources at state, national and local 
levels. Besides the actual programs and service participants there are major participants in MEC and other voluntary educational collaboratives.

Local school districts are ultimately responsible for the actions of the collaborative. The local school district initiates the collaborative and, acting through the board, establish collaborative goals. To ensure responsiveness of the collaborative to the local school district, state guidelines require:

1) each district elect a committee member to serve as a voting member of the collaborative, one member to be elected chairman and one member to be treasurer.

2) collaboratives to prepare an initial fiscal and program audit of the collaborative to be undertaken at least annually by the particular school system. Every third year a report should be forwarded to the Department of Education.

3) the treasurer is the only person authorized to appropriate funds.

4) members can vote out the existance of the collaborative.

5) local funds cannot be committed to a collaborative program without the authority of each member community. 90

Thus there are a number of checks to ensure that the Merrimack Education Center and other collaboratives remain the instrumentalities of the member school districts.

The state role is to encourage and fund the development of MEC and other collaboratives. The Board of Education sets guidelines, and conducts educational programs and services. The Department of Education maintains close contact with the collaborative by requiring that a represen- 
tative of the Regional Education Center (state education agency) sit as an ex-officio member on the board of each collaborative.

The Merrimack Education Center is thus directed within the goals and guidelines set by these two bodies. In their accountability, the collaborative boards are required to formalize communication procedures with member districts by maintaining and distributing the minutes of their meetings to all board members and all member school committees, and the Regional Education Center.

In conclusion, the Merrimack Education Center, and other voluntary educational collaboratives, confer multiple benefits to the member school districts. In particular, MEC:

- implements school improvement programs to aid faculty and administration in better conducting their responsibilities;

- strengthens and supports education programs for the general student body and special needs students;

- supplements the curricula with innovative programs using the resources of other educational institutions and community groups;

- conducts workshops and information seminars for parents and interested community groups;

- provides information services for schools including needs assessments and other data;

- raises funds for school district programs and services;

- generates greater equal education opportunity by providing the districts of smaller budgets and sparser population to provide programs and services not otherwise available.

As the Merrimack Education Center writes, 
The rationale is simple; school people, by necessity, have to devote almost all of their time and resources to operating school programs. This leaves little time for them to research and implement new and improved methods of education. MEC recognizes the urgent need to assist those who manage the educational enterprise during a time of social change and economic stress. The Center constantly reviews the needs of schools and works at bringing resources and schools together in efficient and cost-conscious ways.91 


\section{BOARDS OF COOPERATIVE EDUCATIONAL SERVICES}

Overview A Board of Cooperative Educaticnal Services

(BOCES or Cooperative Board) is an educational agency that serves an assemblage of local school districts within a region. Cooperative Boards are a product of the regional (or 'intermediate') school district movement in New York State. Such regionalism occurs as school district reorganization on a program or service basis for the sharing of resources over a broadened base of multiple districts. Cooperative Boards exist to foster cooperation and collaboration between school systems. They do not establish another educational structure in place of school systems, nor do they consolidate school systems.

In consolidation, the separate school jurisdictions loose their identity as they are merged into a single governing structure. In regionalism, the local districts retain their identity and local boards of education give up only limited responsibility and authority to the intermediate or regional districts. 92

A Cooperative Board is thus a flexible agency which exists in addition to the boards of education of individual school districts for specific collaborative programming.

The State Legislature authorized the first Cooperative Boards in 1948 as"regional agencies through 
which local school districts sould mount a cooperative effort to meet their similar needs... and pool funds, talents, and energies."93 Today there are forty-six Cooperative Boards in New York State serving more than seven hundred local school districts. "A Cooperative Board's classrooms, staff and services are available to every school district in that region to be drawn on according to local needs and as each district sees fit. Accordingly, a Cooperative Boeard's offerings are dictated by local needs and demands." 94 Thus, each Cooperative Board has different characteristics and offers different programs and services according to the particular needs of that region. BOCES in Nassau County is the largest Cooperative Board in the State, serving fifty-six local school districts in 1977.

Conceptually, the Cooperative Board exists to service the local school systems within a region. As the Regents of the University of the State of New York write,

The regents reaffirm the role and responsibility of local school districts and view Cooperative Service Districts as extensions of these districts and the means by which larger pupil bases and greater financial, technical, and professional resources can be brought to bear upon school disrtict operations, with the concurrance of local districts. 95

BOCES Financial Structure
A Cooperative Board is a public agency. It has no taxing authority, but it does have several sources of funding: 
First, the school systems within each Cooperative Board subscribe on an annual basis. Rather than paying dues, the participating school systems pay for the administrative and rental costs of the Cooperative Board which are apportioned among school distticts on a pro-rated basis. In the beginning of the year, the distrcits are charged an assessment which is an estimation of the year's Cooperative Board operating costs. When the year concludes, any fiscal deficit shown by a year-end audit is additionally charged to the local school districts, and any surplus is returned to the districts.

secondly, the Cooperative Boards charge assessments or tuitions for most services and programs offered. These costs are apportioned according to the district's student population and participation in programs. Smaller school districts of sparse population may receive certain services on a part-time basis or may share their membership costs with other smaller districts.

Finally, the Cooperative Boards receive substantial state subsidization through grants or contracts for programs and services. Each Cooperative Board may additionally receive federal financial support.

The state grants, membership assessments, and program/service charges provide the majority of support for Cooperative Boards. 
BOCES

Governance

Each Cooperative Board is governed by a policymaking Board of Education. The members of the Board are elected from the boards of education of the school districts that have elected to join the Cooperative Board for that year. The members may number from five to nine.

The Chief Executive Officer of a Cooperative Board is appointed by the members of that Cooperative Board with the approval of the state Commissioner of Education. He/she must be a district superintendent and an officer of the State Department of Education. The Chief Executive Officer administers the Cooperative Board in accordance with state law and the Board's policy direction.

The Chief Executive officer is accountable to the Cooperative Board and the Commissioner of Education. The Cooperative Board is formally accountable to the school district boards and the Comissioner of Education. However, a study of BOCES for the state Department of Education advocates, "BOCES, in as much as they are dependent upon the support given them by local districts, must be held fully accountable for what they accomplish." 96 


\section{Purpose:}

To establish a manageable and cost-effective vehicle by which local school districts may enlarge the scope, quality, and accessibility of programs and services in education.

\section{Contextual Goals:}

To enlarge the scope, quality, and accessibility of programs and services in education.

\section{Active Goals:}

- To assist school districts provide educational services and programs more efficiently and cost-effectively than the school districts could do individually.

- To assist local school administrators be more responsive to the needs of their academic community and the community at large.

- To cooperate with other BOCES for joint educational programs and services. 97

\section{Programs and Services}

The specific program goals vary with each Cooperative Board and the particular needs of that area. Each Cooperative Board offers a gamut of services and programs based on an annual needs assessment of their region. These services and programs are directed to elementary, secondary, and adult students, as well as special needs and gifted children. Additionally, services and programs are offered to aid school administrators, personnel, and teachers better conduct their jobs. Under law, a BOCES must furnish any educational service that is,

a.) requested by two or more districts, and

b.) approved by the Commissioner of Education, who first determines that the service -

1.) meets an educational need, and

2.) can most effectively and economically be provided at the regional level. 98 
the New York state local school systems as the major BOCES clients. More specifically, BOCEs clients include:

\section{Education Programs}

Impacted :

(direct

beneficiaries)

all students

special needs students

adults
Involved :

(in programs

and services)

teachers

students

administrators

parents

Department of Education

\section{Concerned :}

(with program/ service outcomes) parents

education interests

community groups

taxpayers

Department of Education teachers unions
School Services

administrators

teachers

staff

bus drivers

other personnel

(librarians, etc.)

administrators

teachers

staff

bus drivers

consultants

Department of

Education

students
parents
education interests
community groups
taxpayers
Department of
Education
teachers unions

BOCES

Roles

The above goals and clients establish three

roles for Cooperative Boards. First, Cooperative Boards

are primarily brokering agencies. Cooperative Boards

coordinate and fund the services of education specialists

and other resources to provide staff development, library

services, bus driver training, to name a few school

services. Secondly, the staff of Cooperative Boards

develop and implement educational programs for students

and teachers. Finally, Cooperative Boards generate 
funds for collaborative programs and services. Cooperative Boards exist as intermediate agencies between state and local education authorities to capture additional state funding for its member districts.

BOCES

Participants

Thus, local school systems -- students, administrators, faculty, personnel -- are united in collaborative programs and services with other local school systems within the region. Additionally, education consultants and other community and education resources are linked to meet the service needs of member school systems.

In their role as participants, member school districts contribute staff time, school facilities, and funds (membership and service/program assessments). A school system becomes a member of a Cooperative Board for a year by vote of its local board of education. Once it has joined however, it may not withdraw until the years contract has concluded and is obligated to pay its apportioned BOCES membership assessment. The member school system may opt to participate in Cooperative Boards services and programs, or not, "so long as it meets its legal obligation to provide an adequate education program for each child." 99

Participant Benefits

The member school systems receive multiple benefits from the collaboration within a cooperative 
Board. These benefits include:

- strengthened educational programs available to local school students, as well as innovative programs which would not be feasible without BOCES, BOCES provides the increased "capability to systematically cope with and provide for educational change;" 100

- increased equal educational opportunity for students of smaller school districts or school districts with particularly limited educational budgets;

- greater program efficiency through regional cost savings and minimal duplication of services;

- administrative and faculty support services;

- exchange of ideas and knowledge which ends isolation between school systems, education agencies, and education experts.

As the Regents of the University of the State of New York conclude, "more and more the BOCEs are being viewed as the vehicles through which the educational efforts and human resources of the enlarged community can be focused and have impact." 101 The major problem confronting the BOCES concept is that current legislation does not extend BOCES to the largest school districts of Buffalo, Rochester, Syracus, Yonkers, and New York City creating serious inequities for the students of these urban school districts. Legislation, however, is being sponsored to respond to this restriction on urban BOCES collaboration. 


\section{MUSEUMS COLLABORATIVE INC.}

Overview

Founded in 1970, the Museums Collaborative, Inc.

is a private, non-profit organization which seeks to assist New York's museums, zoos, botanical gardens, and historical societies reach a broader public and address issues of importance to their continued development. These cultural institutions are caught in a viscious cycle of fiscal constraint and increasing external demands. As the Museums , Collaborative writes,

These cultural institutions are facing a fiscal crisis unpresedented in their history. Inflation and recession have caused operating budgets to soar, and private subsidies to diminish. Concurrently, competition for both public and private funding has intensified and the important cultural programs ... especially when compared with overwhelming social problems - has been questioned.... These current economic realities has forced art institutions to depend on public rather than private bases of support. 102

Financial Structure organization and receives no subscription fees. The collaborative receives operating support from the New York State Council on Arts, and solicits financial support for collaborative programs from government agencies, businesses and private foundations. For example, in 1974, the Museums Collaborative received a three hundred thousand dollar grant (which was recently renewed) from the Department of Health, Education and Welfare's Fund for Improvement of 
Postsecondary Education for the Cultural Voucher Program.

Museums

The Museums Collaborative is governed by a policy-

Collaborative

Governancemaking Board of Directors represented by community political

Structure

leaders, academic leaders, community professionals, and

museum officials. An Executive Committee is vested with the supervision and management of the affairs of the collaborative.

However, it is the advisory board, Museums Collaborative program directors and staff, that make all major program decisions, chooses the participants, hears disputes and appeals, and determines funding allocations. The Cultural Voucher Program, for example, boasts an advisory council of museum directors, community representatives, bankers and lawyers, academic leaders, and political leaders. Originally a gesture to coopt political opposition and generate support, the Cultural voucher Council has evolved as an important governance structure, making major policy decisions as well as assuming many of the day to day responsibilities of the program staff. The Museums Collaborative writes, "the advisory board has been anything but a rubber stamp group. It selected the participating institutions and community organizations, and determined the amount of each organization's voucher."108 The Cultural voucher Program, which is relatively unstructured, presents several opportunities for abuse and conflict (including larceny with vouchers, unfilled contracts). The advisory board screened all transactions, cutting the possibility for trouble and increasing program quality. The Council's composition reflects two objectives, 
"(1) to bring together representatives of all factors that could make waves in New York City politics if excluded; and (2) to build support for the eventual institutionalization of the Cultural voucher programs. Institutionalization in this case translates into money and political acceptance." 104 The advisory board for the continuing professional education programs consists of representatives from academic communities, businesses, and cultural institutions working with Museums Collaborative staff to develop, plan and implement individual courses and seminars.

The Cultural Voucher liaison is an additional staff position responsible for much daily decision-making. The Museums Collaborative provides a stipend to each cultural institution participating in this program for the hiring of a liaison. Located in each cultural institution, the liaison is responsible for cataloguing the cultural institution's resources and services available, and working with the community organizations and the Museums Collaborative. The liaison is sensitive to the needs and interests of community groups and knowledgeable of the resources of the cultural institutions.

Half of a liaison's time is supposed to be spent in the field, initiating contact and discussion with community groups. The most conscientious liaisons have aggressively sought out community participants rather than waiting for their phones to ring, and their efforts have proven instumental to an institution's success as a voucher earner. For example, two institutions that did poorly during the program's first year changed liaisons and substantially improved their voucher-dollar standings.105 
The liaison thus serves an important communications link between program participants. As an evaluation concluded, "The success of a cultural institution in working with community groups probably reflects the energy and imagination of its community liaison more than any other single factor."106

Collaborative As a private, non-profit organization, the Museums Financialcollaborative is eligible to apply for private foundation structure and business grants. The Museums Collaborative also receives operating support from the New York State Council on Arts, as well as several federal and state grants and contracts. The participants in the Museums Collaborative are not members and therefore pay no annual dues. However, the Museums Collaborative does charge assessments for programs and services.

Museums The purpose and major goals of the Museums Collaborative

Goalscollaborative include:

Purpose:

To develop and administer cooperative programs which would facilitate communication among cultural institutions, reduce the duplication of services and their costs, and improve the ability of the institutions to serve the public economically.

Contextual Goal:

To increase the service potential of cultural institutions and so extend the resources of cultural institutions to a broader segment of the public.

Active Goals:

- To enable cultural institutions to jointly address issues of importance to their continued growth and 
development (by providing program development and funding, museum service delivery, and information dissemination).

- To assist the cultural institutions in reaching a broader public by sponsoring education programs in conjunction with public school and community based organizations.

- To aid working arts professionals to improve operations within cultural organizations.107

Major

Programs \&

Services A. The Cultural Voucher Program

The Cultural Voucher Program deserves special note as an exciting new model for service delivery which accounts for sixty percent of the Collaborative's 1977 total budget. This is a comprehensive program designed to broaden the audience served by the cultural institutions, and to provide the insitutions with incentives to develop educational services which respond to the express needs of a wider public. Through this program, the Museums Collaborative provides funds in the form of "cultural vouchers", or certificates of credit, to eligible community organizations. Community organizations purchase educational services and programs of their choice and design from participating cultural institutions with the cultural vouchers. Cultural institutions, in turn, who contract with these community organizations to provide a program or service, redeem these coupons with the Museums Collaborative. The Museums Collaborative writes,

the program has had a decided impact on the cultural institutions involved. For the most part, community groups have not purchased services with the institutions routinely offered to the public. The program, therefore, has provided the institution with a basis for evaluating the effectiveness of their ongoing educational programs for new audiences, and several institutions have altered their programs according$1 y .108$

The voucher plan can be best viewed as a general market mechanism for cooperation that permits the purchase and design of particular projects specific to organizational needs. The Collaborative supervises and funds the operations and facilitates in planning; but the community organizations and community groups generally shape the individual project with the assistance of the cultural voucher liaison located within the cultural institution. 
Still a demonstration project, the Cultural Voucher Program has been very popular among community groups. Since 1974, the Cultural Voucher Program has generated more than seven hundred educational programs. The evaluators see the following advantages of such a system:

1) a broader range of people come in contact with cultural institutions;

2) "consumers" learn more from their experiences because they choose them;

3) the public's support for cultural institutions increases;

4) institutions become more responsive to public needs;

5) communication among institutions increases as competition forces them to know what others are offering the public; and

6) a built-in mechanism guarantees that public funds are spent in a way that best satisfies the public's needs.

The enthusiasm of both museums and the public for New York's pilot project suggests that cultural vouchers may be one of the most effective ways to support the arts.109

The Cultural Voucher Program, however, requires constant program supervision over the individual voucher contracts and money transactions. This necessitates a cumbersome administration system (for every dollar spent in the total program, forty-one cents goes to administration). Additionally, an evaluation reveals that the amount of money going to cultural institutions as vouchers must be increased to provide real financial incentive to institutions. 110 These drawbacks are being overcome as the program is modified. Additionally, a discounting system is being designed to allow the poorer community organizations to receive larger vouchers than the community organizations of more resources to create more program equity and spread the funds to more organizations.

\section{B. Museum/School Program}

In this program, the Museums Collaborative works with cultural institutions to develop curricula and educational programs with the city public schools. 


\section{Professional Education Programs}

A. Continuing Professional Education Programs

This area of programs seek to provide sustained training in specific subject areas to working arts professionals.

Services and Publications

Museums Collaborative additionally offers a number of supporting services and publications to benefit cultural institutions and members of the public:

1) a quarterly newsletter provides a digest of information of interest to arts professionals;

2) the "Bread Game" poster, which lists federal arts funding deadines, is distributed annually to arts councils and cultural institutions throughout the nation:

3) an Educational Resources Directory which describes the educational programs sponsored by fifty-one New York City cultural institutions is published and distibuted every two years;

4) a Computerized Mailing List Service is offered to cultural institutions in New York State. The service facilitates bulk mailings to New York cultural and educational institutions;

5) a Planning Calendar is printed annually and made available for purchase by arts organizations throughout the nation.lil

Museums

The purpose and goals of the Museums Collaborative

Clientsestablish the following program and service clients:

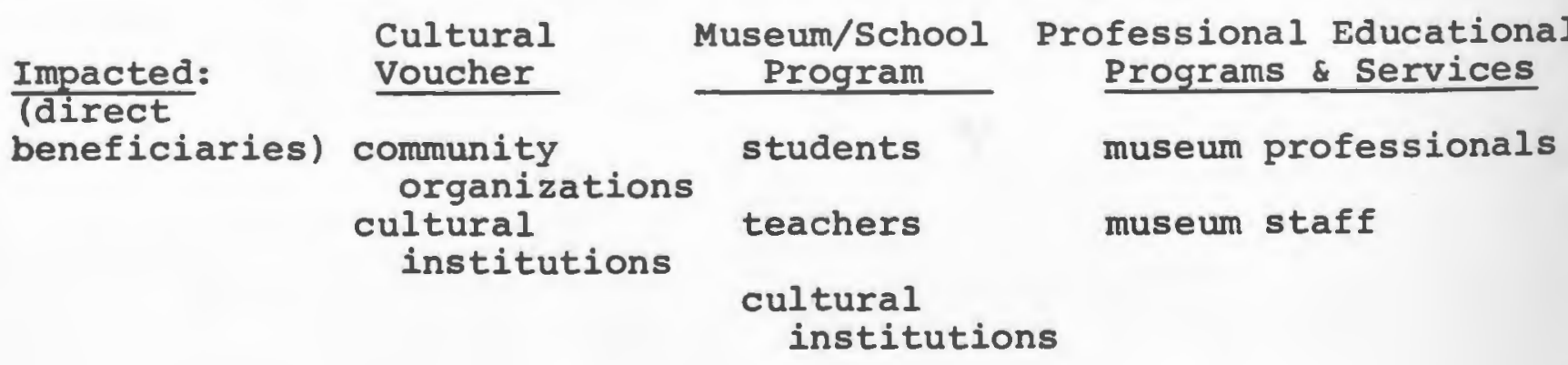


Involved:

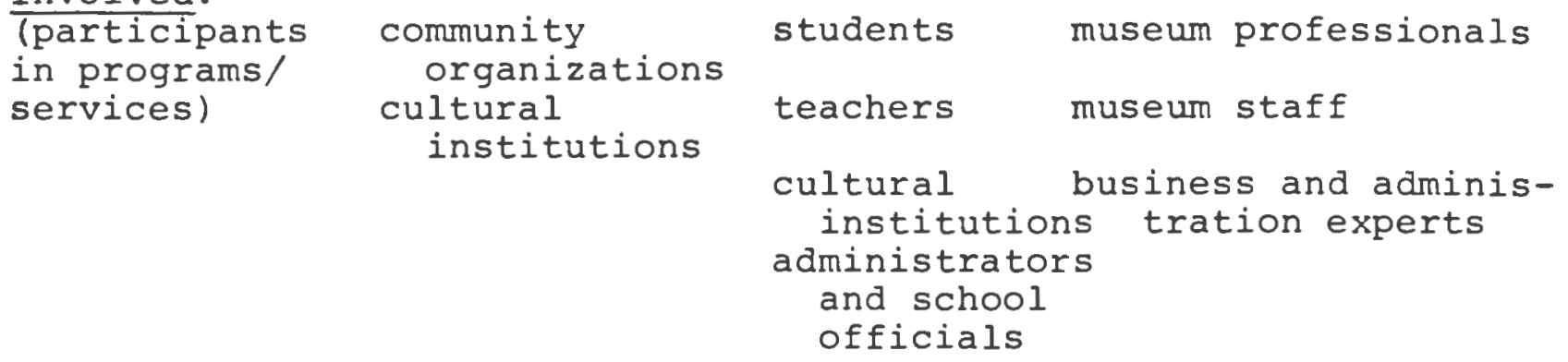

Concerned:

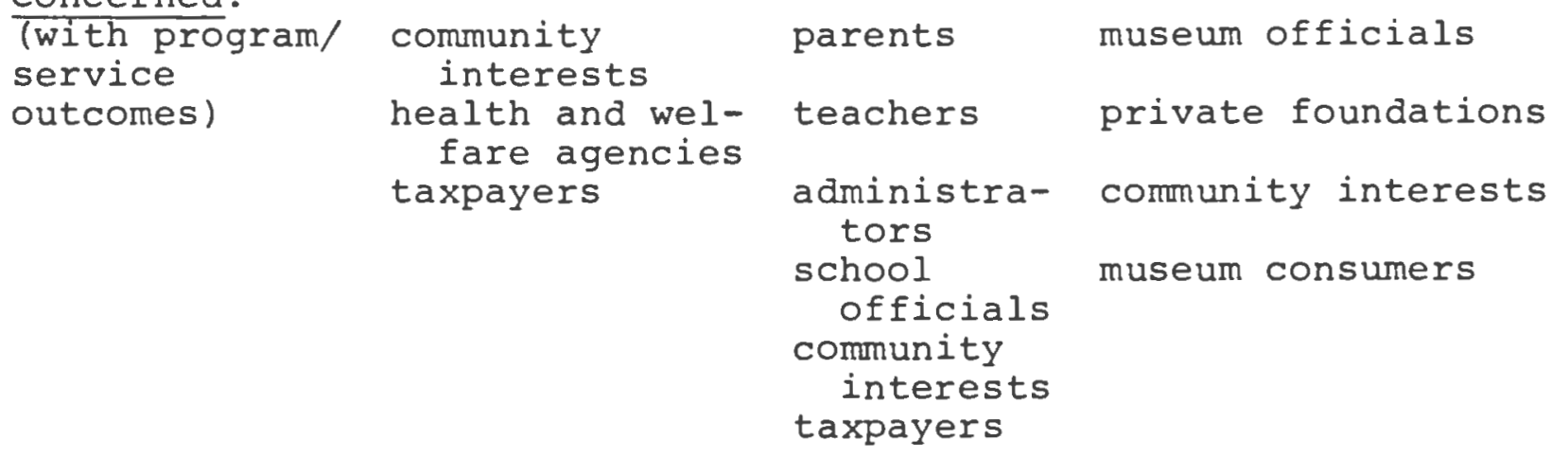

Museums

The above goals and programs establish four roles

Collaborative

Rolefor the Museums Collaborative:

First, the Museums Collaborative staff develops, plans, and sponsors programs and services to meet the needs of museums, schools, and/or community groups. In 1976, the Collaborative conducted a comprehensive survey of two hundred and twenty-five New York City museum professionals on particular needs of museum administration and management, educational training and theory. This provided needs assessment formed the basis for most programs and services. The planning staff at the Museums Collaborative is divided into program areas of cultural vouchers and educational services.

Secondly, the Museums Collaborative staff serves as program and service brokers, linking existing museum educational and administrative resources throughout metropolitan New York to the service needs of the participating museums and the public.

Third, the Museums Collaborative generates private and public funds for collaborative operations, programs and services.

Finally, the Museums Collaborative disseminates informa- 
tion to interested parties. The collaborative provides information to the public about the resources of cultural institutions, and to cultural institutions on issues of funding, administration and management, and museum education.

Museums

Thus, the Museums collaborative unites cultural with Collabroative Participantsother cultural institutions, schools and community organizations in collaborative programs and services. The Museums Collaborative further links museums with business administrators and museum educational resources. The participants in the Museums Collaborative services and programs joins an individual program or service by paying fees, using vouchers, or receiving grants to facilitate programs. In their role as participants, the museums contribute staff time, museum resources, and fees for collaborative programs and services. Public schools contribute staff and teacher time, facilities, academic credit, and fees for the museum/school collaboration programs and services. And community organizations which participate in the Cultural Voucher Program commit their voucher purchasing power. This voucher is only received after an organization has qualified and must be expended or is repossessed by the Museums Collaborative. Thus, the community organization, which may have little financial power, is required to contribute less towards collaboration than any other participants other than an extremely willing clientele.

The cultural institutions face several pressures that encourage their interest in collaboration. In particu- 
lar, the cultural institutions are facing increasing pressures to extend their vast resources to a wider segment of the community. These pressures come at a time when cultural institutions are facing raising operating costs and intensified competition for private funding. Participation in the programs and services of the Museums Collaborative enables cultural institutions to reach a broader public; reduce duplication and costs of services; improve staff work skills; and receive public information and administrative support. Thus, collaboration generates programs which enables cultural institutions 'to respond to escalating community pressures to decentralize services. The shared program costs of collaboration confer cost-efficiency to these fiscally constrained . cultural institutions.

Community organizations serve as advocate groups for the needs of their members and participants. Community groups represent diverse interests from senior citizens and neighborhood block groups to prison inmates. In general, different interests and communities are becoming more conscious of their ethnic and cultural heritage. The demands of society for skills and continuing education, and increased adult leisure time all create a demand for more informal, non-traditional, learner-centered forms of education which cultural institutions can in part provide. These communities benefit from the ability to purchase and receive educational programs from the contracting cultural institutions. 
Finally, schools have been experiencing diverse, and sometimes contradictory, pressures to increase the quality and quantity of education, meet new legislated mandates, and increase citizen participation. These pressures tax the school budget beyond its limits. Public schools therefore benefit from the cost-efficiency and flexibility of collaborative services which provide for innovative student programs, curriculum and materials development, and teacher training based on the educational resources of cultural institutions. Thus, the incentives to participate in collaborative programs are so strong for community organizations, cultural institutions and public schools as to assure a modicum of commitment for the Cultural Museums programs and services. The Cultural Voucher Program, in particular, provides needed public funds to cultural institutions in the form of cultural vouchers for their services to community groups and provide the important opportunity to develop a favorable public image. And the Cultural Voucher Program provides desired cultural institution programs to those eligible community organizations.

In conclusion, collaboration is a mechanism which provides the opportunity for different groups (cultural institutions, community groups, public schools) to "jointly address issues of importance to their continued development."112 collaboration, as a mechanism, facilitates communication between groups of diverse needs, reduces the 
duplication of services at cost savings, generate public and private program funds, and improve the ability of groups to serve their constituency. Museums Collaborative evaluations indicate that greater benefits are evidenced in program development than in service delivery. Collaboration, as coordinated and directed by the Museums Collaborative, extends to fiscally-constrained and/or powerless public schools and community groups resources heretofore impossible. Moreover, collaborative programs establish incentives for those institutions of valuable resources to offer services responsive to new audiences. Thus, the efforts of the collaborative have opened up not only new constituencies but a new market for cultural resources, based on market mechanism of purchasing and selling. The Museums Collaborative describes its organization as, "a collective mechanism through which cultural institutions are reaching new audiences, are developing new and effective educational programs, and are simultaneously documenting their impact on a wide range of citizens."113 


\section{COLLABORATIVE DESCBIPTIVE VARUAL:}

PURPOSE OF COLLABORATIVE

FINANCIAL STRUCTURE

GOVERNING BOARD MEMBERSHIP

dues service

aylng issess-priv: pub public contrl cembors ments grants grants contracts bution.

To prosote facllitete inplement joint ventures cooperaablilty of those who run the adninistration and bustness of schools.

70 join together to Inprove the ablitey of cultural insts. tutions to menege fund the ir in the es in to address lssues. in the adinistration of cultura

AETrOPOLITA CULTURA (ALLIANCE)

LANNING

To plen elternetlve progreses Inf ethnic lsolation dn Boston SMSA

ETROPOLITAN OUNCIL FOR DUCATIONAL PPORTUNITY METCO)

DUCATION

OLLABORATIV UR GREATER STON

EdCo)

DLUN IARY

DUCATIONAL

LLABORA

/EC/AEC)

JARUS OF

JOPERATIVE

DVICS

3OCES)

ISEUMS

To plan I Inpleaent alternative proerons with porents Intereste groups which voluntarlly place inner-clty inorley cudents in suburben schools.

To provide innovative program services to nember school distric at lower costs and higher quality then is feasiblo for eny singlo school district.

To ostablish a manteable 1 cose effective vohicle by which local school districes cooporate to pro supolement existing curricula.

ro estoblish manageable cost effective vehicle by which local vido proprans supplenene en atine currtcula.

To devoloo sadnelntecer prograns To devoloo sadalniscor prozrans cultural insteution duplication, broados cllentale


direct of prof school comunity unlon unsunar cletren Li:
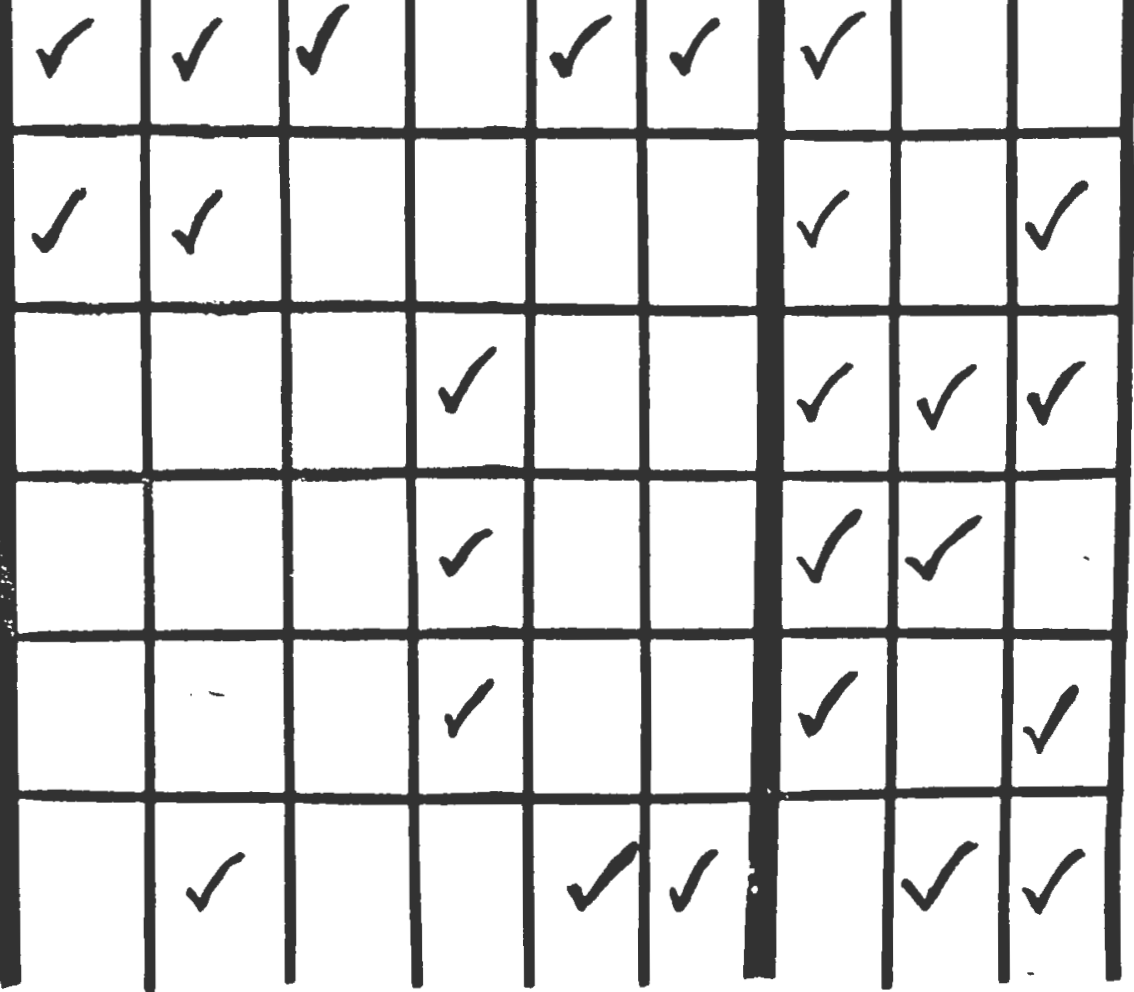
To advance edica-

I on and lessen

the burden of

covernment in

rublic school.

ro edvance

support the erts

reater Boston

to conduct research to provide cooperative

proerane services

.P. To reduce racial

- thnic isolation provlde guality

pportunities

10 reduce racial

ethnic tsolation

provide qualiey

ducational

ipportunitios

10 increase the

uallty of educe:-

ion for sener

tudents

10 increase the

jually of educe-

pectal noeds

tudents

Io increase the

yuslity of educa-

ipeciel needs

itudents

\begin{tabular}{l} 
yoker plan-grais- disso toch. fomouni \\
ing \\
\hline
\end{tabular}

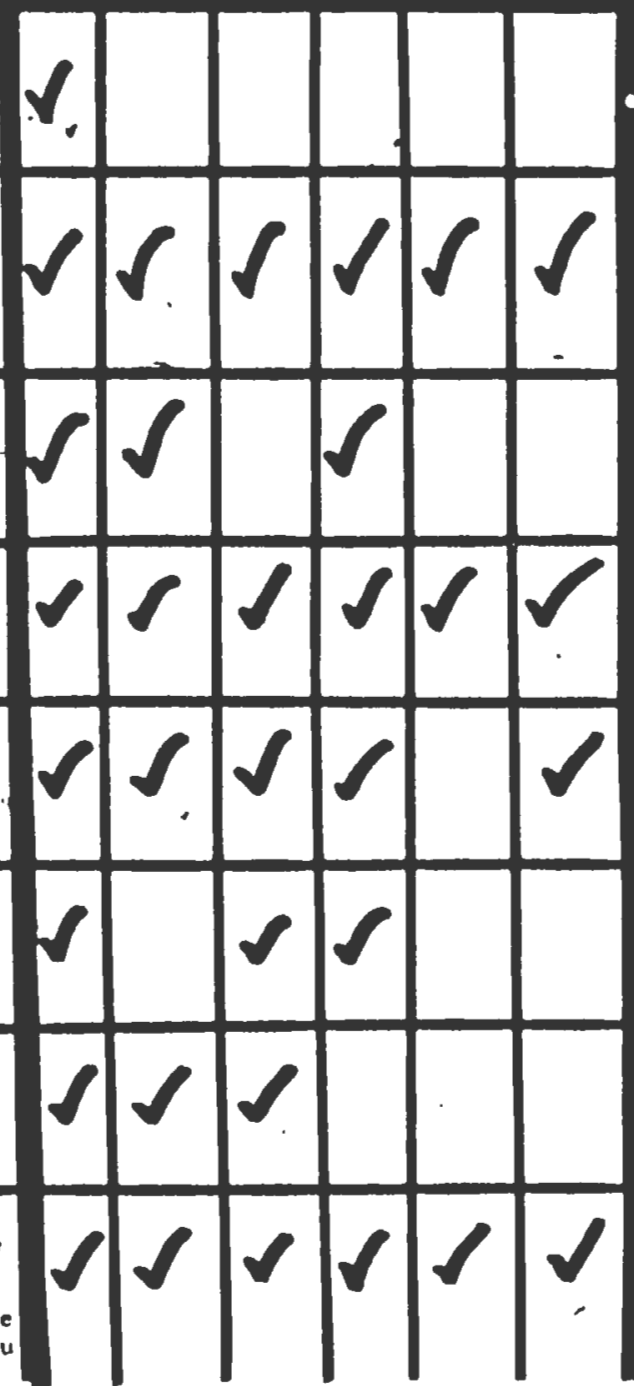

- trensthon comaunications end mangesent in cultura

Institutions

ources of earned Incone

to encourase participation and dielogue betwoen groups to develop a technical infor wetion base

to plan pllot a 10 yr plan

to place ainority inner-city - tudents In suburban schools to diversify curricul. cortices for METCO students

- to provide cost-effective

services to schools noetive oducatlona

- 0 provido cost-eltective

services to schools

- to itrengthen supplenent educational prosians curricula

- to provide cost-eltoctive eorvices to schools

- to strong then supplenent educational proerang - tooperate with other BOCES

to increase the iervice potential cultural insti. ions extend re

- 16 provide steff development

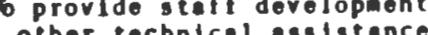
to cultural institutions

co fund develop. Ioplement Innovative prograns which use resources of cultural institu

\begin{tabular}{|c|c|}
\hline Impacted & involved. \\
\hline $\begin{array}{l}\text { chool managers } \\
\text { husiness officiels } \\
\text {. idminintrators }\end{array}$ & $\begin{array}{l}\text { school odainistrators } \\
\text { managers. school officle } \\
\text { business managenent } \\
\text { experts. MASBO INC. }\end{array}$ \\
\hline $\begin{array}{l}\text { members of cultural } \\
\text { institutions } \\
\text { individuals } \\
\text { husiness imployees. }\end{array}$ & $\begin{array}{l}\text { fundine sources } \\
\text { weabers of cultural Inst } \\
\text { tut lons. Individuals, } \\
\text { vendors of bissiness } \\
\text { ausoum servicas, eaployer }\end{array}$ \\
\hline $\begin{array}{l}\text { siudents, foculty } \\
\text { school danlstretors }\end{array}$ & $\begin{array}{l}\text { students, perents, fecult } \\
\text { odainistrators, comanit } \\
\text { group. Mass Dept Educeti } \\
\text { US of ice of Education }\end{array}$ \\
\hline $\begin{array}{l}\text { inner-city bleck } \\
\text { ininority students } \\
\text { inteir parents } \\
\text { suburban students. } \\
\text { perents. faculty }\end{array}$ & $\begin{array}{l}\text { METCo students,perents, } \\
\text { suburban students, perent } \\
\text { suburben scheol ficultyt } \\
\text { edainisratorg. U.S.0.e. }\end{array}$ \\
\hline 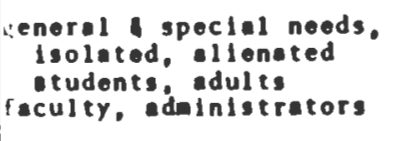 & $\begin{array}{l}\text { studehts, faculty, edinin } \\
\text { atrators, oducetion expe } \\
\text { paronts, advisory comit } \\
\text { Mass. Dopt. Of Educetion }\end{array}$ \\
\hline $\begin{array}{l}\text { eneral spectel noeds } \\
\text { students odults } \\
\text { chool odainistrators, } \\
\text { foculty }\end{array}$ & $\begin{array}{l}\text { students, teachers, odai } \\
\text { nistretors, education } \\
\text { experts, Mass Dept: of } \\
\text { Educetion. parents }\end{array}$ \\
\hline $\begin{array}{l}\text { ienerel speciel noeds } \\
\text { students, edults } \\
\text { chool dininistrators. } \\
\text { foculty }\end{array}$ & $\begin{array}{l}\text { toachers, students, id- } \\
\text { ministrators, perents } \\
\text { consultents, oxperts } \\
\text { State Dept. Educetion }\end{array}$ \\
\hline $\begin{array}{l}\text { ommunlty organizetions } \\
\text { mus ouns } \\
\text { chool adainlstrators, } \\
\text { faculty. museums } \\
\text { museun directbrs staff }\end{array}$ & $\begin{array}{l}\text { community groups, llaison } \\
\text { musoum stafis, student } \\
\text { teachers odninistrator } \\
\text { oxperis consulients. } \\
\text { funding sources }\end{array}$ \\
\hline
\end{tabular}

COLLABORATION

chool buslness, manag ent of Eclal fros lifferent schools in cooperative progra services

ultural Institution directors staff

iris ancies

usinesses thelt employees

tudents, parents foculty principals rom both city uburbin school

IETCO students, subur 2n students, school orsonnel faculty. arents hoje foulit.

inculty students. chool officiels, ron different school lisericts. plus con. iunity resources

aculty, students. chool official. roo different school ystens. plus con

rinity resources

iaculty, gtudents. irom dilferent school ystens, plusicom. unity resources

useums with other muse uns

nuseums with schools, nuseuns with communit Rroups 


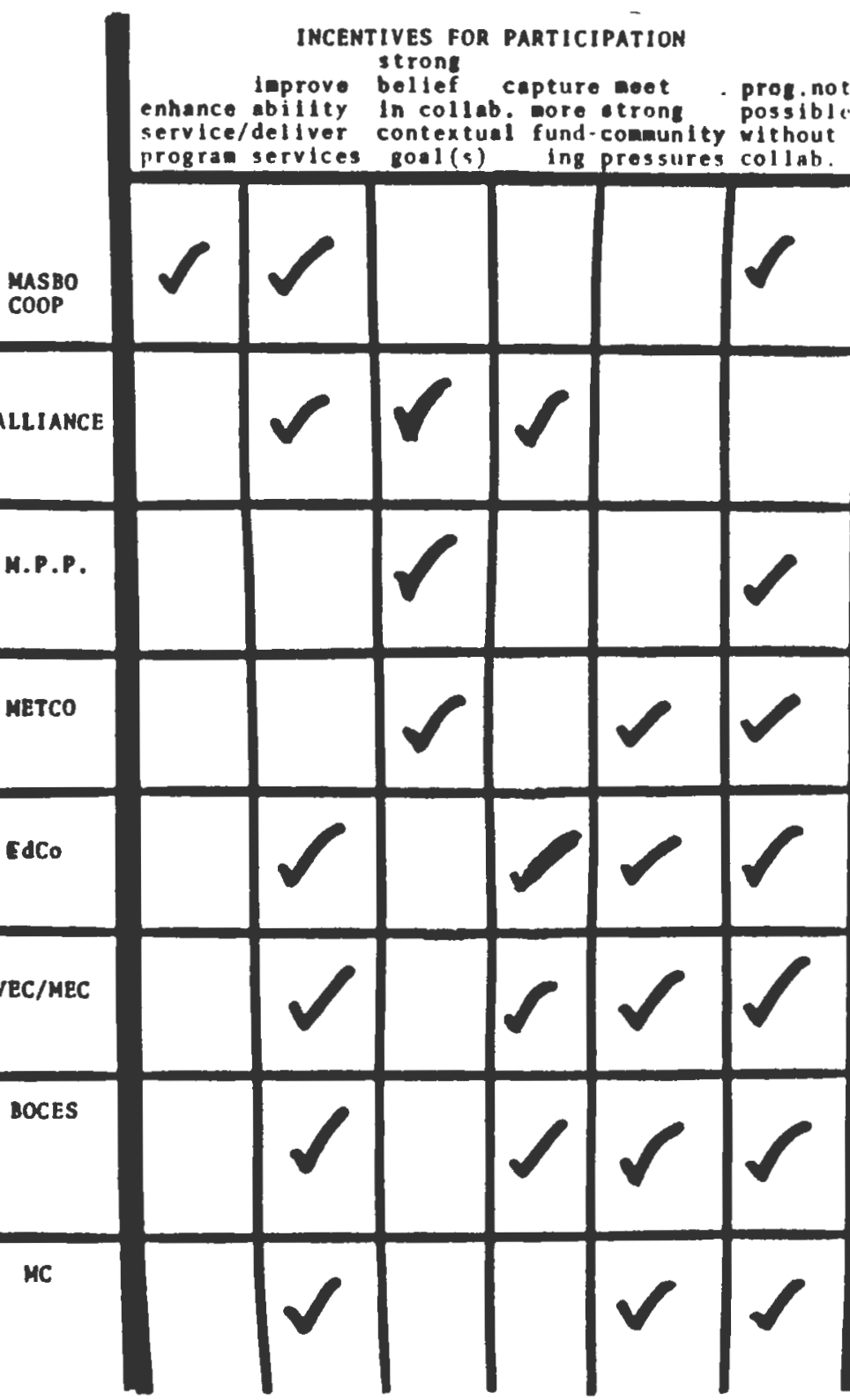

BENEFITS TO PARTICIPANTS

recelve needed programs, training cost-effective services A progran - ccredidation for training

recoivo oquipment training
-recoive technicai essistanco

recoive publications information

incroesed "earned incono". captured funding. share regources ideas recolve cost-offective prograns

business show comanity "rospons ibility" in support of erts, employeo benefits

Integrated Improved educational opportunleles for MErco students

end parents faculty developod currtcula cechnicat asst.

- increased educational opporeunity Innovatie prosrans servicos not otherwise evallablo cost-sevings strongthen supplemented curricule schools meet andates, captured funding

- increased educacional opportunity innovative prograns servicos not otherviso avallable, taff training strengthened supplomented curricula schools meet mandate

increased educational opportunity innovative programs servicen not otherwise vailable, taff training strengthened supplonentod curricule schools meet mandales copturod funding.

-museums receive funds, training, techcheal assistance, lmprovod pubilc lmage prosrans sorvtces currtcule dovolopprent

- cominlty groups recelve inllored properan

increased educational opportunity

reduced racial ethnic isolacton

increased dislogue shered undergetending

improved odcuat lonel onvitronment fording

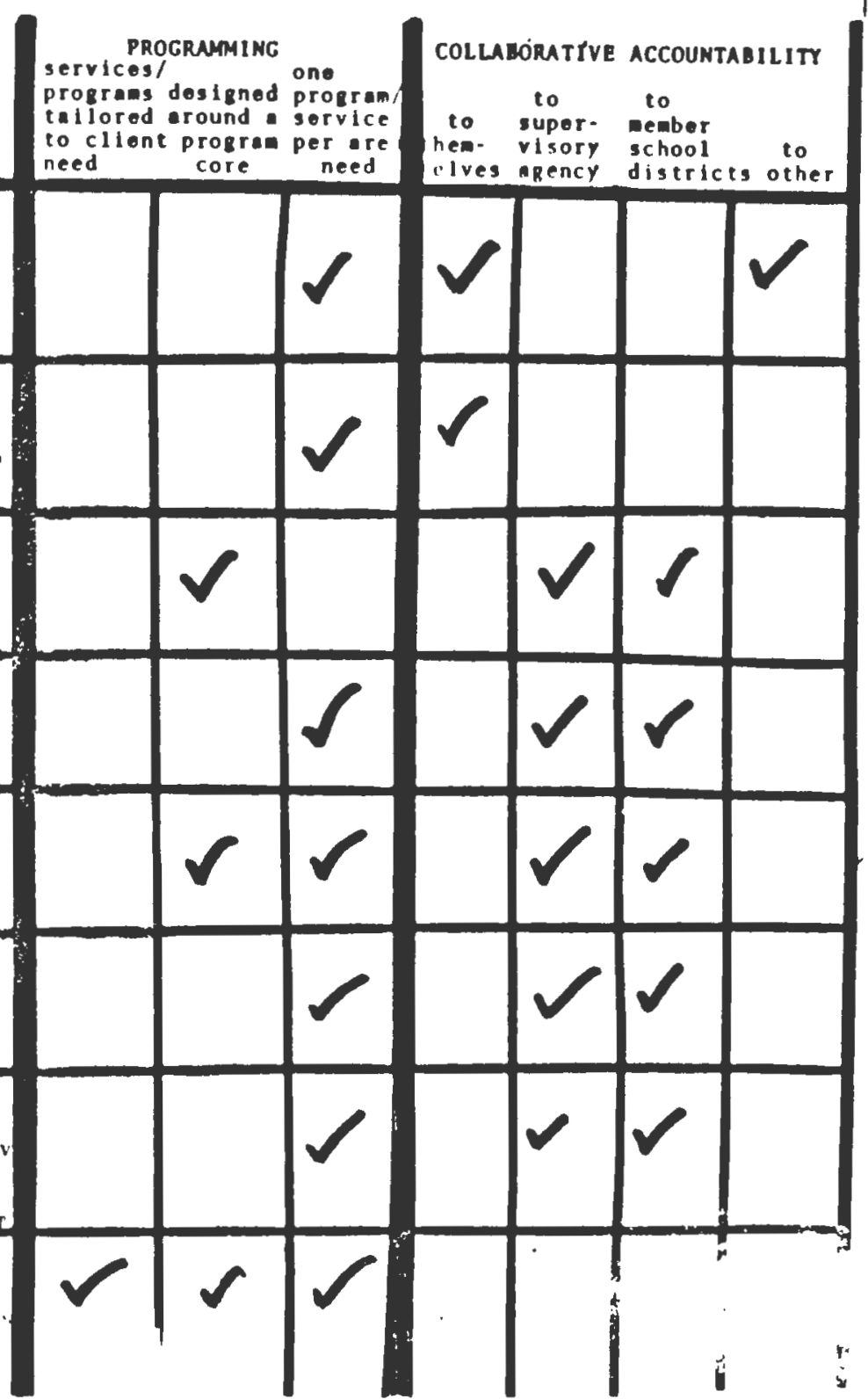




\section{CONCLUSION}

In conclusion, collaboratives display various structures, roles and programming. As a first step, all collaboratives must secure agreement among participating groups on the major goals of the collaboration, must share resources of and between participants, and must have information and communication networks between participant and participant, participant and collaborative, and collaborative and participant. Those collaboratives which are of diversified financial base, and which have strong communications networks, are able to support a maximum number of programming operations and confer the greatest number of benefits to participants and their clients.

Several conclusions can be drawn from the collaborative descriptions and matrices in the previous section. First, the matrices depict collaboratives of four different purposes. These four purposes define the above collaboratives principally as vehicles:

- in which parents, faculty, school administrators, community groups, and other interests cooperate in planning alternative programs and services;

- in which local school districts or agencies cooperate to meet the basic and special education needs of their student populations;

- in which institutions or agencies cooperate in programming designed to improve their internal operations and service capacity; 
- in which institutions and groups cooperate in programs and services which directly aid institutions to reach new audiences and service a broader public.

The purpose of a collaborative determines collaborative structures and operations. However, a collaborative may serve more than one purpose, and will display multiple roles and operations.

Secondly, several collaboratives of similar

purpose but different goals, share many similar characteristics. These typologies include: 
I. Purpose: To provide a vehicle in which parents of school children and friends, community groups, and other interests interact in planning alternative programs which will reduce racial isolation.

M.P.P., METCO, (and to some degree EdCo) are collaboratives which seek primarily to generate programs which are alternatives to the existing order of educational programs. These collaboratives focus on:

- alternative programing

- reduction of racial and ethnic isolation

- participatory planning

- strong commitment to contextual goal

The structures of these collaboratives are distinguished by the following common characteristics:
financial structure -- primarily public grants and contracts (EdCo has a more diversified financial base)
board membership --
primarily citizen and/or con- sumer representation (M.P.P. has superintendent and union repre- sentation, as well; EdCo has school committee representatives)
role - -
principally program development and planning, some collaboration support services (technical assis- tance, communication) some brokering
accountability --
primarily responsible to state/ federal education office which is the source of imost grants, addi- - tionally responsible to school districts which participate
programming --
flexible; a selection of programs around a program concept or a program core (METCO offers a single program with several support services)

Thus, M.P.P., METCO, and EdCo unite city and suburban school students, parents, faculty, administration, and interested groups in planning and coordinating alternative education programs which would not be possible without their efforts. Benefits to participants include: increased dialogue and understanding between for all participants; integrated and diversified educational experiences; strengthened school curricula. 
II. Purpose: To establish a manageable and cost-effective cooperative vehicle for local school districts to cooperate to meet the basic and special education needs of their students.

Voluntary Educational Collaboratives (VEC), BOCES, (and to some extent EdCo) are collaboratives which exist as outgrowths of school districts to enable those districts to strengthen, support, and supplement their curricula, as well as meet state and federal mandates. Without collaboration, school districts would have to provide these services independently, and have relatively strong motivations to participate in collaborative programs. These collaboratives seek to increase the scope, quality and accessibility of education by:

-- providing cooperative programs and services

-- assisting local school districts administer and teach and so be more responsive to local education needs

The structure and operations of BOCES, VEC, EdCo are distinguished by the following common characteristics.

\begin{tabular}{|c|c|}
\hline nancial base -- & $\begin{array}{l}\text { membership assessments, program and } \\
\text { service assessments, public grants and } \\
\text { contracts, private grants (except BOCES) }\end{array}$ \\
\hline role -- & $\begin{array}{l}\text { primarily brokering function, fund- } \\
\text { raising, usually multi-purpose } \\
\text { (BOCES,VE- strong brokering) } \\
\text { (EdCo- strong planning function) }\end{array}$ \\
\hline accountability -- & $\begin{array}{l}\text { to member school districts, are voted } \\
\text { into and out of existance by districts } \\
\text { (EdCo is more independent of member } \\
\text { districts; larger, quasi-public status) }\end{array}$ \\
\hline programming -- & $\begin{array}{l}\text { collaborative designs and offers one } \\
\text { program or service per area of client } \\
\text { need in which schools choose to parti- } \\
\text { cipate or not to participate } \\
\text { (EdCo additionally offers flexible pro- } \\
\text { grams around a core concept) }\end{array}$ \\
\hline
\end{tabular}

These collaboratives unite school districts (students, faculty, administrators) with community resources. These participants receive diverse benefits, including: strengthened and supplemented curricula, innovative programs which meet legislated mandates, supporting services, cost-effective solutions to existing services. 
III. Purpose: To develop cooperative programs and services to improve the capability of personnel to manage their institutions and to provide for the growth and development of these institutions.

Despite their disparate goals, the Metropolitan Cultural Alliance and MASBO Cooperative Corporation (and to some extent the Museums Collaborative) seek primarily to provide cooperative and costeffective programs and services for the internal operations of their respective institutions. These collaboratives provide programs and services which:

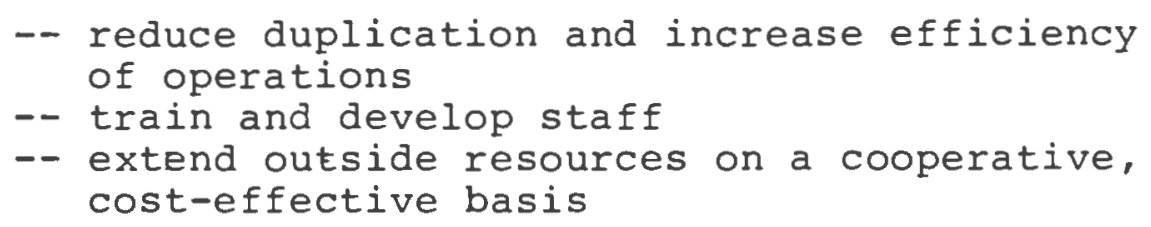
of operations

-- train and develop staff

- extend outside resources on a cooperative, cost-effective basis

The structures and operations of these collaboratives are distinguished by the following common characteristics:

$$
\begin{aligned}
& \text { financial base -- } \\
& \text { sembership dues, assessments for } \\
& \text { private grants, public grants and } \\
& \text { contracts, (Museums Collaborative } \\
& \text { not a membership association) } \\
& \text { board membership-- primarily professionals of the agencies } \\
& \text { or institutions who are the consumers } \\
& \text { of the collaborative services (Museums } \\
& \text { Collaborative has a more diversified } \\
& \text { board) } \\
& \text { principally brokering agencies with } \\
& \text { some program planning (Museums Colla- } \\
& \text { borative and Alliance provide more } \\
& \text { program planning and collaboration } \\
& \text { support services such as communications) } \\
& \text { primarily accountable to own members } \\
& \text { (MasBo, Inc. supervises and aids many } \\
& \text { operations of MAsBo Coop) } \\
& \text { these collaboratives design and offer } \\
& \text { one program or service offering per } \\
& \text { area of client need in which members } \\
& \text { choose to participate or not }
\end{aligned}
$$

The members of these collaboratives have moderate incentives to participate in programs and services. Some collaborative programs and services improve ability of members to deliver their services and programs. Some collaborative programs provide services not feasible without collaboration. Thus members receive costeffective needed programs and services; receive equipment, supplies and computer services on cooperative basis; receive staff development and technical training. 
IV. Purpose: To provide a vehicle for the development of services and programs that aid institutions to directly reach new audiences and service broader publics.

The Museums Collaborative employs the following strategies in support of this purpose:

-- increasing communications between client groups

-- generating program funding

-- effecting joint program planning between client groups

The structure and operations of the Museums Collaborative evidence the following characteristics in support of this purpose:

$$
\begin{aligned}
& \text { financial base -- primarily public and private grants } \\
& \text { and contracts, assessments for } \\
& \text { selected programs and services } \\
& \text { board membership--diversified membership of community } \\
& \text { and political leaders, professionals, } \\
& \text { museum administrators } \\
& \text { role -- both brokering and program planning, } \\
& \text { also fundraising, technical assistance, } \\
& \text { and information dissemination in } \\
& \text { support of collaboration } \\
& \text { accountability -- primarily to participants in colla- } \\
& \text { borative programs } \\
& \text { programming -- programs and services designed by the } \\
& \text { collaborative and individual program } \\
& \text { participants } \\
& \text { provides a selection of programs and } \\
& \text { services around one program concept } \\
& \text { or program core } \\
& \text { designs and offers one program or } \\
& \text { service offering per area of client } \\
& \text { in which museums choose to partici- } \\
& \text { pate or not }
\end{aligned}
$$

Thus, the collaboration creates new clients for the participating museums. The Museums Collaborative unites museums, schools and community groups in collaboration. These participants have relatively high motivations to participtate in programs and services that meet a specific participant need not possible without collaboration. 
Third, the organizational structures of collaboratives are created to respond to the needs of the collaboration. The collaboratives presented above intervene at three different nodes in the process of program and service delivery. Collaboratives are created:

- as outgrowths of institutions or agnecies;

- as planning efforts;

- as innovative efforts to fill a service or program void. Each type of collaborative is developed for different purposes and evidence different characteristics. As outgrowth of institutions or agencies, collaboratives are intended to strengthen, support, and supplement existing service and program responsibilities of the sponsoring agency or institution. Most often, these collaboratives are outgrowths of public agencies, but may also be private efforts in order to receive private funds, and may be incorporated. These collaboratives are principally brokering agencies linking existing resources to client needs. The governance board of these collaboratives are predominantly, if not entirely, represented by officials or professionals of the sponsoring agencies.

As planning efforts, collaboratives are developed to generate alternatives to an established order of services and programs. These planning collaboratives are sponsored primarily by public grants, and contracts, and may or may not be incorporated. In these collaboratives, the planning function is foremost and is designed to be participatory 
with strong consumer and community representation on the board, and on advisory committees.

And, as innovative efforts, many collaboratives provide services in a newly created area of need. These collaboratives are primarily of private status in order to receive private, as well as public funds, and are often incorporated. These collaboratives, which provide both program development and brokering, act as catalysts for new programs and services from the resources of diverse organizations. Moreover, the collaborative may generate new client groups for the collaborating groups and institutions. And the governance boards are most often comprised of community, academic and political leaders, as well as professionals of the participating institutions, in order to generate necessary community and financial support for the collaborative's innovative programing.

In conclusion, many collaboratives have simimlar purposes for collaboration despite dissimilar goals. These collaboratives share common approaches to collaboration in structure, role and programing. Appreciation of the collaborative's general purpose and characteristics is valuable for understanding: how the collaborative relates to other institutions, agencies, and other collaboratives; where competition from other services might arise; and where to focus special efforts to strengthen collaboration. Thus, such a detailing of collaborative types can make explicit the particular elements necessary for most effective collaboration. 
PART TWO

\section{THE CULTURAL EDUCATION COLLABORATIVE}




\section{THE CASE FOR \\ CULTURAL EDUCATION}

Cultural education is an area which has become the focus for increasing collaborative efforts between cultural and education fields. Traditionally, cultural education has been perceived in its narrowest use of increasing cultural understandings thereby decreasing the cultural isolation of diverse community groups. When diverse ethnicities are able to share aspects of their cultural heritages (arts, languages, traditions) with the larger community, greater community understanding and appreciation results. In Boston, the Mayor's office of Cultural Affairs sponsors a public day of arts and festivities for each of the major city ethnicities.

However, many educational and cultural leaders advocate an expanded and systematic use of cultural resources in educational experiences. As the cultural Education Collaborative writes,

It is still true that those who visit museums and attend professional dance or theater performances are most often white, middle class and well-educated From its inception the Collaborative has assumed that even those who do not fit the stereotype of 'the patron of the arts' have a keen interest in and enthusiasm for the riches within the cultural institutions of the state. The work of the collaborative in the Boston Public Schools, where this past year 80 of the 120 schools in the city requested multisession arts or humanities programs, confirms 
this assumption. The persistence of these requests as well as their distribution across the city... serves to reaffirm our belief that when residents or students or teachers know what is available in cultural institutions they will consider them as their personal resources. 114

Cultural education may be defined as the use of cultural resources (performing and visual arts; historical landmarks; museums, zoo and aquaria collections) to create innovative, structured learning experiences that extend beyond the single field trip or performance. Specifically, cultural education seeks the following goals.

First, cultural education seeks to utilize the multitude of resources of the cultural institutions in meeting the fundamental needs of education. Cultural education can improve basic skill acquisition of the three - R's at all levels of education, from preschoolers to adults. For example, "learning kits" and in-depth curriculum-related courses which draw on the cultural institutions' collections can supplement lessons in science and the humanities. Cultural education utilizes most arts institutions as humanities resources. As the Cultural Education Collaborative postulates,

The Cultural Education Collaborative is concerned with the educational services of all cultural institutions rather than the artistic process in and of itself, it can be argued that all of the activities of its sponsors encourage understanding and use of humanistic knowledge. 115

Cultural education can be employed to assist in the teaching of special needs students -- the physically, 
mentally, emotionally, or culturally handicapped students. For example, bilingual students may be aided in their studies with their own cultural artifacts; animals at the zoo may best help special needs students to relate to their lessons. And cultural education can improve all students' ability to absorb and retain their lessons. Cultural education provides a synthesis of experiences -- action and reflection, field work and classroom lessons -- which create an interesting and dynamic learning environment. As the Academy for Educational Development, Inc., writes, "The idea that a child's natural drive to learn flourishes best in an informal, subtly-controlled ciassroom, rich in things to do is being put to the test in a few schools now." 116 Thus, cultural education provides students with the opportunity to learn through experience. The Cultural Education Collaborative writes,

Learning through experience, through self-discovered knowledge involves the child totally in the educational process. It is her adventure, his discovery, not someone else's. It is in this process that children who have previously not developed skills will acquire them to do something they want to do. The children working together with the theater company in developing their own play were self-motivated to improve their reading and writing skills in order to express themselves in writing their play. 117

Second, cultural education extends the resources of the cultural institutions to broaden and enrich the educational experiences of students and teachers in and out of the classroom. Cultural education opens up the environs of the classroom. It may be employed to expand 
and diversify the educational experiences of students. For example, cultural education programs offer in-depth study using museum collections or special internships with practicing artists. Cultural education programs additionally benefit schools by extending special programs to those schools which must usually forego nonessential academic programs. As the United States Office of Education has discovered,

Schools today face a financial crisis bordering on chaos. There is an acute need for reform in school financing, especially in cities, increasingly beset by demands for public services of all knids, where some 65 , percent of the total budgets go to noneducational purposes, leaving 35 percent for schools. 118

And cultural education may be used to improve the ability of teachers to develop interesting and multi-dimensional curricula through the use of such props as hands-on learning with artifacts or creative improvisational exercises. Third, cultural education seeks to develop the child's creativity. A cultural education program may involve writers and performing artists leading students in acting out their own plays or choreographing a piece of their own poetry. Such experiences help students to give form and expression to their untapped thoughts. This creativity is essential to individual growth and selfdevelopment. Dr. Maslow, Professor of psychology at Brandeis Univserity, writes,

The arts are so close to our psychological and biological core, so close to this identity, this biological identity, that rather than thinking of these 
courses as sort of whipped or luxory cream, they must become basic experiences in education... That the fundamental goals of education, the human goal, the humanistic goal, the goal so far as human beings are concerned -is automatically the self-actualization of a person, the becoming fully human; the development of the fullest height that the human species can stand up to or that the individual can attain. In a less technical way, it is helping the person to become the best that he is able to become. 119

Fourth, cultural education seeks to facilitate communication and understanding among children of diverse racial and ethnic backgrounds. Cultural education is being introduced as support programming in the desegregation of public schools. These cultural education programs premise that children working together in creative educational endeavors (acting out a play, making a mural, stocking an aquarium) tend to become more aware of their individual ethnic, racial, relgious, city or suburban differences in a neutral context that allows for tolerance and understanding. The Cultural Education Collaborative writes,

These programs are important because they can succeed in establishing communication and understanding among children from different racial backgrounds where traditional classroom approaches fail. And since they give form to the values and expressions of a pluralistic culture, they provide the opportunity, the only in many cases, for children to experience each other's cultural heritage. 120

Additionally, education programs held outside the classroom at the different cultural institutions or other locations, provide for a neutral third-site location where children and teachers can remove themselves from the past hostilities often associated with the schools. 
Finally, cultural education is increasingly recognized for its potential role in nonclassroom education. Career education and community education utilize the resources of cultural institutions in programs responsive to community needs. Career education programs seek to utilize cultural institutions to demonstrate to students the gamut of jobs and careers associated with cultural institutions and the performing, visual, and literary arts. Community education seeks to extend the resources of cultural institutions to community residents who have hitherto been unable to utilize those resources on an individual basis due to financial or logistical difficulties, health or other mobility obstacles, or though lack of knowledge of the availability of such resources. "Analogously, cultural institutions have been unable to respond to the needs of Boston's adult learners because they do not have an open and easy communication with members of local communities."121 Community education programs involve performing arts groups in museums on a regular basis in cultural education programs. Thus, cultural education as a collaborative effort confers diverse benefits to the community which range from meeting fundamental educational needs, to enriching cognitive experiences, to enabling individuals to better live in and contribute to society. Charles Silberman, in Crisis in the Classroom, writes,

Schools can be human and still educate well. They can be genuinely concerned with gaiety and joy and indi- 
vidual growth and fulfillment without sacrificing concern for intellectual discipline and development. They can be simultaneously child-centered and subject-orknowledge-centered. They can stress aesthetic and moral education without weakening the three-R's. They can do all these things if - but only if - their structure, content, and objectives are transformed. 122

A critical by-product of the various cultural education programs is the education received by cultural education staffs in the needs and concerns of their constituency, the general public. Moreover, cultural education directly benefits cultural institutions by developing youthful and adult audiences. Museum collections and exhibitions, plays and dances, education seminars and other programs which are made more relevant to community needs and desires will serve to attract larger audiences to the cultural institutions. Everyone benfits from the increased communication as a result of cultural education. 


\section{CULTURAL EDUCATION COLLABORATIVE, INC.}

Overview

The Cultural Education Collaborative, Inc. (CEC)

is a non-profit organization of cultural institutions, school systems, and educational associations working together to promote the use of the educational resources of the cultural institutions. Initiated as the Education Project of the Metropolitan Cultural Alliance in 1973, the Project received a grant from the John D. Rockefeller III Foundation and subsequent funding from the Metropolitan Planning Project to explore approaches 1.) to integrating the educational resources of the cultural institutions in programs for the elimination of racial and ethnic isolation in Boston, and 2.) for the development of a state funded mechanism for the implementation of cultural education programs. The Cultural Education Collaborative became an independent organization in December 1975.

The goal of the Cultual Education Collaborative is to link cultural resources to schools in the commonwealth in order to strengthen, enhance, and supplement the educational experiences of the students in Massachusetts. Cultural institutions (museums, historical societies, zoos, science and art centers, symphonies, dance and theater companies) have collaborated with public schools in over 
one hundred and twenty-five programs which:

- broaden and enrich educational experiences for students and teachers,

- utilize the unique talents and resources of cultural institutions,

- expand and diversify the educational services of cultural agencies. 123

The programming efforts of the Cultural Education Collaborative are,

based on the assumption that cultural agencies have great potential for augmenting and complementing the educational opportunities of students and teachers, and on the reality that at present those cultural agencies are not being used to their fullest capacities. Our goal therefore is double-edged: to assist cultural institutions in the development of educationally sound and meaningful services for school children, and to work with education to increase their awareness of the value of working with existing cultural agencies. A corollary to this is that the Collaborative assists schools and cultural agencies in their joint pursuit of financial support for cultural education programs. 124

Prior to collaboration through the Cultural

Education Collaborative, the schools and cultural institu-

tions interacted and cooperated only sporadically, due to:

- lack of communication channels between cultural institutions and schools,

- lack of knowledge of each other's respective needs,

- inadequate school familiarity with the resources of the cultural institutions,

- persistant reliance on the single visit ('field trip') or single program model,

- lack of pedagogical knowledge in cultural institutions,

- high cost of transportation to cultural institutions and/or lack of on-site educational facilities at the cultural institution, 
- lack of adquate funding for programs,

- undeveloped appreciation for the potential of cultural education.

The Collaborative seeks to overcome the barriers to cultural education by catalyzing joint program planning between schools and cultural institutions; generating program funds; conducting workshops and seminars for cultural institution staff and school administrators and faculty; providing public information, technical assistance, and other services designed to strengthen collaboration between cultural institutions and schools. Specific strategies which "lead to wider use of Massachusetts cultural resources by school children " include,

- passage of the Cultural Education Act,

- generation of pilot programs in schools,

- development of teacher training activities,

- continued public awareness campaigns,

- establishment of a computer-based information service for educational resources. 125

As the Cultural Education Collaborative writes, "Massachusetts is richly endowed with cultural institutions whose resources can be applied to the learning process. What is needed is a mechanism to link these resources to the schools for planning, programming and funding: the Cultural Education Collaborative is that mechanism." 126 
Cultural Education

Collaborative Financial

Structure

The Cultural Education Collaborative is estab-

lished as a non-profit, tax exempt organization pursuant to Section 501 (C) (3) of the Internal Revenue Code. The financial operations of the CEC have become more complex over the last two years. As Exhibit Two depicts, total CEC revenues have increased from over five hundred thousand dollars in 1976 to over eight hundred thousand dollars in 1978, and are projected to rise to over one and one-quarter million dollars by the end of 1979.127 The Cultural Education Collaborative receives financial suuport from three sources. First, the Cultural Education Collaborative receives federal and state grants and contracts in support of educational programming. Federal grants from the National Endowment for the Humanities, the National Endowment for the Arts, and the United States Office of Education have increased steadily, comprising eleven percent of 1977 CEC revenues and twenty-four percent of 1978 revenues. State grants and contracts, however, provide the majority of Collaborative revenues. Grants and contracts from the Massachusetts Council on the Arts and Humanities and the Massachusetts Department of Education, Bureau of Equal Educational Opportunity, constitute eighty-three percent of Collaborative revenues in 1977 and seventy-one percent in 1978. In the future, the collaborative plans, "to develop several new programs in areas of common concern, such as community education and special needs projects.Funds for all programs will be raised jointly by the CEC and the 


\section{EXHIBIT B}

SOURCES OF INCOME - CULTURAL EDUCATION COLLABORATIVE

by $\frac{\text { Projected }}{\text { by }}$ FY 1976 FY 1977 FY 1978

$10 / 1 / 78$

$10 / 1 / 79$

\section{FEDERAL}

Nationa1 Endowment for the Arts

National Endowment for the Humanities

U.S. Office of Education

TOTAL FEDERAL

$\begin{array}{ccrcc}\ldots & \$ 13,200 & \$ 10,000 & \ldots & \ldots \\ \ldots & 52,662 & 76,340 & \ldots & \ldots \\ \ldots & \ldots & 102,820 & \ldots & \ldots \\ \ldots & \$ 65,862 & \$ 189,160 & \$ 341,740 & \$ 361,600 \\ & (10.78) & (23.68) & (32.0 \$) & (26.6 \$)\end{array}$

STATE

Mass Council on the Arts \& Humanities

Mass Department of Education

TOTAL STATE

$\begin{array}{rrr}\$ 6,000 & \$ 8,000 \\ \$ 513,903 & 504,000 & 560,000\end{array}$

$\$ 513,903$

$(97.28)$

$\$ 510,000 \$ 568,000$

$\$ 700,000$

$(65.68) \quad(64.68)$

LOCAL/PR IVATE

Foundations

Corporations

Local Schools and Cultural Agencies TOTAL LOCAL/PRIVATE

\begin{tabular}{ccccc}
$\$ 15,000$ & $\$ 35,776$ & $\$ 45,000$ & $\ldots$ & $\ldots$ \\
$\ldots$ & $\ldots-$ & $\ldots$ & $\$ 25,000$ & $\$ 50,000$ \\
$\ldots$ & 2,416 & $\ldots$ & $\ldots$ & 70,000 \\
$\begin{array}{c}\$ 15,000 \\
(2.88)\end{array}$ & $\begin{array}{r}\$ 38,192 \\
(6.28)\end{array}$ & $\begin{array}{r}\$ 4,000 \\
(5.68)\end{array}$ & $\begin{array}{r}\$ 25,000 \\
(2.38)\end{array}$ & $\begin{array}{c}\$ 120,000 \\
(8.8 \$)\end{array}$ \\
\hline
\end{tabular}

TOTALS

$\$ 528,903 \$ 614,054 \$ 802,160 \$ 1,066,740 \$ 1,361 \ldots 6 n$

From Financial Profile Chart- 1 \& 3 Challenge Grant Proposal 


\author{
Collaborative expenses \\ directly related to \\ school/cultural insti- \\ tution programs \\ Collaborative general \\ and administrative \\ expenses \\ Collaborative-generated \\ funds for cultural education \\ programs at schools or cul- \\ tural institutions
}

FY 1975*

$\$ 216,000$

FY $1976 * *$

FY1977 FY 1978

$\$ 443,843$

$(87.88)$

$\$ 444,000 \$ 500,000$

$(73.48)(62.18)$

27,204

21,379
$(4.28)$

$57,468 \quad 147,589$

.

$(4.27)$

$(9.5 \%)$

(18.3\%)

40,734

40,292

(8.0\%)

$103,265157,720$

$(17.18)$

$(19.6 \%)$

TOTALS

$\$ 283,938 \$ \$ 505,514 \$ 604,733 \$ \$ 805,309$

* In FY 1975 the Cultural Education Collaborative was a subsidiary project of the Metropolitan Cultural Alliance.

**Collaborative expenses in FY 1976 are over a nine-month period, December 24,1975 to September $30,1976$. 
participating institutions and schools,"128

Secondly, the Collaborative receives grants from private foundations and several corporations. This source of financial support is still quite small, comprising only slightly over six percent of 1977 Collaborative revenues and over five and one-half percent of 1978 revenues. The majority of tisese grants go directly to programming operations. Very little of the funds may be used for administrative or central support purposes. As the Cultural Education Collaborative concludes, "In sum, the financial profile of the CEC shows a sound financial base for programs, with an administrative and central support system which could use more substantial underpinning." 129

Finally, the Cultural Education Collaborative is preparing to charge assessments for participation in the Collaborative's Information Services Program. Participating schools and libraries will be required to subscribe annually to this program.

The Cultural Education Collaborative expended over six hundred thousand dollars in 1977 and over eight hundred thousand dollars in 1978. As Exhibit Three depicts, Collaborative-generated funds for cultural education programs and services constituted the largest CEC expenditures (seventy-three percent in Fiscal year 1977, sixty-two percent in Fiscal Year 1978). Collaborative expenses related to school/cultural institution programs have increased rapidly 
with the expansion of the programs (nine and one-half percent in Fiscal Year 1977, and eighteen percent in Fiscal Year 1978). Collaborative general and administrative expenses have increased as well, from eight percent in Fiscal Year 1976, to seventeen percent in Fiscal Year 1977, and twenty percent in Fiscal Year 1978, reflecting increased programming operations and the hiring of additional staff. The Collaborative writes,

Funding for increased programs and services will continue to be raised from federal and state sources as well as from private foundations, corporations and local contributions to specific projects. A solid funding base for the Collaborative's central office activities would mean the possibility of greater concentration on services to cultural agencies and on the development of an ongoing mechanism for funding all vital non-programmatic activities. 130

Cultural

The Cultural Education Collaborative is governed Education

Collaborativeby a policy making Board of Directors. The Board of Directors Governance

Structurecurrently numbers twenty-eight members and is composed of educators, cultural institution officials, legislators, union representatives and other individuals interested in furthering cultural education. Each director is elected by the general members at the annual meeting and serves for no more than two consecutive terms of three years each. Each director has a vote and is "entitled to vote on any question at any meeting of the members of the corporation." 131

The officers are elected annually by a vote of the directors. Only the President of the Board need be a director. The President is the "Cheif Executive officer" of the Collaborative and presides at all meetings of the Board. 
The Board of Directors is divided into an Executive Committee and four standing committees of functional responsibility, including: the Nominating Committee, the Public Information Committee, the Program Committee, and the springfield steering Committee. The Executive Committee, currently of eight members, is comprised of the officers of the Board and the Chairpersons of the other standing committees. The Executive Committee meets at least once a month to discuss policy directions and any administrative or programming difficulties which may arise. The Executive Committee is elected by the directors from their numbers, and is vested with the "management of the current and ordinary affairs of the corporation."132 The membership of the standing committees is supplemented by cultural institution and school representatives who are not directors of the Collaborative's Board. The Nominating Committee, which includes educational, cultural and community leaders from across Massachusetts, meets to suggest nominees to the Board who would represent the Board statewide. The Public Information Committee publicizes and promotes public support for the Cultural Education Act, primarily. The Program Committee supervises the Boston area Collaborative programs, particularly the school/cultural institution programs. And the springfield steering Committee, which is composed of the administrators of all of springfield's cultural institutions, the springfield Schools superintendent, and the head of School Volunteers, provides technical support 
and direction to the coordinator of the Springfield office of the Cultural Education Collaborative.

$$
\text { Additionally, the By-Laws establish that, }
$$

The board of directors may create an advisory board of one or more advisors. Members of the advisory board may attend all meetings of the board of directors and may participate fully therein; provided, however, that no member of the advisory board shall be empowered to vote at such meetings. 133

Presently, the Board is advised by several such committees. One such committee, the Advisory Committee to the Humanities Project, includes parents, trustees of museums, and school superintendents. This advisory committee serves two purposes: to advise the Board on the operations of the Project and the needs of students and cultural institutions; and to disseminate information about the program to PTSAs, other cultural institutions, and other school administrators.

The Executive Director of the Cultural Education Collaborative is assisted by a staff which has recently been expanded to include: a Deputy Director; a Coordinator, Information Services; a Springfield Program Coordinator; a Program Assistant; and Office Manager; a Secretary; plus two interns. The Executive Director is appointed by the Board of Directors and is responsible for: carrying out the Board's overall policy direction; developing the CEC's objectives and work plans; structuring and supervising CEC activities; and raising funds. Additionally, the Executive Director seeks to stimulate federal, state, and 
city policy directions to foster a role for the cultural institutions in education. The Executive Director attends all Board meetings, making reports and recommendations to the directors.

Cultural The major purpose and goals of the Cultural Education CollaborativeEducation Collaborative include: Goals

\section{Purpose:}

To plan and develop programs, funds, and administrative mechanisms designed to strengthen the collaboration between educational and cultural institutions and so extend the benefits of cultural education to the residents of Massachusetts.

\section{Contextual Goal:}

To extend the cultural resources of the Commonwealth of Massachusetts to all its citizens and so enrich and advance the educational experiences of the residents of the Commonwealth.

\section{Active Goals:}

- To extend the educational potential of Massachusetts cultural institutions for creating new educational services and generating new audiences and financial support.

- To lead in the formulation of public policy which will create a vital role for the Massachusetts cultural institutions in public education.

- To create through new legislation a state-wide funding system which will finance the purchase of educational services of cultural institutions by Massachusetts schools.

- To provide planning, staff development training, and targeting of funding sources to the cultural institutions and schools in their collaborative efforts so as to strengthen the ability of cultural institutions to offer a variety of educational services to the public.

- To provide joint programming which reduces minority isolation and fosters interracial, crosscultural communication. 
- To provide public information about the educational services and resources of the Massachusetts cultural institutions.

- To promote access to the cultural institutions to those residents of Massachusetts who, because of distance, cost, health, or other restrictions, are not able to take advantage of the diverse educational resources of the cultural institutions.

Cultural Education Collaborative Major Programs And Services

The major programs and services of the Cultural

Education Collaborative include:

A. Cultural Institution Desegregation Program in Boston and Springfield

Program Goal: To provide for ethnic and racial deisolation by encouraging the cooperation and participation of diverse community groups, and to assist in the desegregation of schools by providing quality integrated education in the cities of Boston and springfield.

Program Summary: In his Court Order of May 1975, Federal Judge W. Arthur Garrity called on the city's cultural institutions, businesses, colleges, and universities to provide educational services to the Boston Public Schools. The CEC was designated to coordinate the school/cultural institution pairings by serving as the central coordinating link for the cultural institutions to the Massachusetts Department of Education, the public schools, school committees, and parent groups. The desegregation programs developed through the CEC provide in-depth curriculumrelated programs to students; programs which utilize the resources of metropolitan Boston and Springfield museums, zoos, aquaria, dance and theater companies. "The emphasis in all course now coordinated by the CEC is skills not frills." For example,

improvisational theater techniques are based on the teaching basic writing skills, and students at the Museum of Transportation get lots of math as they plot time and distance calculations on city transporation systems and build scale models. 134

The "Moving Game" is one such cultural institution program. 
program.

The program was designed to draw together urban and suburban children in an innovative and interesting activity. Working in teams, students mapped and explored through a variety of microworlds in greater Boston, discussing structure, history and activities... The goal was to reduce cultural isolation by developing the children's ability to perceive, cope with and make use of the extended city, as well as to master informational, conceptual, and technical mobility skills. 135

B. Collaborative Humanities Project

Program Goal: To encourage elementary and secondary school teachers to strengthen their classroom humanities curricula through the use of museums as primary resources and to enable the cultural institution staff to learn more about the educational needs and concerns of teachers and students.

Program Summary: This three-year interdisciplinary project brings teams of school teachers together with museum educators in two-week summer institutes to develop curriculum materials and classroom activities which utilize the resources of museums collections and staff members. During the academic year, museum and school educators continue to meet together to conduct jointly-developed classroom and museum-related activities. This program benefits hundreds of students through the ripple effect. Teachers who have participated in the program disseminate their new information and curricular skills to the other teachers in their own and nearby schools.

\section{TRI-ARTS Program}

Program Goal: To provide a multi-dimensional, racially and ethnically diverse arts experiences for students in selected ESAA-eligible schools in an effort to reduce minority isolation and to foster interracial, crosscultural communications.

Program Summary: This program, administered by the Massachusetts Council on Arts and Humanities, brings together the resources of three existing arts and cultural education agencies in its attempt to provide a multi-faceted cultural complement to the curricula of the Boston Public Schools. TRI-ARTS 
provides elementary school children, parents, teachers with: 1.) exposure to outstanding visual and literary artists through the Massachusetts Arts and Humanities Foundation's "Artists in Residence Program"; 2.) reduced rate admission through a special voucher program of ARTS/Boston to a wide range of performing arts events throughout the city; and 3.) the opportunity to explore the richness and excitement of Boston's cultural institutions through in-depth curriculum programs sponsored by the Cultural Education Collaborative. The CEC directs the participation of the performing arts groups and museums in this new program.

c. Career-Education Training Project *

Program Goal: To develop and demonstrate successful ways of training education directors of cultural institutions to conduct career education program.

Program Summary: This year long training project is designed to assist education directors from selected Boston and springfield cultural institutions in developing career education programs based on the variety of jobs and careers associated with their own cultural institutions. Participating directors seek three outcomes of this project: l.) to acquire a broad background on the goals and characteristics of career education; 2.) to develop with school persornel a career education program; and 3.) to develop a long range plan for their institution's continued commitment to career education. Career education programs will then be offered as educational services of the cultural institutions to schools in Massachusetts.

D. Cultural Information Services Project *

Program Goal: To make available up-to-date and easily accessible information on the educational resources (collections and special happenings) of the cultural institutions to schools throughout Massachusetts and so promote the educational potential of the cultural institutions.

Program Summary: This project seeks to develop a computer-based information service which will make up-to-date information on cultural educational resources available to teachers, students, parents, and libraries throughout the state. Information to be disseminated to subscribing schools and libraries include: descriptions of exhibits and performances; special collections; classroom kits; courses for students, teachers, and parents. 
Cultural Education

Collaborative clients of the Cultural Education Collaborative:

Clients

A. Cultural Institution Desegregation Programs

Impacted: $\quad$ students, teachers, cultural institution (direct staff and administrators, school adminibeneficiaries) strators,

Involved: $\quad$ students, teachers, cultural institution Tparticipants staff and administrators, school adminiin programs/ strators, Federal District Court, services) Bureau of Equal Educational Opportunity

Concerned: students, faculty, school administrators, (with program/ Massachusetts Department of Education, service outcomes) Federal District Court, United States Office of Education, cultural institution staff and administrators, Massachusetts Council on the Arts and Humanities, interest groups, taxpayers, community

B. Humanities Project

Impacted :

Tirect

beneficiaries)

Involved: (participants

in programs/ services)

Concerned: (with program/ service teachers, cultural institution staff students

teachers, cultural institution staff, education specialists, National Endowment for the Humanities

students, parents, teachers, administrators Massachusetts Department of Education, s) United States Office of Education, cultural institution staff and personnel, Massachusetts Council on the Arts and Humanities, interest groups, taxpayers, community at large 
c. Career-Education Training Project

Impacted:

(direct

beneficiaries)

Involved:

(participants

in programs/

services)

Concerned:

(with program/ service outcome

cultural institution administrators, students, parents, teachers, administrators, s) Massachusetts Department of Education, United States office of Education, community groups, taxpayers, employers

D. TRI-ARTS Program

Impacted:

Tirect

beneficiaries)

Involved:

(participants

in programs/

services)

Concerned:

(with program/

students, parents, teachers, administrators, artists, individual consumers, cultural

institutions

service outcomes)

students, parents, teachers, administrators, artists, individual consumers, Massachusetts Arts and Humanities Foundation, ARTS/Boston cultural institutions, Màssachusetts Council

students, parents, teachers, administrators, artists, individual consumers, Massacusetts s) Department of Education, United States Office of Education, Massachusetts Council on the Arts and Humanities, Massachusetts Arts and Humanities Foundation, ARTS/Boston community interests, taxpayers, cultural institutions

E. Cultural Information Services

Impacted :

Tirect

beneficiaries)

Involved:

(participants

in programs/

services)

Concerned:

(with program/ service students, teachers, administrators, parents libraries, cultural institutions

teachers, students, parents, administrators, cultural institution, libraries

teachers, students, parents, administrators, cultural institution administrators,

es) libraries, Massachusetts Department of Education, United States office of Education, Massachusetts Council on the Arts and Humanities, community groups, taxpayers 
Cultural

Education

Collaborative

To achieve these goals and objectives, the Cultural Education Collaborative works in cooperation with local, state and federal agencies, and corporations in the development of public policy, the dissemination of public information, the extension of cultural education services, and the development of innovative programs. Specifically, the Cultural Education Collaborative serves the following roles.

First, the Cultural Education Collaborative engages in policy planning and advocacy with state and federal agencies to generate a role for cultural education. Although not a lobby group, the Cultural Education Collaborative supports passage of the Cultural Education Act to establish a state-wide funding base for the purchase of educational services by Massachusetts schools. The Collaborative writes, "The Cultural Education Act has been a priority at the Collaborative for the past three years because, when funded, it will provide a solid financial base for joint schoolcultural institution educational programs."136

Secondly, the Collaborative catalyzes joint programming between cultural institutions, schools, and community agencies. The Collaborative staff develops, plans, sponsors, and supervises the monitoring of programs and services to meet the needs of cultural institutions and schools.

Thiraly, the collaborative staff serve as pro- 
gram and service brokers, linking education and museum experts and consultants, existing services, and other community and arts resources to the services needs of participating cultural institutions and schools. For example, the collaborative has organized a series of workshops and seminars conducted by education and human relations consultants for the cultural institutions and schools participating in the joint programs. The topics for these workshops are derived from questionnaires sent to principals, teachers, and cultural institution staff.

Fourthly, the Collaborative generates public and private funds for collaborative operations, programs, and services.

Fifthly, the Collaborative staff provides technical assistance to cultural institutions in program design, proposal writing, budgeting, and contracting for state funds. As part of this responsibility, the collaborative acts as a central coordinating link to the Massachusetts Department of Education, the Boston public schools, the Boston school committee, and the participating school systems in the cultural institution/school programs. In this role, the Cultural Education Collaborative,

- submits the proposals and contracts for cultural integration programs in a package to the respective education agencies;

- follows the proposals through the approval and contract process and informs applications of the status of their proposals

- establishes the fiscal agents and coordinates reports. 
Additionally, the collaborative provides a central communications link between participating cultural institutions and schools, community agencies, and the education agencies. Finally, the Cultural Education Collaborative disseminates public information on cultural education: to focus public and media attention on the important roles Massachusetts cultural institutions can, and are now playing in public education; to generate public enthusiasm for and commitment to the use of cultural institutions as partners in education; to communicate the improtance of the collaborative's role as facilitator/catalyst to local, state, and federal agencies, as well as private funding sources; and to direct national attention to the Collaborative's programs as possible national models. In particular, the Cultural Education Collaborative coordinates the overall press effort for cultural education programs, publishes a Newsletter and a Bulletin, and is developing a major marketing campaign for the Cultural Information Program.

Cultural Education Collaborative Participants
Thus, the Cultural Education Collaborative

unites cultural institutions with schools in collaborative programs and services. The Cultural Education Collaborative further links cultural institution staff, school administrators and faculty, students and parents with existing resources in education, human relations, and museum education.

Cultural institutions have a growing need for 
collaboration. These cultural institutions are facing increasing pressures to apply their vast resources (artifacts, collections, talents) to structured and extended learning opportunities for students and community groups. At the same time, cultural institutions are experiencing rising operating costs, may be much understaffed, and may have little knowledge in museum education.

As participants in collaboration, cultural institutions contribute staff time, resources and facilities. In return, the cultural institutions receive funds and technical assistance to initiate or expand programs in cultural education and so become more involved in education and the community. These institutions additionally benefit from the public information dissemination of cultural resources. And many cultural institutions benefit from the technical assistance and information services which develop the skills of their own education staff or administration. As an evaluation for the school/ cultural institution program concludes,

The cultural institutions again are self-selected; they have volunteered to offer these programs and are eager for their success. Their ability to work with the public schools, to adjust to their needs while using their own strengths and areas of expertise, varied from institution to institution... A significant statistic is that only five of twenty-three institutions offering programs in 1976-77 did not propose them again for the following year. 138

Public schools have been experiencing diverse pressures for increased quality and quantity of educational 
programming that provides basic skills, yet is developmental and will hold the student's attention. Additionally, schools must meet state and federal mandates for increased educational opportunities for minority and special needs students. As participants in collaboration, the public schools contribute administration and faculty time, and facilities. Participating schools may be also required to pay assessments for selected services. In return, the public schools collaborate in cost-effective and innovative services and educational programs which teach basic skills, subject area curricula, human relations, self-development, and meet state and federal mandates. As the Cultural Education Collaborative writes,

Despite the ever spiraling costs of education, the use of cultural resources can represent a cost savings to schools; with the cut back in state school construction funds the cultural institutions can serve as sites and classrooms for instruction. The planetariums, laboratories, museum collections, auditoriums, and staff expertise can be used by schools rather than schools expensively duplicating them. The cultural institutions can also bring their resources to bear on pressing educational problems such as integration, special education, and career education. By using these specialized resources students can learn in high interest courses designed to meet their basic educational needs. 139

For example, an evaluation reports that one principal saw "the program in his school as a demonstration of different ways and places children can learn important subject matter -- surely an opening up of views about schooling that allows for the active help of the cultural institutions. Another looked to the programs for actual 'assistance in change'." 140 
The Massachusetts Department of Education endorses and financially supports several of the cultural education programs of the Cultural Education Collaborative. The assisted programs are efforts to meet state legislation for equal educational opportunity and aid the desegregation efforts of the Boston and Springfield public schools. Anne Hawley, former Executive Director of the Cultural Education Collaborative, writes, the CEC "format fits in the with state Department of Education's aim of spreading state and federal funds more evenly among Boston's 162 public schools."141 In April, 1977, the Massachusetts Board of Education issued the following "Resolution on Behalf of Cultural Institutions".

Whereas, The arts, as a basic form of human communication, can offer varied experiences to interest, to motivate, and to engage students.

Whereas, The Commonwealth is uniquely endowed with museums, historical societies, performing and visual arts organizations, and other cultural institutions, and

Whereas, the Board of Education has designated as one of its ten educational goals the development of individual values and attitudes, and the development of creative interests and talents, and

Whereas, the Board has issued a policy position on the arts in education that calls for a comprehensive program, infused into the total curriculum that will provide for greater utilization of our cultural institutions,

Be It Resolved,

that this Board of Education reiterated its support for the passage of the Cultural Education Act although cognizant of limited state funds available at this time to fully implement the law and further that the Board states its appreciation to the Cultural Education collaborative for its efforts in the schools of Massachusetts and supports this organization's attempt to seek both federal and private grants for this program. 
In conclusion, collaboration is a mechanism which benefits cultural institution administrators and staff, school administrators and faculty, students and parents. Collaboration facilitates communication between groups of diverse needs, reduces the duplication of services, provides cost-effective services, generates public and private program funds, and improves the ability of groups to serve their constituency. The special efforts of the Cultural Education Collaborative serve to increase cooperation of cultural institution, school, and community; encourage social and racial de-isolation; improve the ability to teach basic and developmental skills; and generate innovative programs which open up the environs of the classroom. As the Cultural Education Collaborative concludes,

The experience of the CEC has demonstrated that a central coordinating body for educators in cultural institutions and in schools can encourage a level of concern and thoughtfulness about program guality, professional standards of evaluation and assessment, public educational policies and current intellectual issues that is rarely attained by individuals working alone in separate institutions. Specifically, the CEC has focussed the attention of cultural institutiona in the city of Boston on the catalysmic social disruptions caused by desegregation and on their role in alleviating the tensions of a divided city. Likewise, it has given attention to current professional issues including teacher training and retraining, criteria for determining high quality programs, and the impact of career education. Thus, the CEC serves not only day-to-day technical needs of cultural educators, but also provides a forum for consideration of braoder social and humanistic issues. 142 


\section{CRITICAL ISSUES}

As the description denotes, the Cultural Education Collaborative has at least three major issues confronting its present programing and future development.

First Issue: Resting on soft money, the Collaborative administrative and central support system requires more substantial underpinning.

Second Issue: Dealing with so many varied participants and interests, the Collaborative needs to carefully define its audience(s).

Third Issue: As a young and growing organization providing a new area of service delivery, the Collaborative needs to develop and project a strong public image.

These issues must be addressed in order for the Collaborative to effectively fund operations, target programs and services, and operate in an environment of support for the programming of the Cultural Education Collaborative.

First Issue: The Collaborative Administrative and Central Support System Requires More Substantial Underpinning

It has been the Collaborative's experience that program funds are much easier to generate than administration and operating funds. Without a solid funding base, the collaborative spends most of its time seeking essential operating funds, and is constrained from moving into new program areas. Moreover, the Collaborative's general and administrative expenses have more than doubled in the last 
two years. Clearly, the Collaborative needs additional sources of operating funds.

As the typologies depict, the Collaborative has two alternatives for sources of operating funds: membership assessments and program and service assessments. Presently, the Collaborative has no subscribing members and receives little program and service assessments. Alternative One - Membership Assessments:

The membership assessments have been employed to at least partially support the operations of five of the above collaboratives. These collaboratives, however, are of two types. The first type of collaborative are those educational collaboratives which seek principally to strengthen and supplement the services and programs of school districts. As Dr. Lavin, of the Merrimack Education Center, expressed above, these assessments, albeit small, serve to generate school district interest in the operations of the collaborative. Conversely, the collaborative has a fiscal accountability to the school districts for the wise expenditure of their funds. The second type of collaborative which charges membership dues are the collaboratives whose purpose it is to provide cooperative programs and services for the effective management and administration of their respective institutions.

The collaboratives which assess membership dues share additional characteristics. These are largely brokering agencies and have a constituency of institutions similar 
in purpose and responsibility. The programs and services these collaboratives receive are the primary function of that subscribing institution and would have to be provided independently without collaboration. The members are therefore paying for necessary cost-effective programs and services. Clearly, the Cultural Education Collaborative shares very little in common with characteristics, roles and strategies of these subscribing membership collaboratives. The Cultural Education Collaborative unites in collaboration diverse groups of diverse means in programs and services which may be additional to the normal programing of the institution.

Moreover, the Collaborative is philosophically diametric to these collaboratives. Whereas the subscribing membership collaboratives seek to internally service a limited constituency, the collaborative seeks to extend the resources of the cultural institutions outward, to as many educational institutions as possible. To charge membership assessments, however small, would not only mean pricing out cultural institutions of little means and discouraging future clientele, but would not be consistent with the Collaborative's contextual goals. Thus, charging membership fees is not the best alternative for the collaborative. Alternative Two - Program and Service Assessment:

With the exception of the two "planning collaboratives", all of the above collaboratives assess participants for selected programs and services. These assessments also 
go towards the administration and operation of the collaborative. These assessments are charged for on-going services for central office operations such as staff development, technical assistance, seminars, and in-service training. Assessments may take the form of tuition for a continuous program, an annual subscription for participation in regular services, or single payment for a seminar or program. Moreover, of the above collaboratives, the Museums Collaborative has many of the similar goals, roles and operations of the Collaborative. The Museums Collaborative charges assessments for seminars, publication and information services, and continuing professional educational programs. The Museums Collaborative, however, conducts the educational programming under the support of grants and contracts.

The Collaborative is increasingly providing supportive services to cultural institutions and schools, and should consider assessments for many of these services. The Collaborative is already planning to charge for subscription to the computer information service. However, there are additional areas of supportive services for which the Collaborative could charge assessments and not jeopardize or limit the collaborative's constituency. These are services which might be considered important to school or cultural institution operations. For example, the collaborative could charge selected institutions for workshops and seminars. These payment, however small, might cover the cost of these services (plus cover some staffing or other administrative 
operations). Additionally, the Collaborative might charge a small fee for participation in such cultural education festivals as the "Culture Connection". The participant receives valuable public exposure and publicity and might be induced to pay a nominal fee, or the cost of the festival, prorated. Finally, the Collaborative might charge a small tuition for participants in the career education program. This is a program which is in increasing demand from public schools.

Whatever assessments charged, they must be small so as not to limit the present collaborative participants nor limit future audiences. These assessments can only be charged of supportive services that are required by the clients. Tuition or fees for innovative educational programing might be enough negative incentive to discourage participation in cultural education programs that are still seeking legitimacy. These service incentives, necessarily small, will not cover the entire operating expenses. Other sources of incentive, such as business contributions and grants that provide additionally for office operations, must continue to be solicited. But program and service assessments should be an important consideration. These assessments, albeit small, further help to diversify the financial base of the collaborative, decreasing the presently heavy reliance upon public and private grants. 
Second Issue: Who Is The Collaborative's Audience?

Another way of framing this question is to ask:

"Who do we have to reach to meet our goals?" In collaboration, there may be several audiences, or clients. Each audience may require separate strategies. Therefore, careful identification of the different audiences is critically important for the Collaborative in order to prioritize and target scarce resources for effective strategies and programming.

To answer the question, "Who is the audience?", one must examine the history of the Collaborative, to determine its founding intention and mandate, and the Collaborative purpose, goals and current strategies.

As mentioned, the Collaborative was initiated as the Education Project of the Metropolitan Cultural Alliance to plan the integration of education programs and resources into the curricula of metropolitan Boston schools. In 1973.

ten directors of Boston museums and arts organizations formed an Education Committee to begin planning how their institutions could diversify and enliven their education services. They began meeting under the aegis of the Metropolitan Cultural Alliance....

From the outset they were concerned with developing new programs and services jointly with the public education sector and determining mechanisms to fund these services in an on-going way to embed themselves in the school curriculum; to become partners in the education system. 143

Thus, the Collaborative was initiated to foster cooperation between cultural institutions and education institutions. 
Secondly, the strategies actively employed by the Collaborative focus on the collaboration between educational and cultural institutions in three ways:

1) by providing programming which utilizes the resources of cultural institutions in innovative educational experiences;

2) by providing services to the cultural institutions to develop the education capacity of the cultural institution staff;

3) by engaging in policy planning and advocacy with public agencies to secure a permanent role for cultural agencies in public education.

The strategies may focus on either schools or cultural institutions but all goals seek to promote cultural education. Thus, the primary clients, or audience, of the collaborative are the cultural and educational institutions.

To be most effective then, collaborative programs must provide for the various needs of both client groups. If, for example, the Collaborative focused on the cultural institution as the only client, the schools may be neither receptive to, nor prepared for, cultural education programs and services. Further, the clients have different motivations for participation in collaboration. Large museums, for example, may have less need for the benefits of collaboration as small performing companies or schools. In such a case, it would be unrealistic to expect full cooperation by all parties without special efforts to encourage the institutions of lower incentive. Thus it is necessary to identify the needs and characteristics of the primary clients. Specifically, several recommendations can be made to strengthen the 
Collaborative operations at each level.

First, the Collaborative should focus attention on building incentive for participation of cultural institutions. Many of the cultural institutions have less need to participate enthusiastically, if at all, in collaborative programs. Indeed, cultural education may be considered as a secondary, or tangential, function of cultural institutions. Any public relations campaign supporting the merits of cultural education may, as a by-product, encourage more cultural institutions to participate. More importantly, strong efforts must be made to expand and emphasize the benefits of participating in the Collaborative's program and services. Second, the Collaborative should focus on establishing to schools the value of cultural education programs and services. Too often, school administration is caught up in the daily operation to be receptive to'innovative programs. Therefore, endorsement for the educational value of cultural education programs must be made forcefully and publicly by those school administrators and faculty who have participated in cultural education programs.

Finally, the Collaborative should increase communication networks between museums and schools, and ensure participation in program design and decision-making of both so that the needs of both are included in the programming. Further, participation in programming tends to strengthen concern for the success of the program. 
However, the Collaborative has additional levels of audience. A second audience level includes the participants in collaboration programs and services beyond cultural institutions and schools. These participants include state and federal officials contacted in public policy development; the educational, business and museum experts utilized in collaborative seminars, workshops and services; and the funding sources and the agencies that establish criteria for program operations (such as Bureau of Equal Educational Opportunity, National Endowment for the Humanities, the Federal District Court, etc.). These program and service participants must additionally be considered program and service clients. If the diverse needs of these participants are not provided for, programs and services will bogg down for lack of communication. These program participants are distinguished from the direct clients in their motivations for participation. It is the business of these program participants to fund and supervise programs, or contract out services. As a result, the Collaborative need be less conscious of building motivations among these participants. Communication and coordination, however, are very important to ensure the proper functioning of programs and so confer the maximum benefits to schools and cultural institutions. There is a final level of audience for the collaborative efforts. This audience includes the diverse groups which may be concerned about collaborative program and service outcomes. This audience may include the employers who 
may be concerned about career education, ethnic and racial groups concerned about integration and ethnic heritage programs, and so on. In addition to specific interest groups, taxpayers and the community at large may be concerned, if aware of, the cost-effectiveness and innovative approach to quality education. Finally, other education agencies may be concerned over the outcome of the cultural education programs as possible positive models for innovative educational programming. It is important that the Collaborative recognizes this audience level. For the ultimate success and extension of cultural education, the general public must be knowledgeable of the operations and supportive of the value of cultural education.

Thus, the Collaborative has three levels of audience. Each level of audience presents different imperatives for action by the Collaborative. The Collaborative would therefore benefit by recognizing the different motivations, needs and value of each client group within each level. Third Issue: The Collaborative Must Develop and Project a Strong Image

The Collaborative, as a private non-profit collaborative, must project a strong public image in order to receive contracts and grants, and generate new participants in collaborative activities. The Collaborative must appear cost-effective, successful and innovative to be considered by agencies for grants and contracts. Indeed, the collaborative must appear more attractive in process and product than other organizations which are competing for scarce 
funds. For example, a funding source may look to see that the Collaborative project:

- is not otherwise available;

- is cost-effective;

- meets a strong need and not be frivolous.

Additionally, the Collaborative seeks to sustain and attract participation in programs and services. The Collaborative must appear to the present and potential participants to:

- provide programs of merit;

- provide programs and services which meet client needs;

- respect the suggestions and inputs of the participants;

- follow through on commitments.

Thus, the Collaborative must establish itself in the eyes of present and future funding sources and participants as: to offer services of value to the participant; to best provide these services; and to conduct operations in a most professional manner. A thorough evaluation should establish the degree to which the Collaborative meets these criteria, and should provide recommendations for improvement in any area of service weakness.

There are several strategies that the Collaborative should employ to solidify a public image as an innovative and professional organization. Most importantly, the Collaborative must direct attention to the success of its programming thus far by documenting the results of its programs and services. Additionally, the collaborative staff might 
develop policy papers and articles for professional journals, lectures, and other forms of dissemination. The Collaborative might publish an attractive brochure or resume of the Collaborative's purpose and programs for dissemination to interested groups. A polished document would confer the impression of Collaborative competance, in the way that EdCo logos capture the essence of each program area in one visual representation and leave the impression that the EdCo staff is specialized and confident in their work. A marketing analysis or public relations campaign could certainly be of value in projecting a professional public image for the Collaborative. A bold track record will be the best public statement in behalf of the Collaborative.

Ultimately, however, the Collaborative must spend as much, if not more, time on promoting cultural education. The Collaborative must promote through increased information dissemination the value of the Collaborative for several reasons.

First, as was established above, the Collaborative must convince potential funding sources that their funding will go towards a valuable program that produces results. Second, the Collaborative is generating collaborative programs between at least two diverse groups. The programs are not only non-traditional in their delivery, but the resultant products are also innovative. Through innovation, the collaborative is introducing a new approach to education based on the resources of cultural institutions. 
The Collaborative must therefore persuade fiscally-constrained schools and cultural institutions of the strong educational value of cultural education. A climate of acceptance for cultural education, in general, and the Collaborative services, in particular, must be generated.

Third, the collaborative must generate public support (third level of audienc) for cultural education. If parents believed in the educational value of cultural education, they might pressure Parent Teacher Student Associations and school administrators to participate in cultural education programs. If ethnic, racial, historical or other interest groups were made aware of the potential for curricula development and human development of cultural education, they might pressure schools and cultural institutions to participate in the Collaborative's programs. Taxpayers might be more amenable to cultural educational programs if knowledgeable about the ability of cultural education to generate resources other than local property taxes. And parents might be more supportive of cultural education if made aware of the education and creative development results of such untraditional approaches to learning.

To the general end of promoting cultural education, the Collaborative should employ the following strategies. First, the Collaborative should document and publicize the results of the Collaborative's programs, thereby demonstrating the basic educational value of cultural education. Secondly, the Collaborative should seek and publicize the endorsement 
of the federal and state education offices, for the educational value of cultural education. The Massachusetts Department of Education has already endorsed the Collaborative, but should more publicly promote cultural education. Third, the Collaborative should spread the value of cultural education and the Collaborative through participants: principals to principals, teachers to teachers, LEA to LEAs. The Collaborative has sought to generate a base of support by including community and political leaders, interest group representatives, and union officials on the board. This leadership should be expanded, and/or representatives given a greater role to play in publicizing and promoting cultural education.

Thus, the Cultural Education Collaborative, must not only generate audiences for collaborative programs but must generate a need and climate of acceptance for cultural education. Without increased public support for cultural education, the collaborative will be continually struggling to generate a need for their programs. The issue, here, is not the justification of cultural institution programs. The justification has already been proven by many cultural education programs. Collaboratives involved in cultural education must believe in the value of cultural education as a starting point. Rather than be concerned over the justification of cultural education, the Collaborative must be concerned over promoting cultural education generally and over the quality and direction of cultural education programs. 


\section{CONCLUSION}

Thus, the Cultural Education Collaborative seeks to enrich and advance the educational experiences of residents of the Commonwealth by planning and developing programs, services, funds and administrative mechanisms to strengthen collaboration between educational and cultural institutions. What Impacts Does the Cultural Education Collaborative Seek?

In developing the educational potential of cultural institutions, the Collaborative seeks three areas of impact. First, the Collaborative seeks to provide structured educational experiences that employ the resources of cultural institutions. To this end, the Collaborative provides innovative programming between cultural institutions and schools. Such programming requires that the Collaborative develop and monitor programs, and raise program funds. The complexity of these programs requires the Collaborative provide communications and information between the various parties as well as technical assistance to cultural institutions and schools. Additionally, the Collaborative seeks the formulation of public policy which will create an established role for cultural institutions in public education. This objective requires that the collaborative engage in public policy and advocacy with state and federal agencies to 
generate a role for cultural education in Massachusetts. In particular, the Collaborative publicizes and supports passage of the Cultural Education Act which will finance the purchase of education services of cultural institutions by Massachusetts schools.

Secondly, the Collaborative seeks to develop the educational capacity of cultural institution staff and the ability of school personnel to fully utilize cultural education. To this end, the Collaborative sponsors workshops and seminars and creates new services for both cultural institution staff and school personnel in teaching and documentation techniques, human relations, curricula development, for example.

Thirdly, the Collaborative seeks to increase the audiences using the resources of cultural institutions. In addition to the cultural education programming, the Collaborative seeks to promote the use of cultural institutions as educational resources by teachers and individuals. To this end, the Collaborative provides computer information services and information dissemination of the educational resources of the cultural institutions. Additionally, the Collaborative seeks to promote access to the cultural institutions for all individuals. This objective requires that the Collaborative provide public information about the resources of the cultural institutions, as well as provide opportunities for individuals to experience the resources of cultural institutions (such as Tri-Arts programs). 
What Impacts Can the Cultural Education Collaborative Have?

As a collaborative effort, the Collaborative provides innovative programming in cultural education to fill a program or service void. The Collaborative stands between cultural institutions and schools. The Collaborative makes of these disparate institutions a new service - cultural education. Without the special efforts of the Collaborative, cultural and educational institutions would have minimal communication and interaction. Schools would utilize the cultural institutions predominantly on a single visit basis. Further, without the Collaborative, the schools and cultural institutions would not be able to interact in any depth due to multiple obstacles such as lack of funding, different technical abilities, and lack of governance and coordination. The Collaborative thus facilitates collaboration between cultural institutions and schools and catalyzes a new area of educational services.

Such innovative efforts, however, necessitate that the Collaborative generate an appreciation of the value of cultural education among educational agencies, cultural institutions, and the general public and create a demand for the programing of the Cultural Education Collaborative. In the future, the Collaborative can expand on the concept of cultural education. The collaborative can continue to develop the ability of cultural institution staff to develop and teach cultural education by providing cost-effective collaborative services in staff development, long range planning, and resource development. Secondly, 
the Collaborative can extend cultural education programs to new education groups - special needs, gifted and handicapped students, community groups. Again, cultural education programing for new education groups must be accompanied by additional staff development and technical assistance for cultural institution staff that they may better understand the needs of, and service, the new education groups.

What is Needed for Successful Cultural Education Collaborative Collaboration?

The Collaborative is similar in many respects to the Museums Collaborative. Both collaboratives facilitate and catalyze collaboration between disparate groups to provide innovative programing. To provide for the most effective collaboration and programming, the Collaborative shares with the Museums Collaborative the need to:

- generate program funds to support collaborative operations and programming;

- develop a diversified financial base for support of multiple collaborative roles and complex programing;

- provide both program planning to catalyze joint programs between cultural institutions and schools, and brokering to develop the service ability of the respective cultural and educational institutions (staff training, curricula development, computer information):

- provide communication networks to generate information on the diverse needs of the participating institutions and their clients, and to coordinate complex programming;

- disseminate information to interested parties and the public at large to generate a climate of acceptance for cultural education in general, and the collaborative programing in particular; 
- have a diversified governance board to, again, generate support for cultural education, particularly among professionals in the cultural institutions and education fields, political and community leaders.

Thus, the Collaborative has a number of imperatives in order to support complicated programing, create a demand, and generate public and financial support for a new area of services. Moreover, the Collaborative must hold together in collaboration institutions of varying motivations (schools tend to have greater incentive to participate than larger cultural institutions), which would otherwise have minimal networks of communication and exchange of information. To be most effective, the Collaborative should, therefore, spend as much time maintaining and supporting collaboration (technical assistance, fundraising, communication, supporting services, motivation building), and promoting cultural education (public image building, information dissemination, public policy development), as in innovative programing. For, without strong collaboration, and demand and support for cultural education, innovative collaborative programs will be marked by low motivation, poor communication and little demand. 


\section{CONCLUSION}


In conclusion, collaboration is an effective and innovative mechanism for the delivery of services and programs by two or more groups which have joined in voluntary cooperation. This cooperation is distinguished by:

- the pooling of participant resources;

- shared decision-making by participants;

- agreement on major goals of the collaboration. Collaboration occurs for diverse purposes and in different models. Groups may collaborate to develop innovative programs and services beyond the scope of the individual groups; to reach new audiences and service broader clients; to jointly address issues important to their own organizational growth and development; to capture additional funding and so strengthen and supplement their present program and service provision; and/or coordinate multiple activities already in existance and so prevent service overlap, duplication, or contradiction. Collaboration offers an innovation to the existing order of services.

Thus, collaboration creates partnerships between different groups in serving needs and seeking defined goals. In one model of collaboration, groups with resources may be linked through collaboration to other groups with specific needs for those resources. In another model of collaboration, 
different groups with varied resources but similar needs or goals are united in programs or services designed to meet those needs or goals. Or collaboration may unite organizations of similar purposes and organizations of diverse purposes. In a final model, collaboratives exist as outgrowths or extensions of a particular organization(s), institution(s), or agency(s). A collaborative which is conducting several operations and is serving both program planning and broker roles may find itself dealing with hundreds of groups and organizations.

The "collaborative" is the organization that exists to facilitate and coordinate collaboration. The collaborating groups may have no reason to work together save for the special product achieved through collaboration. Again, many collaboratives may be grouped as types according to similar approach to collaboration - purpose and characteristics. To be most effective, collaboratives should generally

- have diversified financial base to support collaborative programming;

- have continuous opportunities for communication and information and must allow for exchange of ideas in many directions;

- be responsive to the needs and problems of the participating organizations;

- work with organizations of high incentive for collaboration and concentrate to build motivations for organizations of less compelling needs;

- provide programs and services which are not duplicated within that service area. As the MPP writes, "the product of the collaboration must be perceived by potential clients as unique and highly desirable alternatives to the status quo."144 
As the typologies demonstrate, each collaborative type requires special structures, roles, programming and other characteristics to be most effective in achieving collaborative purpose. The characteristics that may be manipulated to best achieve collaborative purpose are: financial structure, board membership, legal status, decision-making, role, and programming. There is a growing need for such a model of service delivery. In education, cultural arts, science, etc., structured cooperation is becoming increasingly valuable for non-profit groups,

- as resources and financial support become more scarce;

- as organizations face increasing pressure to become more involved in the community;

- as management and administrative operations become more complicated, sophisticated and expensive;

- as problem areas require interdisciplinary responses;

- as increasing federal and state regulations requires organizational adjustment for additional programming.

Thus, there is a growing role for collaboratives to stand between organizations. Collaboration is the only model of delivery that

- provides innovative programming not otherwise possible by catalyzing the resources of disparate organizations;

- generates cost-effective programs and services through cooperative programs and the pooling of resources;

- captures additional funding for which a single participant might not be eligible.

Additionally collaboration confers

- shared understandings and communication between different organizations and their clientele; 
- a higher level of community through a wide range of participation in goal setting and decision-making;

- the reduction of feelings of powerlessness and alienation experienced by small organizations of limited resources when dealing with larger, possibly unresponsive organizations and institutions;

- a greater degree of accountability to collaborating organizations by according the opportunity to respond to various government and community pressures.

Again, as a cooperative venture, collaboration confers benefits to the participating organizations and the community which are beyond their individual scope. Collaboration provides a systematic approach to perceived pressing social and organizational needs, and allows an organization to respond to changing environments. Collaboration serves, therefore, as a vehicle for innovation and social change. 


\section{FOOTNOTES}

i. "Abstract", Museums Collaborative, p. 1.

ii. Ethel Sadowsky, "Public Schools: Are They Responsive To Social Change?", Radcliffe Quarterly, March 1978, p. 20.

iii. Paul Cook, Jr., Modernizing school Governance for Educational Equality and Diversity, (Boston: Massachusetts Advisory Council for Education, 1972), p. 80.

1. Massachusetts General Laws, Chapters 797, 71B.

2. Massachusetts General Laws, Chapter 180 Section 4 .

3. Massachusetts General Laws, Chapters 636, 622, 766.

4. Internal Revenue Code of 1954, Section 501 (c) (3).

5. Department of Social and Rehabilitation Services, "Management Training Seminar", University of Rhode Island, Urban Field Center, Providence Rhode Island (1975) (mimeograph).

6. Janet Reiner, Everett Reimer, and Thomas A. Reiner, "Client Analysis and the Planning of Public Programs", in Bernard J. Frieden and Robert Morris, Urban Planning and Public Politics, New York: Basic Books, p. 391.

7. MASBO Cooperative Corporation brochure p. 3 .

8. Ibid., p. 1

9. Interview with Robert Pritchard, March 8, 1978.

10. By-Laws of the MASBO Cooperative Corporation

11. Goals adapted from MASBO Cooperative Corporation brochures and By-Laws.

12. MASBO Cooperative Corporation brochure, p. 3 .

13. Ibid.

14. Interview with Robert Pritchard, March 8, 1978.

15. Metropolitan Cultural Alliance brochure, June 1977, introduction.

16. Ibid.

17. Annual Report of the Metropolitan Cultural Alliance, 1976-1977, p. 2. 
18. Ibid., introduction.

19. Ibid.

20. Ibid,, p. 2 .

21. Annual Report of the Metropolitan Cultural Alliance, 1975-1976, Part II.

22. By-Laws of the Metropolitan Cultural Alliance, Article III.

23 Annual Report of the Metropolitan Cultural Alliance, 1975-1976, introduction.

24 Ibid.

25 Annual Report of the Metropolitan Cultural Alliance, 1976-1977, introduction.

26 Ibid.

27 Ibid.

28 Ibid.

29 Ibid.

30 Metropolitan Cultural Alliance, brochure, June 1977.

31 Ibid.

32 Annual Report of the Metropolitan Cultural Alliance, 1975-1976, introduction.

33 "Metroways to Understanding", the Metropolitan Planning Project, 1975, p. xiii.

34 Ibid., p. 1.

35 Ibid.

36 Ibid., p. xiii.

37 The Boston Metropolitan Planning Project, proposal submitted to the Department of Health, Education, and Welfare, United States Office of Education under the Emergency School Aid Act, 1972, Section 709 (a) (2), (April 1973), preface.

38 By-Laws of the Metropolitan Planning Project, Section I. 39 Ibid., Article v. 
Ibid., Article II.

41 Metropolitan Planning Project ESAA Proposal, p. 14-15.

42 "Metroways to Understanding", p. i.

43 Ibid., p. ii.

44 Ibid.

45 Ibid., p.i.

46 Ibid., p.xiii

47 Bureau of Equal Educational Opportunity, Schools and Programs of Choice: Voluntary Desegregation in Massachusetts, (Boston: Massachusetts Department of Education, April 1977), p. 24.

48 Ibid.

49 "Guidelines for Metropolitan Boston Communities Interested in Participating in METCO", METCO,Inc., p. 2-3.

50 Schools and Programs of Choice: Voluntary Desegregation in Massachusetts, P. 89 .

51 METCO, Inc. flier

52 Parent Handbook 1977-78, METCO, inc. p. 7.

53 Ibid., p. 8-9.

54 Ibid., p. 5 .

55 "Guidelines for Metropolitan Boston Communities",p. 1.

56 Bureau of Equal Educational Opportunity, METCO Handbook (Boston: Massachusetts Department of Education, 1976), p. 28 .

57 "Guidelines for Metropolitan Boston Communities", p. 2.

58 Parent Hanabook: $: 1977=78$ p. 11.

59 Springfield operations are the responsibility of the Springfield Department of Education.

60 Massachusetts General Laws, Chapter 636.

61 Parent Handbook, p. 11.

62 Ibid. 
63 Bureau of Equal Educational Opportunity, METCO Handbook, p.6.

64 Ibid., p. 47.

65 Bureau of Equal Educational Opportunity, METCO Handbook, p. 6.

66 - Schools and Programs of Choice, Voluntary Desegregation in Massachusetts, p. 42 .

67 Interview with Jack Green, Executive Director EdCo, March 17, 1978 .

68 By-Laws of the Educational Collaborative of Greater Boston, Inc.

69 Metropolitan Planning Project ESAA Proposal, p. viii-76.

70 Program abstract for EdCo, Inc.

71 Interview with Jack Green, March 17, 1978.

72 Interview, with Jack Green, March 17, 1978.

73 Metropolitan Planning Project ESAA Proposal, p, viii-99.

74 Massachusetts Board of Education, "Policy on Educational Collaboratives", ( May 24, 1977), p. 1 .

75 Annual Report of the Merrimack Education Center 1977, p. 1

76 Some collaboratives are presently organizaed under Chapter 71B that provide for a host community to act as fiscal agent and recipient of all funds which support the collaborative. However, all collaboratives must comply with Chapter 797 or Chapter 40 , Section $4 e$, by July $1,1979$.

77 Massachusetts General Laws Chapter 40, Section 4 e was amended in 1972 by Chapter 753.

78 Massachusetts General Laws Chapter 797.

79 Massachusetts Board of Education "Policy on Educational Collaboratives", p. 4 .

The issue of when a collaborative has achieved its purpose in meeting the needs of school systems is an interesting one. Dr. Richard Lavin, Executive Director of the Merrimack Education Center, agrees that this is a difficult question because new needs constantly arise. To keep from becoming too institutionalized, Dr, Lavin believes that MEC must "continually adapt to meet client needs." Peehaps, then, the issue of ever concluding its job is tautological. We should ask instead, "is it responsive to local need?" or "is it becoming too systematized, too institutionalized." 
80 Dr. Richard Lavin, Executive Director of the Merrimack Education Center, interview April 12, 1978.

81 Merrimack Education Center brochure, p. 2.

82 Dr. Lavin, interview.

83 Massachusetts Board of Education, "Policy on Educational Collaboratives", p. 5 .

84 Most goals presented here are taken from the Massachusetts Board of Education guidelines, supra.

85 Merrimack Education Center brochure p. 4.

86 Ibid., p. 5.

87 There are also single purpose and multi-service collaboratives. MBE defines these collaboratives as follows:

Single Purpose Collaboratives - are formed to solve one particular problem for their member school systems. With the enactment of Chapter 766 many collaboratives have been formed to provide programs to serve children with low-incidence spcial needs. other single purpose collaboratives have been designed to provide transportation or media services for a group of towns or to purchase equipment and supplies collectively.

Multi-Service Collaboratives - may provide programs or services which not only meet the educational needs of the local school systems or State Department of Education goals but also may provide programs or services in accordance with policies recommended by the Department of Mental Health, Department of Public Health, Department of Public Welfare, Department of Youth Services, Office for Children, and the Massachusetts Rehabilitation Commission.

In general, informal collaboratives are formed for a singlepurpose while formal collaboratives may be single-purpose, multipurpose, or multi-service.

88 Annual Report of the Merrimack Education Center, 1977, p. 1.

89 Ibid.

90 Massachusetts Board of Education, "Policy on Educational Collaboratives," p. 14

91 Merrimack Education Center brochure, p. 6

92 Ewald B. Nyquist, "How BoCES Serves the Metropolitan School Systems Concept in New York State," Phi Delta Kappan, September 1973 , p. 28 .

93 Board of Cooperative Educational Services, "What's a BOCEs?", brochure, p. 7

$1 ! \quad \because 1, \because \div$ 
94 Ibid., p.8

95 "Educational Services: Structure, Governance, and Organizations," (New York: Regents of the University of the State of New York, (May 1976), p. 14.

96 Ibid., p. 13.

97 Ibid., p. 9.

98 BOCES brochure, p. 8.

99 Ibid., p. 7.

100 Ibid.

101 Board of Regents, p. 12.

102 "Cultural Voucher Program" Abstract, p. 1.

103 Gary Bridge, "Cultural Vouchers", Museum News (Journal of the American Association of Museums, March/April 1976), p. 25

104 Ibid.

105 Michele Kort, "Community Groups Vouch for Culture", Grantsmanship Center News, Vol. 4., No. 2 (March/April 1978), p. 15.

106 "Cultural Voucher Program" Abstract, p. 6.

107 Resume, Museums Collaborative, Inc. provides information for the goals.

108 "Cultural Voucher Program" Abstract, p. 7.

109 "Craft Horizons" (newsletter), April 1977, p. 6.

110 Gary Bridge and Julie Blackman, "Second Year Evaluation Report: New York City Cultural Voucher Program", (May 1977), p. v.

111 Resume, p. 7

112 Ibid., p. 1.

113 "Cultural Voucher Program" Abstract, p. 1.

114 Challenge Grant Proposal, "A Cultural Credits Program for Adults", Cultural Education Collaborative, (January 11, 1978), introduction.

115 Ibid., p. 2 


\begin{abstract}
"Leadership in Public Education:
116 A Look at the Overlooked", Academy for Educational Development, 1972, p. II.
\end{abstract}

117 "Proposal for the Cultural Institution Integration Program," Cultural Education Collaborative, p. 5 .

118 "Leadership in Public Education: A Look at the Overlooked", p.8.

119 Nancy Hank, "Education Through Art: A Gateway."Journal of

the National Art Education Association, Vol. 24, No. 7, October 1971

120 "Proposal for the Cultural Institution Integration Program," Cultural Education Collaborative, p. 4.

121 Challenge Grant Proposal, Cultural Education Collaborative, introduction.

122 Nancy Hank, "Education Through Art: A Gateway".

123 "Proposal for the Cultural Institution Integration Program," Cultural Education Collaborative, p. 1 .

124 Challenge Grant Proposal, introduction.

125 Ibid.

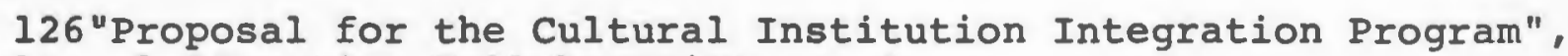
Cultural Education Collaborative, p. 3 .

127 Challenge Grant Proposal, financial profile.

128 Ibid., introduction.

129 Ibid.

130 "Proposal for the Cultural Institution Integration Program", Cultural Education Collaborative, p. 2 .

131 By-Laws of the Cultural Education Collaborative, Article III, section 7 .

132 Ibid., Article III, section 10.

133 Ibid., Article III, section 11.

134 Diane Casselberry, "Bringing Museum, Arts To Integrated Classrooms", The Christian Science Monitor, Tuesday March 15, 1977, p. 9.

135 Bureau of Equal Educational Opportunity, Schools and Programs of Choice: Voluntary Desegregation in Massachusetts, p. 38. 
136 Cultural Education Collaborative flier.

137 "Proposal for the Cultural Institution Integration Program," Cultural Education Collaborative, p. 3.

138 Evaluation Summary Report,1976-77, Program Evaluation and Research Group, October 1977, p. 10 .

139 "Proposal for the Cultural Institution Integration Program," Cultural Education Collaborative, p. 3.

140 Evaluation Summary Report, 1976-77, p. 10.

141 Congressional Record Reprint, 94 th Congress, Thursday, September 2, 1976.

142 Challenge Grant Proposal, intoduction.

143 Brief history of the Cultural Education Collaborative (monograph), Anne Hawley, Fall 1977.

144 Metropolitan Planning Project ESAA Proposal, p. 43. 


\section{BIBLIOGRAPHY}

\section{BOOKS AND PUBLICATIONS}

Bureau of Equal Educational Opportunity. METCO Handbook. Boston: Massachusetts Department of Education, (1977).

- Schools and Programs of Choice: Voluntary Desegregation in Massachusetts. Boston: Massachusetts Department of Education. (April, 1977).

Clasby, Miriam. Together: Schools and Communities. Boston: Massachusetts Advisory Council on Education. (1975)

Cook, Paul w., Jr. Modernizing School Governance for Educational Eguality and Diversity. Boston: Massachusetts Advisory Council on Education. (1972).

Frieden, Bernard J. and Morris, Robert, eds. Urban Planning and Social Policy. New York: Basic Books, Inc., 1968.

Governor's Commission on School District organization and Collaboration. Effectiveness, Efficiency and Equal opportunity. Boston: Massachusetts Advisory Commission on Education. (1974).

Ieadership in Public Education - A Look at the Overlooked. Academy for Educational Development, Inc. (1972).

Policy on Educational Collaboratives. Massachusetts Board of Education. (1977).

Student Desegregation Plan: The Public Schools of the City of Boston. (December 16, 1974) In accordance with the order of October 31, 1974 of the United States District Court, District of Massachusetts, Establishing Filing Date and General Contents of A Student Desegregation Plan.

The Arts: A Priority for Investment. Boston: Governor's Task Force on the Arts and Humanities. (1973).

The Metropolitan Cultural Alliance Education Project Report to the Metropolitan Planning Project: "Cost/Capacity study". Boston: Metropolitan Cultural Alliance. (1974).

Wertheim, Edward G., Ph.d. Education and the Arts: A Survey of Massachusetts Cultural Institutions Collaboration

- with School Systems. Metropolitan Cultural Alliance. (1975).

Widmer, J. What Makes Innovation Work in Massachusetts? Boston: Massachusetts Department of Education. 
Davies, Donald. "Making Citizen Participation Work." National Elementary Principal. Vol. 55, No. 4, March/April 1976.

Hanks, Nancy. "Education Through Art: A Gateway." Journal of the National Art Education Association. Vol. $\overline{24, ~ N o . ~ 7, ~}$ October 1971.

Kort, Michele. "Community Groups Vouch for Culture". Grantsmanship Center News. Vol. 4, No. 2, March/April 1978.

Nyquist, Ewald B. "How BOCES Serves the Metropolitan School systems Concept in New York State." Phi Delta Kappan. (September 1973).

Sadowsky, Ethel. "Public Schools: Are They Responsive to Social Change?" Radcliffe Quarterly. (March 1978).

PUBLIC LAWS

Massachusetts: General Laws, Chapters 797, 71B, 180 section 4 $636,622,766$.

Internal Revenue Code of 1954, Section 501 (c) (3).

OTHER

Any printed material supplied from the collaboratives surveyed, including :

By-Laws, Annual Reports, Evaluations, Program Descriptions, Proposals, Fliers, Resumes, Brochures, Leaflets, etc.

Mimeographed Notes from the Social and Rehabilitation Services.Dept. "Management Training Program", University of Rhode Island, Urban Field Center; Providence, Rhode Island. (1975). 